\title{
Sustainable Community-run Development: Experiences from the ADIO Project in Ostional, Costa Rica
}

\author{
By \\ Katja Klopfer \\ A thesis submitted in partial fulfilment of the \\ Master of Development Studies
}

School of Geography, Environment and Earth Sciences

Victoria University of Wellington

New Zealand

March 2014 
Contact: katja.klopfer1@gmail.com 


\title{
Canción de Ostional
}

\author{
Detrás de las Montañas \\ arrullados por el mar \\ se encuentra un lindo pueblo \\ su nombre es Ostional \\ de gentes muy humildes \\ dispuestas a luchar \\ su meta es solo una \\ es el bien comunal. \\ Y Dios los ha bendecido \\ y del mar dejo salir,
}

miles de tortugas loras para que puedan subsistir.

El pueblo se ha convertido en una sola familia

Hombres mujeres y niños todos están convencidos

que en la unión esta la fuerza

y nadie los detendrá el progreso está muy cerca y de todos lo será.

Este pueblo ha demostrado que jamás se va a extinguir

la tortuga que le ha dado el sustento para vivir

El pueblo se ha convertido en su amigo protector

hombres mujeres y niños lo defienden con amor

En la unión esta la fuerza y nadie los detendrá

el progreso está muy cerca y de todos lo será!

Song by Carlos Rodriguez 



\section{The song of Ostional}

Behind the mountains

lulled by the sea,

there is a beautiful village,

its name is Ostional

made of very humble people

ready to fight

their goal is only one

it is the communal good.

And God has blessed them

and has let out of the sea,

thousands of Lora turtles so they can be sustained

The village has become one family,

men women and children all are convinced

that in union there is strength

and no one will stop them,

the progress is very close and it will be for everyone.

This village has shown that it will never extinguish

the turtle that has given them sustenance

The people have become their protector friend

men, women and children will defend it with love

in union there is strength and nobody will stop them,

progress is very close and it will be for everyone!

Translation by Carlos Navarrete 



\section{ABSTRACT}

In the face of the current global sustainability challenge, seeking out and strengthening sustainable alternative methods for community development has become an urgent task for development professionals and academics.

In order to explore one of such alternatives, in this thesis I draw on research conducted with the Associación de Desarollo Integral de Ostional (ADIO). Located on Costa Rica's rural Pacific coast, ADIO was initiated by the local community of Ostional and resulted in the Project of Sustainable Use, Conservation and Management of the Olive Ridley Sea Turtle in 1987. Co-managed by the University of Costa Rica (UCR) and the Ministry of Natural Resources (MINAE), ADIO practices conservation and scientifically monitors the management of the Olive Ridley sea turtle species. Surplus eggs from the turtle arribadas (the mass nesting's of sea turtles) at the optional beach are being legally harvested and marketed by ADIO. This project has successfully contributed to the protection of the Olive Ridley turtle population whilst returning socio-economic benefits into the community.

The aim of this research is to gain a better understanding of ADIO's work and the significance of ADIO to the local community. My research draws on the experiences of community members to identify their perception of the benefits of ADIO to their own community, and unpack areas in need of improvement.

Qualitative data were collected from community members through: semi structured interviews, participant observation, a reflective workshop, a questionnaire and field notes. The findings of this research identify key elements for the success of ADIO, and demonstrate the benefit of this Project toward the sustainability of the local community. This research demonstrates that socio-economic benefits can be gained through appropriate community participation in sustainable conservation projects, which can further enhance the desire of the local community to be better stewards of natural resources.

This thesis seeks to contribute in some small way to an existing body of knowledge on the topics of sustainability, community-run conservation, and development.

Key Words: sustainable community-run development, community participation, community perspectives, conservation and management of sea turtles, Costa Rica, natural capital, social capital, community sovereignty 


\section{ACKNOWLEDGEMENTS}

I have greatly enjoyed studying under the Development Studies Masters programme, and would like to thank everyone who has shown support and guidance during these last two years of my study and research.

I am especially thankful to my supervisors, Marcela Palomino-Schalscha and Sara Kindon, who have provided endless support, encouragement and exceptional feedback for this thesis.

I would also like to thank the lecturers and guest lecturers from the School of Geography, Environment and Earth Science at Victoria University of Wellington, particularly John Overton, Gerard Prinsen, Nicole Wrighton and Warwick Murray, who have created a great learning environment and made lectures a fun place to be.

I would also like to thank Victoria University Student Learning Support, for helping me with my English and the Victoria International Leadership Programme, for providing me with assistance for my exchange year in Chile prior to my Master's Degree. This experience was essential for my decision to conduct research in Latin America and has provided me with the necessary language skills for conducting fieldwork in Spanish.

And of course, for the infinite support and making the last two years a journey of joy and laughter, thank you to my fellow graduate students, especially my office companions Tagan Paul and Nadine Dodge and to my friends Mark, Zizi, Clint, Anna, Chiara, Imogen, Ursula, Christian, Mike, Anton, Piki and Andria.

Gracias to Carlos Navarrete for translating the song of Ostional and for helping me with my Spanish.

Thanks to Janina Schan and Green Life Volunteers for her help, friendship and encouragement and for connecting me with the community of Ostional.

Also to Rodrigo Morera Ávila for mentoring me in Ostional, to Maxima Magdalena Vega Figueroa, the president of ADIO, and Gilberth Rojas Araya, the ex-president of the Association. Without their tremendous kindness, support and cooperation, this research would not have been possible. Muchísimas Gracias to the family of María, Gilberth and el Abuelo for welcoming me into their home and treating me like one of their own.

Gracias y Pura Vida to my guest brother Freddy and the friends I have made in Ostional, to Adriana, Darien, Yessenia, Jaikel, Andy, Becc, Buka, Gredy, Miguel and Olivia.

Gracias, Danke, Thank you in all languages to my Latin, German, 'Kiwi' and international friends.

I would like to thank my family. Danke to my late father Rolf, my mother Karin and my brother Daniel for believing in me and always encouraging me to study and go and discover the world.

Special thanks to Emma Yixuan Liu, Daniel Wellbrock and Anna Carter for proofreading my thesis. 


\section{TABLE OF CONTENTS}

ABSTRACT

ACKNOWLEDGEMENTS

TABLE OF CONTENTS V v

LIST OF ABBREVIATIONS viii

LIST OF TABLES IX

LIST OF GRAPHS $\quad$ x

LIST OF FIGURES $\quad$ xi

LIST OF APPENDICES X xii

CHAPTER I: INTRODUCTION 1

1.1 Problem statement 2

1.2 Case study and research objectives 2

1.3 Definitions and key themes 4

1.3.1 The history of sustainable community development 4 and why it is important

1.3.2 Conservation, tourism and participation in sustainable community 5 development

1.4 Research approach $\quad 8$

1.5 Thesis Outline 9

CHAPTER II: BACKGROUND AND CASE STUDY 11

$\begin{array}{lll}2.1 & \text { Introducing Costa Rica } & 11\end{array}$

2.2 National context and conflicts over land 16

2.3 Case Study: Ostional 19

2. 2. 1 The community of Ostional 19 
2.3 Ostional Wildlife Refuge and 'arrival' dynamics 24

2.4 ADIO: Associación de Desarollo Integral de Ostional 26

CHAPTER III: LITERATURE REVIEW 31

3.1 Contextualisation of relevant concepts 31

3.1.1 Natural and social capital 33

3.1.2 Community Participation 36

3.1.3 Conservation, environment and development 38

3.1.4 Sustainable tourism 41

3.2 Significance of research and reasons for using ADIO as a case study 45

CHAPTER IV: APPROACH AND METHODOLOGY 47

4. $1 \quad$ Epistemological approach 47

4. 2 Research design 48

4. 2. 1 Case study 48

4. 2. 2 A hands-on approach with ADIO 49

4. 2.3 Research methods $\quad 50$

4. 2. 4 Purposeful sampling: choice of participants 51

4. 2. 5. Mixed methods 51

4. 2.5.1 Participant observation 53

4. 2.5.2 Interviews $\quad 54$

4. 2.5.3 Questionnaire survey 55

4. 2.5.4 Reflexive workshop $\quad 58$

4.3 Positionality: working in a small rural Costa Rican community 60

$\begin{array}{lll}4.4 & \text { Data analysis } & 61\end{array}$

$\begin{array}{lll}4.5 & \text { Ethical concerns } & 63\end{array}$

$\begin{array}{lll}4.6 & \text { Success and Limitations } & 65\end{array}$ 
$\begin{array}{lll}5.1 & \text { Research results } & 67\end{array}$

5. 1. 1 History and evolution of Ostional and ADIO 68

5. 1. 2 How do community members perceive ADIO? 71

5. 1. 3 Organisational and legal framework 72

5. 1. 4 Benefits from ADIO 75

5. 1. 5 Impact of ADIO in livelihoods $\quad 81$

5. 1.6 The role of tourism 83

5. 1.7 Other issues to be improved 85

5. 1.8 Land ownership $\quad 92$

CHAPTER VI: DISCUSSION AND CONCLUSIONS 93

6.1 $\quad \mathrm{ADIO}$ and sustainable development 93

6.2 ADIO and community participation 94

6.3 ADIO and conservation, environment and development 96

$\begin{array}{lll}6.4 & \mathrm{ADIO} \text { and tourism } & 97\end{array}$

6.5 ADIO and challenges around land ownership 98

$\begin{array}{lll}6.6 & \text { Conclusion } & 103\end{array}$

CHAPTER VII: CONCLUSIONS

$\begin{array}{lll}7.1 & \text { Summary of my findings } & 105\end{array}$

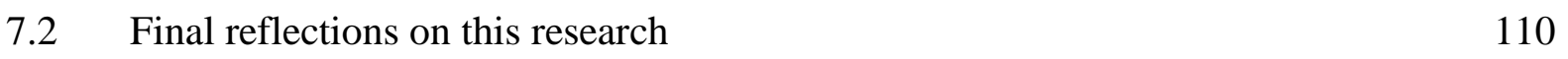

$\begin{array}{lll}7.3 & \text { Areas of future research } & 111\end{array}$

$\begin{array}{ll}\text { APPENDICES } & 113\end{array}$

$\begin{array}{ll}\text { REFERENCES } & 126\end{array}$ 


\section{LIST OF ABBREVIATIONS}

ACT

ADIO

DINADECO

FODEA

HDI

HPI

INCOPESCA

ISV

IVHQ

MAG

MDGs

NEAPs

NWR

MINAE

TIES

UCR

UNCED

WTO

ZMT
Área de Conservación Tempisque: Area of Conservation Tempisque

Asociación de Desarrollo Integral de Ostional:

Ostional Integral Development Association

Dirección Nacional de Desarrollo Comunal: Association for Rural Economic Development

Promotion of Agricultural Production

Human Development Index

Happy Planet Index

Instituto Costarricense de Pesca y Acuicultura: The Institute of Marine Fisheries

International Student Volunteers

International Volunteer HQ

Ministerio de Agricultura y Ganadería: Ministry of Agriculture and Livestock

Millennium Development Goals

National Environmental Action Plans

Project Monitoring Nesting of Turtles in Ostional

Ministerio de Ambiente, Energía y Mares de Costa Rica:

Ministry of Natural Resources

The International Ecotourism Society

University of Costa Rica

United Nations Conference on Environment and Development

World Tourism Organization

Zona Marítimo Terrestre: Maritime and Terrestrial Zone 


\section{LIST OF TABLES}

Table

Description

Page

2.1 Employment by province and sector (construction, hotels and

restaurants, real estate activities, business and rentals \% of total)

5.2 Investment in community infrastructure and materials for the development of the Project, conducted by the ADIO during the period from 2007 to 2011. 


\section{LIST OF GRAPHS}

Graph

Description

Page

5.1

Usefulness of Project for community

5.2:

Participants perceptions on beneficial aspects of ADIO

76

5.3

Motivations to participate in the Project

80

5.4

Participants perceptions on aspects of ADIO that do not

86

work so well for the community and could be improved

5.5

How could the Project be improved?

89 


\section{LIST OF FIGURES}

Figure

Description

Page

2.1

Map of Costa Rica

Map of Costa Rican provinces

Map of Nicoya Peninsula

Ostional community map

View over central Ostional

ADIO tourist information and ADIO guides meeting house evaluate the Five Year Plan for the Management and Conservation of Lora Sea Turtles 


\section{LIST OF APPENDICES}

Appendix

1.

2.

3.

4.

5.

6.

7.

8.
Description

Page

Letter from the association ADIO, Costa Rica

113

Human Ethics Committee approval

114

Participant Information Sheet: Interviews with Project Managers

115

Participant Information Sheet: Reflexive Workshop

117

Consent Form: Interviews with Project Managers

119

Consent Form: Reflexive Workshop

120

Anonymous Questionnaire Survey:

121

Ostional Community Members

Interview Guide 


\title{
CHAPTER I
}

\author{
INTRODUCTION
}

The empowerment of communities around the world has proven to be an essential element in the pursuit of sustainable development (Vivian, 1992). Increasingly, communities are using alternative, bottom-up and participatory approaches as development strategies. Communityrun development aims to ensure that the poorer people do not become "subjects of development but rather active agents in bringing about their own development" (Burkey, 1993, p. 55). However, modernist top-down and western-centric perspectives still exist and to a certain extent are still dominant. Nevertheless, international development policy and practice have increasingly utilised alternative approaches, such as participatory approaches to development. It is seen as being of increasing importance that development should come from 'within' the community, rather than from ready-made development solutions being imposed from 'outside' (Botes \& Van Rensburg, 2000). Hence, the implementation of what has come to be known as 'sustainable community development' should be based on local level solutions derived from community initiatives (Devas et al., 1992). Development is then a means of creating conditions within which people may choose to empower themselves so that they are able to initiate actions, and accordingly influence the processes and outcomes of their own lives. According to this view, development ideally leads to the equitable sharing of power and to a higher level of political awareness and strengths among people in both developed and developing countries (Paul, 1987). Hence, the pattern of telling developing countries 'how' to develop, by providing specific resources that lead communities into a certain direction has been countered by the encouragement of community empowerment and participation.

Although the effectiveness of projects that rely on community participation has been criticised (Mansuri \& Rao, 2004), it is the communities themselves who know best about their own needs and aspirations (Chapman et al., 2002). Hence a shift in development policy and practice can be noticed, which is a result of realising the full scope of benefits in letting the communities control their own development strategies in order to reach viable long-term development goals (Warburton, 2013; WCED, 1987). Keeping in mind that conclusions around community-run development and its effectiveness are context-specific (Mansuri \& 
Rao, 2004), findings from the case study for this thesis suggest that community-based development is of increasing importance in order to fulfil the needs and aspirations of community members, while at the same time, encouraging ecological sensitivity and longterm sustainability as the principles of communal participation.

The themes of community participation, conservation and ecological tourism and community empowerment are of particular interest in the context of the case study for this thesis and will be explained and drawn upon in the following chapters.

\subsection{Problem statement}

Current scientific data suggests that "global resource depletion and pollution are forcing recognition that existing patterns of development and resource use are not sustainable" (Roseland, 2000, p. 75). In fact, there is almost worldwide academic consensus on the importance of sustainable community-run development projects as a way of improving the environment and people's livelihoods and well-being (Chambers, 1997; Chinsinga, 2005; Helling et al., 2005; Hussein, 2003; Mancini \& Marek, 2004; Pomeroy et al., 2005). Many agree that, if global agreements on environmental sustainability are to show success, action at the local level is required (Agyeman \& Evans, 2003; Brugmann, 1996; Ghai \& Vivian, 1992; Roseland, 2000). Still, fairly little attention has been given to examining and documenting small scale local incentives within the global context. This outstanding academic gap is centred on the fact that even though there is almost worldwide consensus on the importance of sustaining projects as a way of improving people's livelihoods, often projects have struggled to survive or have not been sustainable (Mhango, 2010). Therefore, this study acknowledges that despite highlighting the centrality of sustainability of community-driven projects, little has been done to document and study the factors that led to the success and failures of such projects. Thus, my research intends to make a contribution to the academic literature on sustainable community-run development by exploring a successful case study.

\subsection{Case study and research objectives}

Currently, there is limited research on sustainability of community-run development projects despite being advertised as the best way to scale up poverty reduction through sustainable 
development interventions (Dongier et al., 2003). Therefore, the aim of this thesis lies in analysing a specific experience of a sustainable community-run programme that has survived and improved over nearly three decades. The small community of Ostional in Costa Rica (approximately 600 residents) has managed to co-exist with a natural abundance of Olive Ridley sea turtles, benefitting both the community and the sea turtle population. Together with the University of Costa Rica, the community association Associación de Desarollo Integral de Ostional (ADIO) has created a legal framework for the conservation and management of the Olive Ridley sea turtle, from which the project Proyecto de Aprovechamiento Racional, Conservación y Manejo de los Huevos de la Tortuga Marina Lora or Project of Rational Use, Conservation and Management of the Olive Ridley Sea Turtle originated. The Project's main responsibilities include scientific monitoring of the turtle population; the protection of the turtles, their eggs and hatchlings from poachers and predators, and the preservation of the beach, while at the same time creating income and community development from the sale of a small portion (less than $1 \%$ ) of turtle eggs.

ADIO's main goal is to conserve the natural abundance of Olive Ridley sea turtles, while developing the community with funds from the egg harvest and creating an alternative means of income for the population of Ostional. Although the community has successfully managed to co-exist with and benefit from the natural abundance of sea turtles, the community and the Association are facing internal and external problems. Internal problems are related to mainly administrative and organisational issues, while external problems are primarily related to a conflicting situation with the government, due to the creation of the Wildlife Refuge Ostional (these and other issues will be discussed in detail in Chapter V and VI of this thesis).

My research therefore is an investigation into an association which has established a legal framework for the rational use, conservation and management of the Ridley sea turtle as a means to ensure sustainable, community-run development. It examines ADIO's unique context and discusses experiences from community members related to the Project.

The research objectives of this thesis are as follows:

1. Understand some community members' experiences of being involved in, or affected by, ADIO in Ostional, Costa Rica.

2. Explain aspects of ADIO that work well and are perceived as beneficial for community members, and unpack aspects of ADIO that do not work well for community members and could be improved. 
3. Identify key elements for the success of ADIO

4. Contribute to current literature around sustainability, community-run conservation and development.

\subsection{Definitions and key themes}

\subsubsection{The history of sustainable community development and why it is important}

In ecological terms, it has become clear that human activity has damaged major ecosystems on every continent, seriously threatening the livelihoods of the societies that depend on these ecosystems, and increasing inequalities between societies (Ulgiati \& Brown, 1998). Concurrent with the loss of biodiversity, human cultural diversity is rapidly disappearing worldwide. One reason for this is the displacement or acculturation of 'traditional' communities and the loss of languages, traditions and knowledge related to biodiversity and the coexistence with nature (Grainger, 2003).

The shift in development policy and practice, away from the modernisation paradigm and towards the empowerment of communities around the world, originates from the Seventh Special Session of the United Nations General Assembly in 1978. The document stresses the need for "self-reliance to be seen as central to the development progress, and for the emphasis to be placed on endogenous (internal) rather than exogenous (external) forces of change" (Potter, 2008, p. 114). In 1987 the World Commission on Environment and Development (WCED) report 'Our Common Future' brought the concept of sustainable development into government's and public spotlight. In the corresponding Brundtland Commission sustainable development is defined as: meeting "the needs of the present without compromising the ability of future generations to meet their own needs" (WCED, 1987, p. 43) in a context where neo-liberal economic policies and sustainable development in their extremes seem incompatible (Giddings et al., 2002). Consequently, since the late 1980s, development workers, amongst others, have pinned their hopes to sustainable development as a solution to urgent environmental and societal problems.

Later, in 1992, the United Nations Conference on Environment and Development (UNCED), the Earth Summit, was held in Rio de Janeiro. The result was a document that described a global programme of action for sustainable development (UNCED, 1992). It resulted in the adoption of national strategies for sustainable development. These National Environmental 
Action Plans (NEAPs) were seen as a way to place environmental concerns in a country's economic and social development plan, in order to gain harmonisation throughout the various sectors (UNCED, 1992). The key to successful implementation was believed to be that each country would choose its own solutions to the problems that needed to be overcome in order to move successfully towards a more sustainable path of development. In the process, strategies that originated from local knowledge which express what was perceived as "true national identity" had been acknowledged as the most successful (Woodland et al., 2006).

Since the 1990s, sustainable development has become one of the leading development paradigms, stressing the need to preserve natural biological systems that underpin the global economy (Redcliff, 2005 as cited in Potter, 2008). More recently, the Millennium Development Goals (MDGs) emphasised the integration of sustainable development into country policies and the need to reverse the loss of environmental resources. Among an array of global environmental policies, high hopes to counteract environmental degradation were placed on implementation at the community level.

Hence, sustainable development means more than preserving natural biological systems. There is a logical assumption within sustainable development, that the poor and disadvantaged are not forced to pollute or depredate their environments in order to survive (Desai \& Potter, 2013; Drakakis-Smith, 1996; Eden \& Parry, 1996). Furthermore, it is suggested, that the only way out of processes of unequal exchange, in global as well as in regional terms, is to increase self-sufficiency and self-reliance (Potter, 2008).

\subsubsection{Conservation, Tourism and Participation in Sustainable Community Development}

Academics have taken into account the potential of existing knowledge systems from communities when talking about sustainable development (Cash et al., 2003). In this regard, it is helpful to view 'community' as a web of relationships defined by a significant level of mutual care and commitment. It has been found that many communities have functional knowledge systems pertaining to their resources and environment, which are based on unique experience and epistemologies, and which have practical significance for the rest of the world (Berkes, 1999). The nature of traditional local knowledge and its unique values might hold promising prospects for the future of development; however, they need yet to be recognized 
by the public. Local knowledge and alternative bottom-up projects continue to be marginalized because of the dominance of conventional top-down approaches, pressures of their own government, big-scale tourism development, scientific professionalism, and for other political-economic reasons (Terry et al., 2006), which has also partly occurred in Ostional, the case study of this thesis.

It is now generally accepted that the world's biodiversity is being lost at a faster rate than at any previous time in the Earth's history. The poor conservation outcomes that followed decades of intrusive resource management strategies and planned development have forced policy makers and scholars to reconsider the role of community in resource use and conservation (Agrawal \& Gibson, 1999; Chambers \& McBeth, 1992; Chitere, 1994). Different to previous work on development which considered communities a hindrance to progressive social change, current writings promote the role of community in bringing about decentralization, meaningful participation, and conservation (Agrawal \& Gibson, 1999).

As will be seen in more detail later, there are three key areas of the ADIO Project that have proved crucial for its successful contribution to conservation and sustainability. First, community members undertake and re-invest into conservation activities. Second, members respect and are proud of conservation activities and link them to the long-term survival of their village and the marine turtle populations. Third, the Project's legal framework allows for interruption if evidence suggests that the harvest is damaging the turtle populations (Campbell, 1998).

Tourism and alternative forms of tourism such as ecotourism, community tourism and volunteer tourism are a way for communities to transform their natural heritage and ways of living into income opportunities. The International Ecotourism Society (TIES) defines ecotourism as "responsible travel to natural areas that conserves the environment and improves the welfare of local peoples". Sustainable tourism, as outlined by the World Tourism Organization (WTO), should make optimal use of environmental resources that help conserve natural heritage and biodiversity, respect the socio-cultural particularity of host communities and provide socio-economic benefits to all stakeholders. Another form of alternative tourism is Volunteer tourism which has been also developed in Ostional. Volunteer tourism is a field of tourism in which travellers visit a destination and take part in projects in the local community (Wearing, 2001). Nevertheless, the fields of community, eco and volunteer tourism have also been criticised - arguing that such forms of tourism can have 
negative impacts on communities (Ismail et al., 2013; Lincoln, 2014; McGehee \& Andereck, 2009b; Singla, 2014).

Also, tourism development and community participation are interlinked. Hill (1993, p. 629) argues on this matter that "local community participation is considered an essential step to ensure tourism development is sustainable, but true active participation or empowerment has received little attention in the tourism development literature". As highlighted by the case study for this thesis, the community of Ostional has made use of the help from volunteers and their own ecotourism initiative to support sustainable development of the community and the sea turtle programme.

Successful tourism and community development require active support and involvement of the local community. Hence, community participation can be seen as a process of raising awareness within the community, mainly through processes of reflection, learning together (Gaventa \& Cornwall, 2001 as cited in Palomino Schalscha, 2011) and the ability to exercise choices (Gonsalves and Mendoza, 2006 as cited in Palomino Schalscha, 2011). Furthermore, Warburton (2013) argues that sustainable development and community participation must go hand in hand and actions at the local level need to be permanently nurtured by their host communities in order to deliver long term environmental and social goals.

It is important to recognize that host communities have a stake in ensuring that tourism does not compromise their quality of life. This can include issues such as overcrowding at traditionally local venues, rapid changes in social values, increased demand that raises the price of consumer commodities, and degradation of the natural environment (Gutierrez et al., 2005). In addition, land tenure, indigenous peoples' rights, poverty, and lack of access to basic services are core community issues, that exist globally and may significantly impact the viability of tourism and community development (Gutierrez et al., 2005). The most conspicuous aspects in advocating for participatory approaches include the enhancement of chances for meeting the needs of the beneficiaries which is associated with project ownership and which in turn culminates in project sustainability (Pomeroy et al., 2005, p. 375). Community participation in the case of Ostional is crucial for the continuation of the sea turtle Project, as it is a hundred per cent community-run, and people's concern about their own 'backyard' drives their efforts. The above concepts will be discussed in further detail in Chapter II of this thesis. 


\subsection{Research approach and case study}

Numerous communities around the world have found ways to co-exist with their environments without damaging their natural resources in the long run. In light of the astonishing levels of global ecological degradation, these communities are of growing importance as they present sustainable alternatives to development. The most relevant development theory, social reform and policy analysis have much to offer in regard to fulfilling material human needs, but are virtually mute on the other sustainable development components such as advancing social equity, maintaining environmental assets for future generations, avoiding irreversible damage to local resources, expanding organizational effectiveness, and building capacity towards sustainability (Roseland, 2000).

Using a mixed method approach for data collection, I placed myself in the position of a volunteer/intern of ADIO for the duration of one and a half month. Under the mentoring of the resident biologist Rodrigo Morera Ávila and with the help of my host family and Ostional friends, I learned about the Project and collected data in the form of questionnaires, interviews and a reflective workshop. Participant observation and journal entries helped me to reflect on my research and build connections between the key themes extracted from the data collected. My fluency in Spanish was crucial during the fieldwork as well as in the analysis of data collected.

In consideration of what we know about sustainable community projects and community participation it is important to learn about, and respond to, community members' perceptions about their involvement and the Project. Community members' thoughts about the programme as a whole are crucial and the integration of those views helps to ensure the sustainability of the Project in the long run, whilst holding potential to improve some aspects in the pursuit. Therefore, the research objectives for this thesis were designed to gain an indepth understanding of ADIO from a local community perspective and contribute to academic debates with concepts that are relevant for the people from Ostional. 


\subsection{Thesis Outline}

CHAPTER II provides an overview of the context by giving essential background on Costa Rica and the community of Ostional. It presents the situation of ADIO: the case study of this thesis. It also explores some challenges the Association is facing or has been facing in the past.

CHAPTER III provides the development framework of the research and a review of the relevant literature pertaining to the sustainable community-run projects. It discusses the academic ideas of conservation, tourism and community participation, which situate the research in its academic context and demonstrates its contribution to the academic literature. Finally, it explores the reasons for using ADIO as a case study in light of these findings.

CHAPTER IV presents the approach and methodology used in my research: offering a detailed description of the research design. It describes and details the methods, tools and techniques used in this research. In addition, this chapter discusses the reflexivity and positionality of the researcher and challenges I have come across during the fieldwork. It also includes my contribution to ADIO and my participation in the community Project. Finally, it explains the limitations and benefits of the processes of data collection and data analysis.

CHAPTER V presents the research findings and analysis. This chapter provides information gathered about ADIO, with its history, evolution and its organisational framework. I discuss how it is to be living in rural Ostional and reflect on the impact of ADIO on local livelihoods. I discuss participants' motivations and perceptions on beneficial aspects of ADIO and on aspects of ADIO that can be improved.

CHAPTER VI offers the discussion and conclusions of this thesis. The discussion reconnects the findings with the wider literature. This section reflects on ADIO's current status and discusses notions around possible positive changes as suggested by the findings of 
my research. While coming back to the research questions, I stress wider issues in the field of sustainable community development.

CHAPTER VII presents the conclusive section of the thesis. It summarise the achievements and strengths of $\mathrm{ADIO}$, along with its current issues and remaining challenges. It returns to the initial objectives of this thesis and presents the findings of this study along with its contribution to the field of development studies. I then reflect on my research experience as a researcher, drawing upon my personal insights and learning regarding this field of work. Finally I identify areas of gaps for future research. 


\section{CHAPTER II}

\section{BACKROUND AND CASE STUDY}

As described in my introductory chapter, I have chosen the community of Ostional in Costa Rica as the setting of my research study, in order to gain insight into a sustainable community-run development project. The following section will outline the context of my research. It introduces Costa Rica and gives a description of Ostional and ADIO to set the socio-geographic framework for my case study.

\subsection{Introducing Costa Rica}

Figure 2.1: Map of Costa Rica

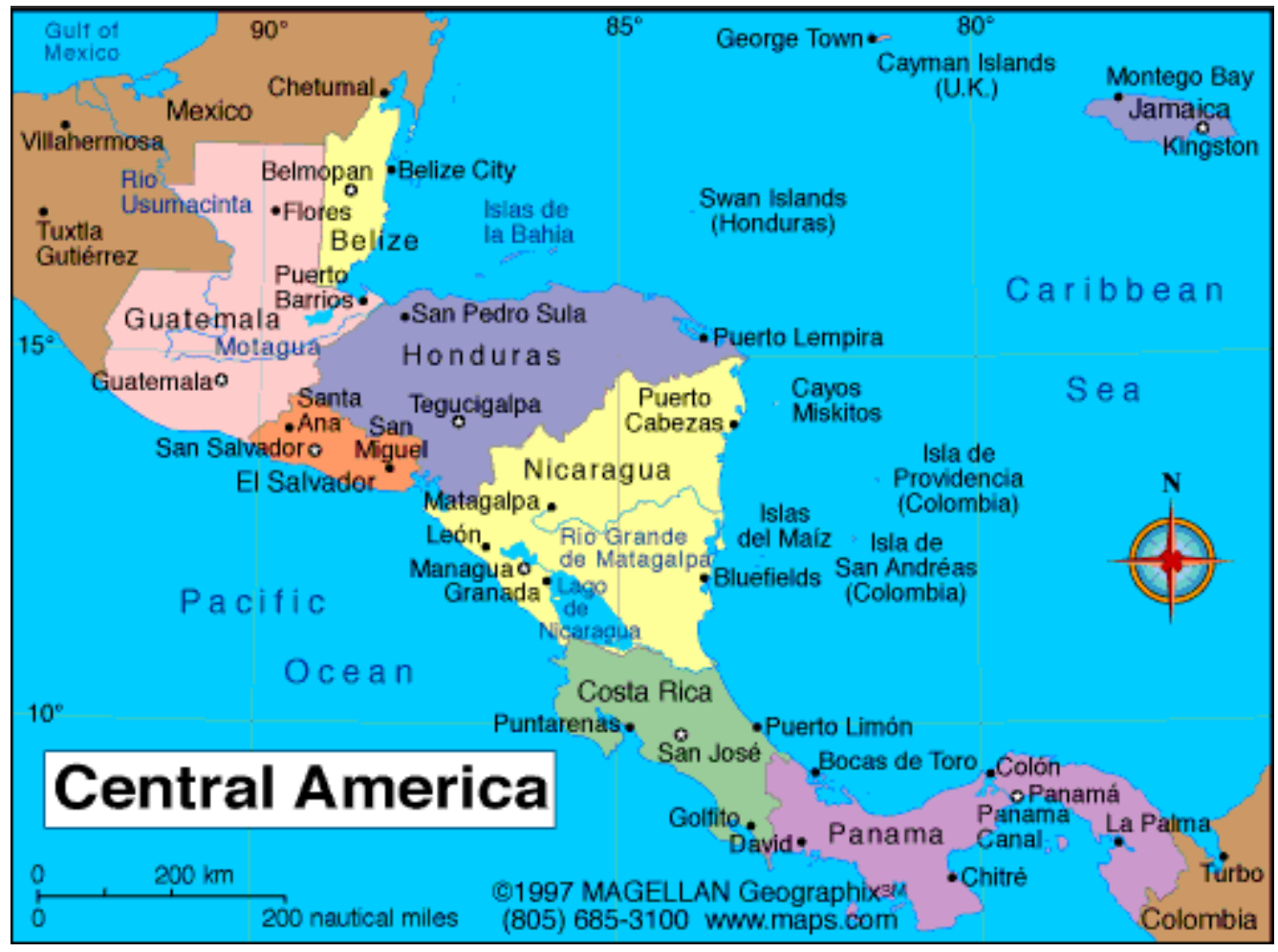

Source: http://www.infoplease.com

The Republic of Costa Rica is one of the smaller Central American countries, bordered by Nicaragua to the north, Panama to the southeast, the Pacific Ocean to the west, and the Caribbean Sea to the east. The country is part of a chain of nations that together comprise the 
isthmus of Central America. Costa Rica's climate is tropical; however, the country has many microclimates depending on elevation, rainfall, topography, and the geography of each particular region. Costa Rica's particular geography comprises an enormous amount of plant and animal life within a modest 51,100 square kilometres amongst which are different species' of sea turtles. Sea turtle populations arrive at both the Caribbean and the Pacific coast (see Figure 2.1) of the country whereas the latter holds the location for the case study for this thesis. Further, while the country has only about $0.1 \%$ of the world's landmass, it contains $5 \%$ of the world's biodiversity, which makes it a popular destination for ecotourism and research (Hickman, 2008).

This research was conducted in the community of Ostional in the region of Guanacaste on the Nicoya peninsula of Costa Rica (see Figures 2.2 and 2.3). Ostional is a community, a beach and a National Wildlife Refuge, located $360 \mathrm{~km}$ from the capital city San Jose, in the Peninsula, Santa Cruz, Guanacaste.

Figure 2.2: Map of Costa Rican provinces

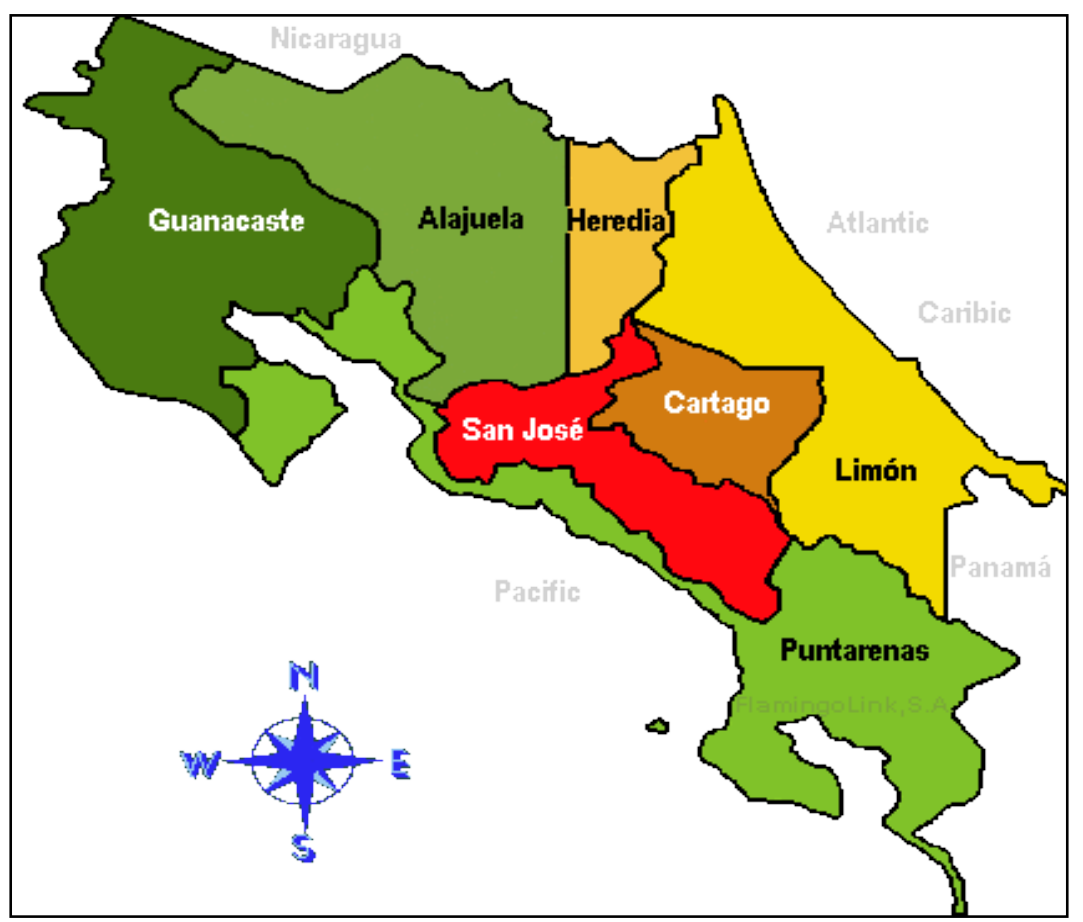

Source: http//: costaricalink.com 
Figure 2.3: Map of Nicoya Peninsula

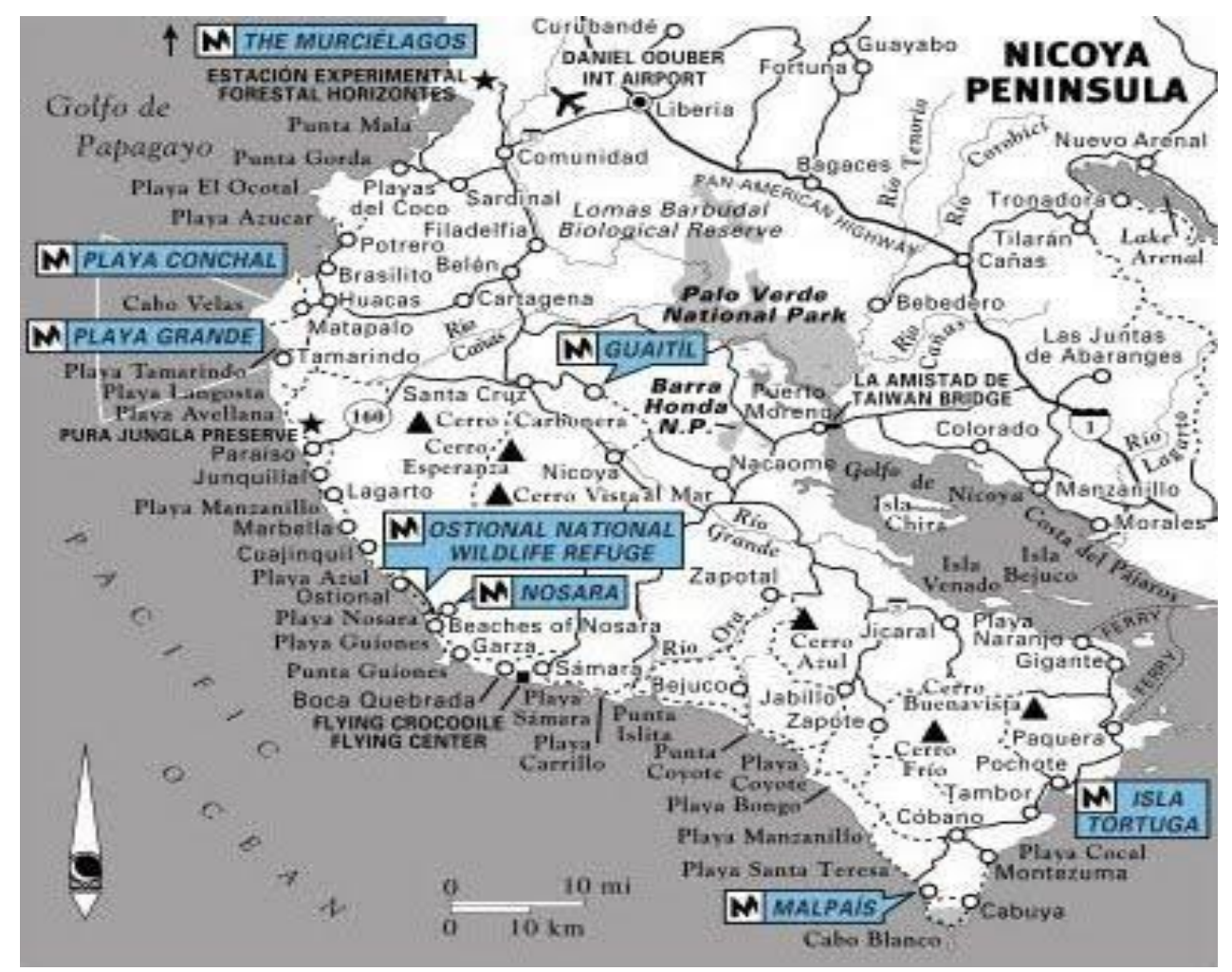

Source: http://www.nosarabeachvillas.com

Costa Rica's economy is stable. Having a small population and a limited domestic market, Costa Rica has facilitated economic growth via an export-oriented, open economy, largely centred on tourism, agriculture and electronics exports. Costa Rica's rich and fertile soil enables the growth of cash crops such as coffee, bananas and variety of other fruits and vegetables (Campbell, 2002). Over the years, the country has maintained transnational alliances, in particular good relations with North America (Clark, 1995). Also, Costa Rica's geographic location provides easy access to American markets as it has the same time zone as the central part of the United States and direct ocean access to Europe and Asia (Clark, 1995).

Costa Rica in tourism terms stands as the most visited nation in the Central American region, with 2.3 million foreign visitors in 2011, followed by Panama with 1.6 million visitors (UNWTO, 2013). Over the years, Costa Rica has earned its reputation as the premier ecotourism destination in the world and is considered ecotourism's poster child (Honey, 1999). Ecotourism draws many tourists to visit the extensive national parks and protected areas around the country. Costa Rica was a pioneer in this type of tourism, and the country is recognized as one of the few with true ecotourism (Honey, 1999). Costa Rica is one of 
several countries in the world that has been embracing ecotourism as a national conservation and development strategy (Stem et al., 2003). However, Costa Rica is unique due to the magnitude of its ecotourism industry and its maturity when compared to other developing countries. Costa Rica's rise as a popular destination for ecotourism is because it has all of the key components. The country has excellent national parks, a stable democratic government with no army, a pleasant climate, and friendly people. It also has one of the highest standards of living, the largest middle class, the best public healthcare system, the best public education through the University level and the highest literacy rate in Latin America (Buchsbaum, 2004; Honey, 1999). Through the demilitarisation of Costa Rica at the end of the 1940s and initiated by President Jose Figueres Ferrer, the government was able to invest greater funds in education and medicine, improving dramatically the standard of living of its inhabitants in less than 10 years (Savage, 2002).

Costa Rica is an active member of the United Nations and the Organization of American States. The Inter-American Court of Human Rights and the United Nations University of Peace are based in Costa Rica. A main foreign policy objective of Costa Rica is to foster human rights and sustainable development as way to secure stability and growth (Ministry of Foreign Relations Costa Rica, 2013). Costa Rica was cited by the United Nations Development Programme (UNDP) in 2010 as one of the countries that have attained much higher human development than other countries at the same income levels. The Human Development Index (HDI) aims for a broader definition of well-being and provides a combined measure of three basic dimensions of human development: health, education and income. Between 1980 and 2012 Costa Rica's HDI rose by $0.7 \%$ annually from 0.621 to 0.773 today, which gives the country a rank of 62 out of 187 countries with comparable data. The HDI of Latin America and the Caribbean as a region increased from 0.574 in 1980 to 0.741 today, placing Costa Rica above the regional average (UNDP, 2013). On a different index, the New Economics Foundation ranked Costa Rica first in its 2009 Happy Planet Index (HPI), and once again in 2012 and 2013. The HPI results show the extent to which 151 countries across the globe produce long, happy and sustainable lives for people that live in them. The overall index scores rank countries based on their efficiency, how many long and happy lives each produces per unit of environmental output (NEF, 2013). The index uses global data for life expectancy, experienced well-being and a country's Ecological Footprint to calculate this index (HPI, 2013; Seager, 2009). 
According to the World Bank's poverty profile for Costa Rica, the country has had notable success in reducing poverty and improving social welfare. Poverty affected $48 \%$ of households in 1982; gradually though, by 1994 , only $15.8 \%$ of households were estimated to be living in poverty (WorldBank, 2013). With the rise in tourism, particularly resort tourism and the explosion of residential tourism, the job market has gone through many changes. In the provinces of Guanacaste, which is the province of my research setting, and Puntarenas, the employment rates in construction and hotel and restaurants represented $15.3 \%$ and 12.7 $\%$ of total employment in 2003. In 2006, these numbers had risen to $36.8 \%$ and $32.9 \%$ of total employment in those regions (see table 2.1).

The real estate bubble in Costa Rica and the increase in tourism visits have created a large proportion of the new employment, mainly in construction related areas, and resulting in the high demand in unskilled labour (Barrantes-Reynolds, 2011). Nevertheless, jobs in construction are not permanent and depend on the real estate market. From 2007 to 2012 employment opportunities in the construction and hotel sector were affected, since the countries hit hardest by the global economic crisis, such as the USA and Spain, were the same countries whose populations massively invested in and visited Costa Rica (Haddock, 2012).

Table 2.1: Employment by province and sector (construction, hotels and restaurants, real estate activities, business and rentals \% of total)

\begin{tabular}{|c|c|c|c|c|c|c|c|c|}
\hline \multirow{2}{*}{ Branch of Actlvity } & \multirow{2}{*}{ Total } & \multicolumn{7}{|c|}{ Province } \\
\hline & & San José & Alajuela & Cartago & Heredla & Guanacaste & Puntarenas & LImón \\
\hline \multicolumn{9}{|c|}{2003} \\
\hline Total & 554,036 & 296,118 & 66,424 & 40,888 & 56,971 & 19,683 & 29,528 & 44,424 \\
\hline Construction & $7.1 \%$ & $7.6 \%$ & $5.3 \%$ & $8.1 \%$ & $6.3 \%$ & $12.7 \%$ & $8.6 \%$ & $2.5 \%$ \\
\hline Hotels and Restaurants & $6.2 \%$ & $6.7 \%$ & $5.8 \%$ & $7.0 \%$ & $6.2 \%$ & $2.6 \%$ & $4.1 \%$ & $5.2 \%$ \\
\hline $\begin{array}{l}\text { Real Estate Activities, } \\
\text { Business and Rentals }\end{array}$ & $11.0 \%$ & $15.0 \%$ & $5.5 \%$ & $9.3 \%$ & $10.3 \%$ & $4.0 \%$ & $3.2 \%$ & $3.4 \%$ \\
\hline \multicolumn{9}{|c|}{2006} \\
\hline Total & 662,261 & 346,008 & 80,409 & 44,884 & 75,077 & 28,850 & 37,582 & 49,451 \\
\hline Construction & $7.3 \%$ & $7.0 \%$ & $6.5 \%$ & $9.2 \%$ & $4.5 \%$ & $15.5 \%$ & $15.3 \%$ & $2.0 \%$ \\
\hline Hotels and Restaurants & $5.9 \%$ & $5.0 \%$ & $4.6 \%$ & $2.2 \%$ & $4.3 \%$ & $21.3 \%$ & $17.6 \%$ & $2.7 \%$ \\
\hline $\begin{array}{l}\text { Real Estate Activities } \\
\text { Businesses and Rentals }\end{array}$ & $13.3 \%$ & $17.8 \%$ & $6.5 \%$ & $10.7 \%$ & $15.7 \%$ & $5.8 \%$ & $4.2 \%$ & $3.4 \%$ \\
\hline
\end{tabular}

Source: Haddock (2012)

It is important to note also that the tourism industry does not always offer secure and stable employment, and often offers jobs paying under the minimum wage. Many jobs created as 
result of the tourism boom were often not available to Costa Ricans in rural areas as they required a certain level of education and proficiency in foreign languages. (Haddock, 2012).

Also, rural-urban migration is common in Costa Rica and can be primarily explained by economic 'push' and 'pull' factors from agriculture and relatively high urban wages (Gabriel, 2011). At the same time, rural-urban migration in Central American countries is leaving agricultural lands abandoned. Therefore, an important conservation strategy in rural areas has been to invest in community-based sustainable development projects (Andereck et al., 2005)

\subsection{National context and conflicts over land}

There has been a shift in the patterns of ownership of land and businesses along the Costa Rican coast lines. From the 1980s to the 1990s, there was a shift from a mainly endogenous tourism (national tourists staying in Costa Rican owned hotels) to a tourism industry increasingly composed of businesses financed by international or transnational capital (Haddock, 2012). The former model permitted the revenues and profit to stay in the local economy, but the latter one is systemically prone to import and export leakage (UNEP, 2012). According to UNEP, foreigners own $65 \%$ of hotels and most of the high-end resorts belong to foreign corporations. Although this number seems quite high, foreign ownership in the hospitality businesses is widespread and "coastal zones have become areas where foreign cultures and the English language dominate" (Haddock, 2012, p. 20). With the rise in land prices and the increase in real estate development there have been many incentives for locals to sell land or instances of forced or distressed sale of land to foreigners and real estate companies (Haddock, 2012).

There are many instances of conflicts of interests and corruption found in coastal tourism destinations, speculative land markets, and countries with slow bureaucratic processes (Belisle \& Hoy, 1980), as is the case in Costa Rica. A conflict of interest is linked to the desire of the municipalities to increase their land tax revenues by having wealthier inhabitants in the Zona Marítimo Terrestre or Maritime and Terrestrial Zone (ZMT), thus failing to protect the local populations by favouring foreign citizens based on wealth and nationality (Haddock, 2012). The Law of the Maritime and Terrestrial Zone No 6043 of March 2nd 1977 is the core of the Costa Rican 'integrative coastal management legislative framework'. It defines a fringe of land 200 meters wide as the Zona Marítimo Terrestre or 'Maritime and 
Terrestrial Zone' (ZMT), part of the 'national heritage' and inalienable property of the State. In certain situations, the local government can see eye to eye with national tourism strategies and big developers' plans because of the future taxes that will be collected. Salaries of municipal government bureaucrats can be positively affected by an increase in property tax and concession revenues (Haddock, 2012). This can incentivize the removal of local communities or specific individuals from the coast. This perversion of incentives is confirmed in the Food and Agriculture Organisation (FAO) (2006) document on legislative studies No 93: "In many countries, terrestrial zoning and land use restrictions are administered at the local government level and are consequently frequently affected by local politics and the desire to increase municipal revenues by encouraging developments which would increase local property values and rates payable to municipalities" (FAO, 2006 as cited in Haddock, 2012).

Corruption has increased with coastal tourism development related to the facilitation of construction permits, 'closing one's eyes' to environmental degradation caused by construction, procedural omissions, officials demanding or accepting bribes, and officials being accomplices in the illegal transactions of land (Haddock, 2012). Corruption is not limited to coastal land managed by the municipalities; coastal land managed by the Ministerio de Ambiente, Energía y Mares de Costa Rica or Ministry of the Environment and Energy (MINAE) is also under intense scrutiny and there are many cases that have been reported in the press. The claims that coastal development attracts this sort of opportunistic and illegal behaviour are supported by national statistics that have shown higher instances of the perception of corruption in coastal provinces and a higher instance in rural settings. (Haddock, 2012)

Critical to issues discovered in this study is the concept of unequal power relations in regards to local land and resource use and resulting extra-community conflict, reflecting common struggles related to community-run development approaches. In the case of Ostional, the creation of the wildlife refuge limits the possibilities of land use for the Ostional community. This will be discussed in detail in Chapter VI of this thesis.

The following section introduces the literature on the Territorios Costeros Comunitarios law project or Coastal Community Territories Law Project (TECOCOS) and its relevance for the ADIO and the Ostional community. 
The TECOCOS law project was initiated in reaction to a recent wave of planned evictions threatening a number of coastal communities on the Pacific Coast of Costa Rica, following a decade of aggressive coastal tourism development. The TECOCOS movement has produced two historic law projects that have currently passed the first round in the Legislative Assembly of Costa Rica. If passed, the law would secure coastal communities by providing that land cannot be sold. The law opposes the demand for social justice by "breaking down the oppressive structures and the institutionalization of the moral/social exclusion of coastal communities" (Haddock, 2012, p. 22), and opposes those who request the "continued use of the coast primarily for tourism development which has led, until now, to unhindered urbanization" (Haddock, 2012, p. 22).

As legal representation of Ostional and with many members affected by eviction pressures from the Refuge, ADIO is particularly concerned about the success of the TECOCOS law project. According to Guanacaste News, if passed, TECOCOS would benefit more than 50,000 families that have traditionally inhabited the maritime zones of the Costa Rican coasts. The project was approved by the Legislative Assembly in the first debate on the 30th of April 2013 and then sent to the Constitutional Court for review. However, in August the court ruled on two points: that the first 50 meters of the maritime land zone cannot be inhabited under any condition, and that additional studies were required for the case of Ostional Refuge (Evans, 213).

Juan Félix Castro a social psychologist states in the context of Ostional and TECOCOS:

It is a project that gives a chance to the community to manage its own territory. It is a project that would achieve to protect the cultural heritage of the community, and the customs they have been building over many years. These are people who do not deserve that their ancestral territory which they are defending is been taken away from them ("EraVerde," 2009a).

In this vein, control over local resources by local people is often equally, if not more, important to gaining support for conservation activities (Campbell, 1998; Heinen, 1993). Promoters of community-based conservation argue that project participation and control by local people can enhance economic and social security and can cause community members to feel that it is in their interest to sustain their wildlife resources into the future (Western \& Wright, 1994 as cited in Campbell et al., 2007). 
Aforementioned background on Costa Rica, the themes of employment, development, gentrification, land ownership, corruption and conflicts of interest, are relevant to the case study, and will return throughout this thesis.

\subsection{Case Study: Ostional}

\section{2. 1 The Community of Ostional}

The community of Ostional consists of approximately 600 people and has 27 years of experience with conservation, sustainable development and volunteer projects organised by ADIO and the government organisation MINAE. There are several cabins and some families that rent out rooms to visitors and volunteers who come to Ostional to see the turtle arrivals. Olive Ridley Sea Turtles or Tortugas Marinas Loras (Lepidochelys olivacea) arrive almost monthly in one particular sector or across the whole beach (Vargas-Sánchez et al., 2011). Most of community life takes place along the main road with the plaza and along Ostional main beach. Next to the plaza are the Ostional Education Centre and School, Casa Multiusos and Cen Ostional where students can get meals (see Figures 2.4, 2.5 and 2.6). 
Figure 2.4: Ostional community map

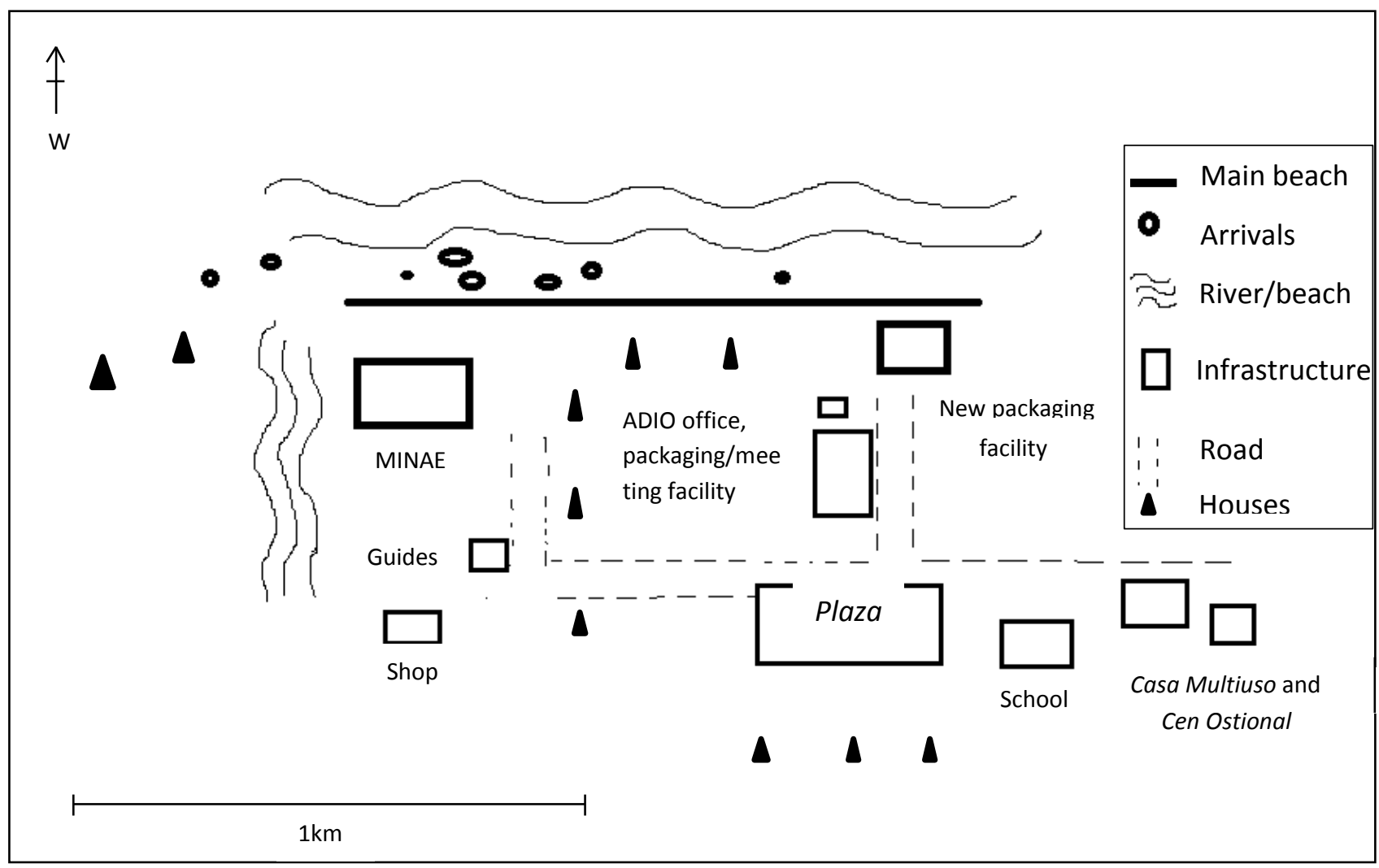

Source: The author

This bird's eye view of the Ostional community (Figure 2.4) lends a better idea of where resources, activities, problems, and opportunities are located in the context of a community map. It adds details on specific characteristics (beach, facilities, and vegetation) that further enhance the understanding of the area and the interactions between the physical environment and human activities described in this thesis. 
Figure 2.5: View over central Ostional

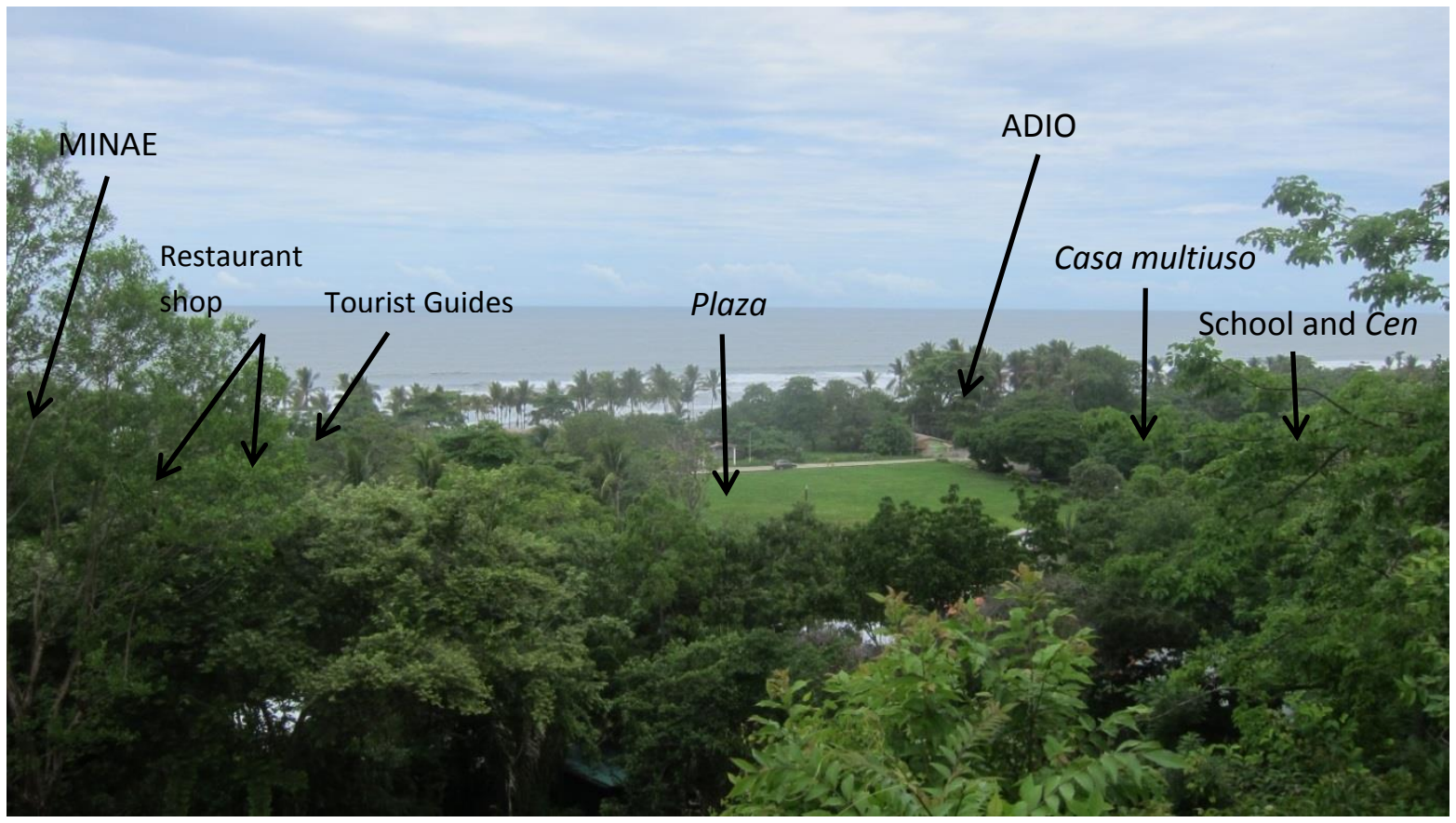

Source: The author

Figure 2.6: Ostional School, Cen Ostional and Casa Multiusos

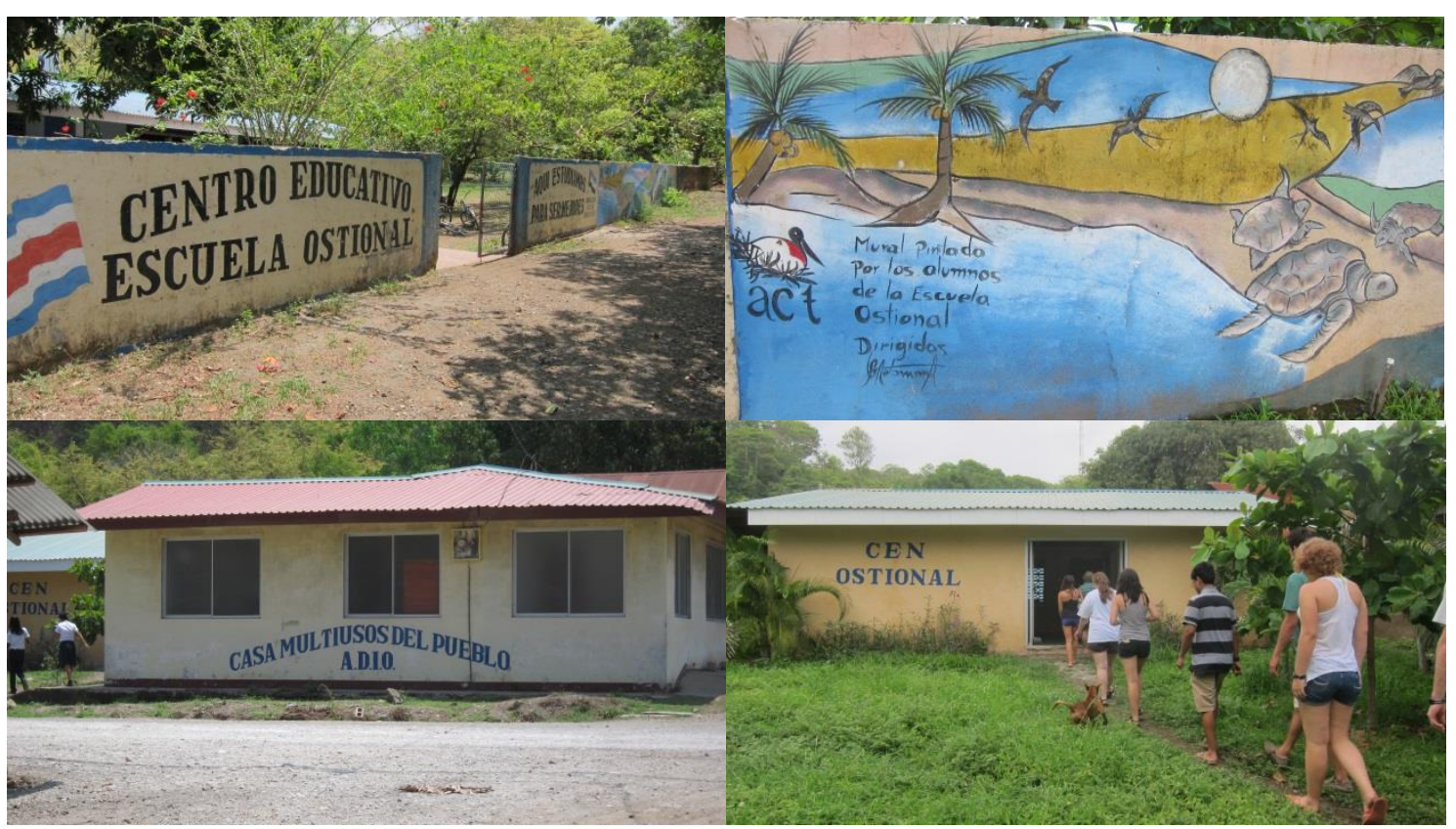

Source: The author 
ADIO, located at the main beach, has a packaging facility that is also used for community meetings (see Figure 2.7), and a small office for administration purposes next to it, where the junta directiva or board of administrators meets. During my fieldwork a new turtle egg packaging facility was built, which is located closer to the beach to simplify the harvest processes of extraction, washing, carrying bags and packaging for further transport to local markets.

Figures 2.7: ADIO turtle egg packaging facility and meeting house

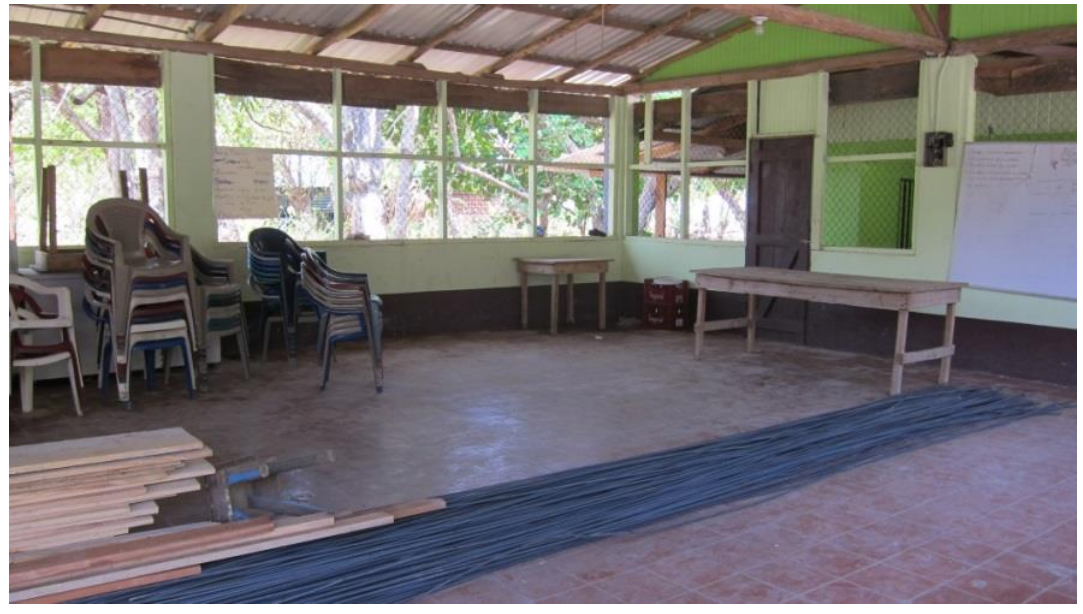

Source: The author

Figure 2.8: Newly built packaging facility of ADIO

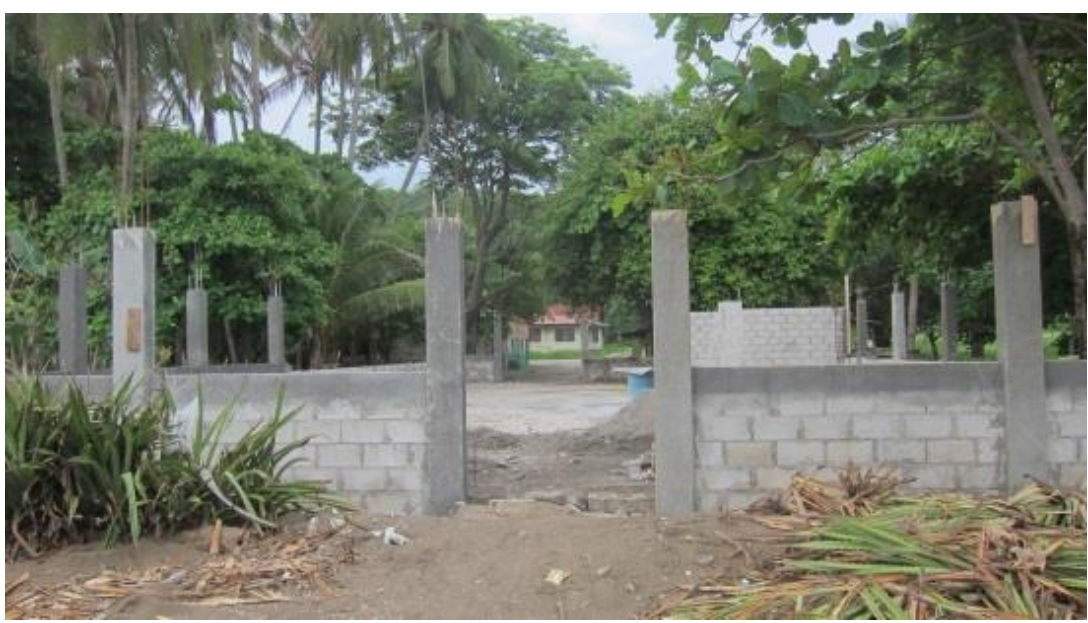

Source: The author 
On the south end of the main beach the government organisation MINAE runs a scientific station and quarters for volunteers (see Figure 2.9). The volunteer scheme is different to the one from ADIO and will be further explained later.

Figure 2.9:

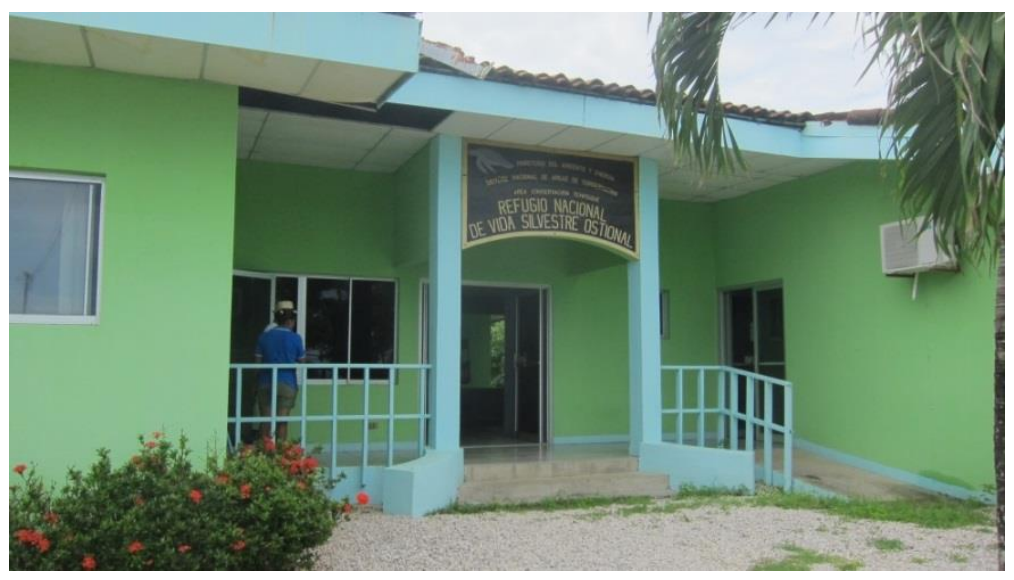

Source: The author

A small house about a hundred meters down the road towards the main street functions as a tourist guide meeting point, where visitors can pay a small price to get a guided tour of the beach during an arribada (see Figure 2.10).

Figure 2.10: ADIO tourist information and ADIO guides meeting house

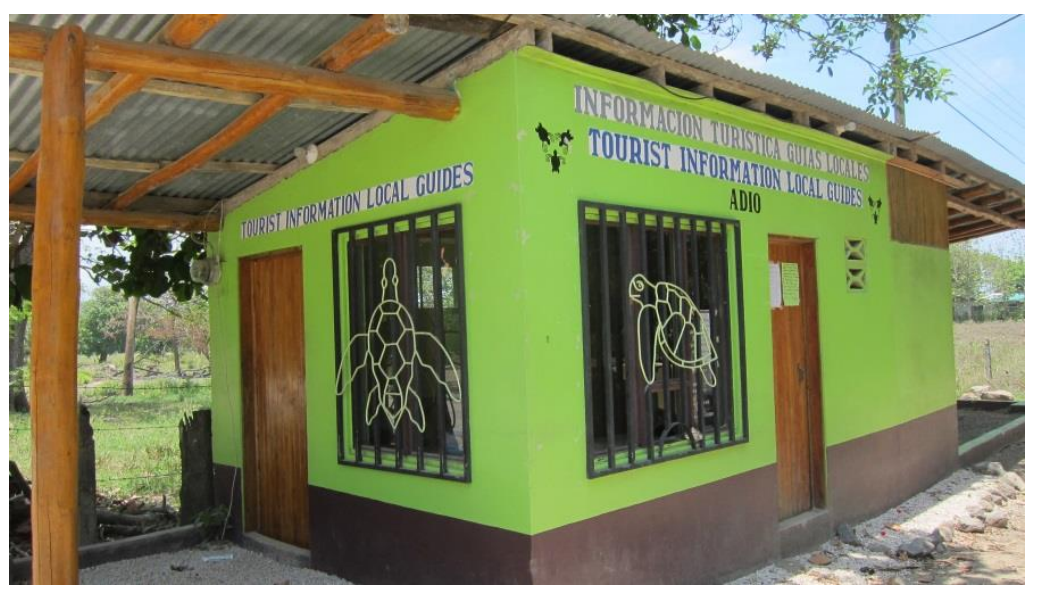

Source: The author 


\subsection{Ostional Wildlife Refuge and 'arrival' dynamics}

The Refuge was established in 1983 and is co-managed by a number of different groups and institutions: the Ministry of the Environment and Energy (MINAE), the University of Costa Rica (UCR), the Ostional Development Association (ADIO), and representatives from the local community. The Refuge encompasses 400 acres of land and 4050 acres of ocean on the Nicoya Peninsula of which 7 kilometres are Ostional beach (ADIO et al., 2012).

Being a wildlife refuge where ecosystems are tropical dry forest and mangroves, it is possible to observe flora and fauna typical of these ecosystems, including several species of birds, howler monkeys, several nocturnal animals, including raccoons, skunks and others. In the swamps near the beach you can see crocodiles, lizards, iguanas, and waterfowl in the marshes and mangroves. The mission of the National Wildlife Refuge Ostional is to fully protect marine ecosystems including coastal and breeding habitats of sea turtles, to remain indefinitely while benefiting local communities, and fostering participation in the conservation process through the sustainable use of resources, research, monitoring, ecotourism and environmental education.

The Olive Ridley Sea Turtle that arrives almost monthly at Ostional beach is considered the most abundant sea turtle in the world. But only on very few beaches such as Ostional, groups of hundreds of female turtles are found who nest simultaneously. In Costa Rica, there are two mass nesting beaches found in the province of Guanacaste. One of them located in Nancite within Santa Rosa National Park and the other within the National Wildlife Refuge in Ostional. Both were discovered simultaneously in 1970 during aerial tours, but the people of Ostional living in the region for over 100 years indicate that the arrivals began suddenly in the late 1950s (ADIO et al., 2012).

During big arribadas it is not possible to distinguish separate turtle tracks, since they overlap, due to the vast number of turtles arriving simultaneously. The arribadas or 'arrivals' happen every month, always associated with a certain moon phase, and are most predictable over the winter months from May to November, because more turtles arrive in the rainy season. Generally the turtles come out at night but large arrivals in the rainy season sometimes last from about two in the afternoon until seven o'clock in the morning of the next day. 'Arrivals' in summer usually last three days but some winter nights can last up to eight days continuously. During these big arribadas turtle numbers are increased to around 1,000,000, of which each turtle lays on average 100 eggs. Between 45 and 55 days after the eggs were 
laid, thousands of turtles are born. They begin their journey across the sea, facing many predators that attack them on their way. But, fortunately the Ostional beach is protected by residents of the community and volunteers, so that the baby turtles can reach the sea and return to Ostional between 10 and 15 years later (Morera, 2013).

Figure 2.11: Arribada during the rainy season (winter)

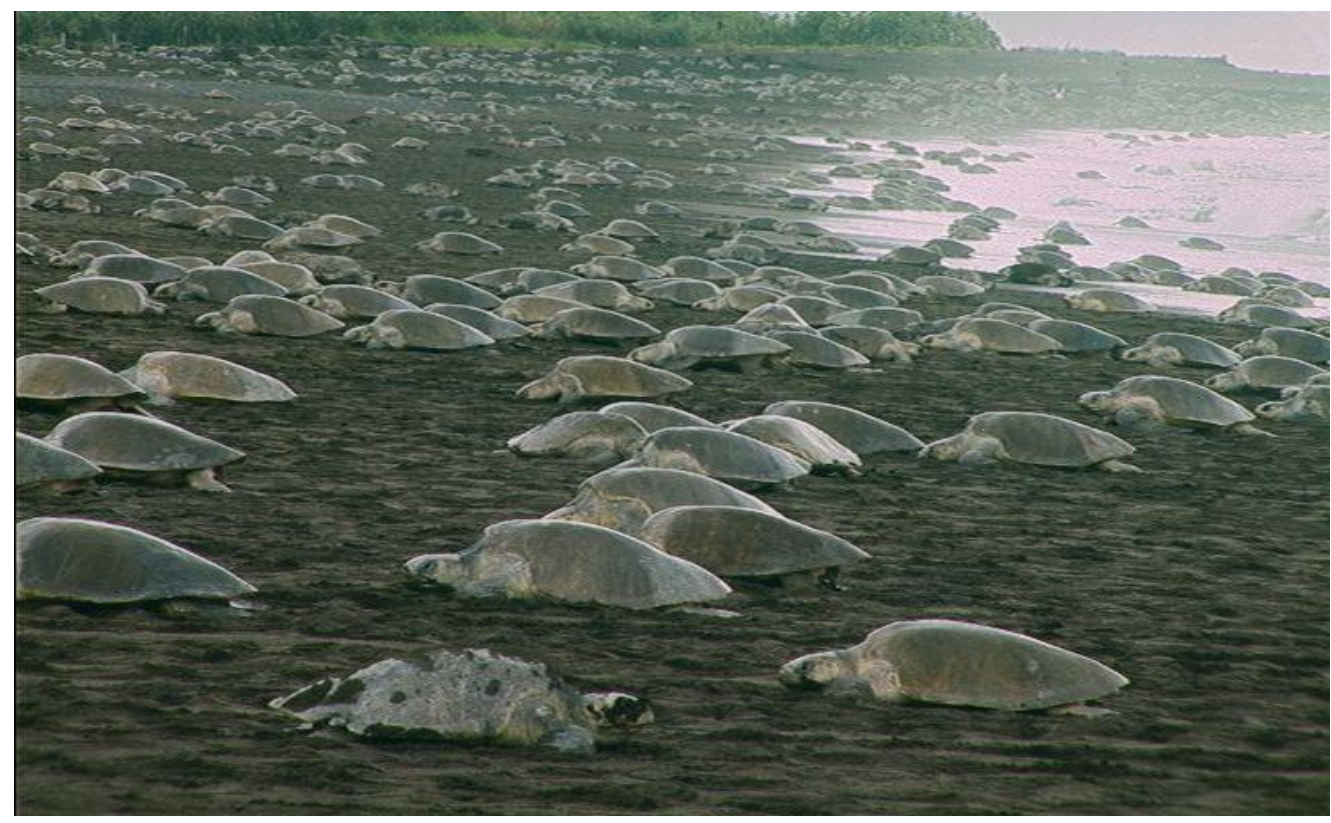

Source: (Morera, 2013)

Tourists who come to the beach to watch the arrival and birth of the baby turtles must comply with some requirements: they must be accompanied by a local guide; it is recommended not to use torches with strong light, preferably red cellophane over the light of the lantern (no light directly over the head and eyes of turtles); no flash photography; no moving of marks and other signs at the beach because they are used for the research of sea turtles; all groups should be divided into teams of ten people who will be accompanied by authorized local guides; it is not allowed to enter the beach with vehicles; no camping or campfires on the beach; no coolers or alcoholic beverages are allowed; and during the arrivals surfing activities are prohibited (Morera, 2013).

From 1959 until the beginning of the 1980s the turtle arrivals in Ostional occurred in the central mile of Ostional and Nosara beaches (Chaves, 2007). In the Project Monitoring Nesting of Turtles in Ostional (NWR) by the University of Costa Rica and ADIO, both the arrivals and the solitary nesting of sea turtles have been monitored from 1970 to the present 
(Cornelius and Robinson, 1985 cited in Campbell, 1998). Every morning for approximately 340 days a year, seven kilometres of the beaches Ostional and Nosara are monitored by the resident biologist (Chaves, 2007). Since the 1950s the arrivals have spread gradually and from 2002 to the present they started to occupy the totality of Ostional and Nosara beaches (ADIO et al., 2012).

Scientific data about the turtle populations obtained through the continuous monitoring and evaluation of the resident biologist and by the University of Costa Rica suggests stability of the population throughout the years (ADIO et al., 2012). The process of harvesting and marketing the turtle eggs, and the involvement of the Ostional community are described in more detail in the following paragraphs

\subsection{ADIO: Associación de Desarrollo Integral de Ostional (Association of Integral Development of Ostional)}

Legally established in 1987, ADIO's main goal is to conserve and coexist with the natural abundance of Olive Ridley sea turtles, while developing the community and creating an alternative means of income and community development for the population of Ostional.

The local conservation aspect of the Project aims to protect and preserve endangered sea turtles now and for future generations while managing and monitoring the turtle populations. Finances come partly from tourism, but mostly from selling about $1 \%$ of the eggs laid during the great 'arrival' times.

In order to take advantage of this resource, legally as well as rationally, the community is organized by the ADIO, which, through Article 55 of Law No. 7064 for the Promotion of Agricultural Production (FODEA) of May of 1987, authorizes ADIO to the extracting and marketing of Lora turtle eggs. This Project is supported by the national and international scientific communities, as well as the American Convention on Protection and Conservation of Sea Turtles. A number of institutions have an involvement in the Ostional wildlife refuge and get together regularly to create a five year management plan for the refuge. The management plan is developed and supported by MINAE, INCOPESCA, UCR, SENASA, ADIO and GUARDA COSTAS (see Figure 2.12). Every five years, all the rules related to the use of eggs are established in this plan, including the extraction or harvesting, marketing, 
control and monitoring, visitation, research and other issues related to a sustainable resource use of the eggs.

Figure 2.12: Logos of the institutions that annually develop and evaluate the Five Year Plan for the Management and Conservation of Lora Sea Turtles

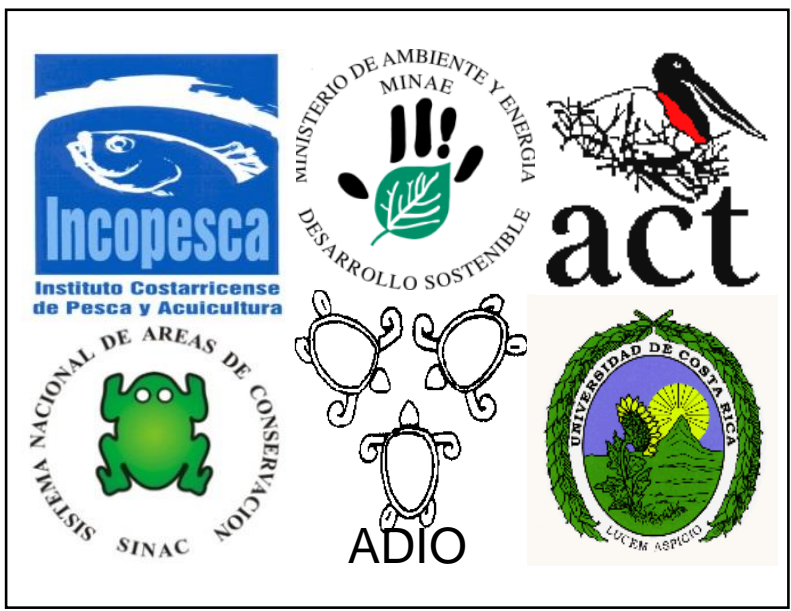

Source: Morera (2013)

The Wildlife Directorate of the Ministry of Environment and Energy (MINAE) is responsible for the Ostional Wildlife Refuge (and for all national wildlife refuges). MINAET is authorised through Tempisque Conservation Area (ACT) to act as administrators of the National Wildlife Refuge Ostional. The Institute of Marine Fisheries (INCOPESCA), which is part of the Ministry of Agriculture and Livestock (MAG), is responsible for overseeing the administration of the Project, while the Association for Rural Economic Development (DINADECO) is the government liaison with ADIO.

In each arribada between $70 \%$ to $90 \%$ of the eggs are being lost, this is due to the destruction of nests by the other Lora turtles, sand contamination by microorganisms (fungi and bacteria) that result from the decomposition of eggs, predation of eggs by animals, beach erosion by waves and flooding of the marshes. From the number of eggs laid in each arribada, about $0.5 \%(900 \mathrm{~m}$ of the $7 . \mathrm{Km}$ beach) is extracted for commercialisation or private use for ADIO members (see Table 2.2). This extraction is done only during the first two and a half days of an arribada as spawned eggs are destroyed by turtles that come in the following days. The monitoring and data generated by the School of Biology at the University of Costa Rica suggests that eggs laid during the first two and a half days of an arrival have a survival probability that is close to zero, due to the high density of turtles on 
this beach. This knowledge is important for the design of the sustainable-use Project of the Olive Ridley eggs, and the corresponding work of ADIO (ADIO et al., 2012).

Turtle eggs are usually extracted from the Main Nesting Beach, but other beach areas have also been used before when the arrival has not occurred on the main beach, however, this has been rare (ADIO et al., 2012).

Table 2.2: Turtle eggs extracted in the Project on Ostional main beach

\begin{tabular}{|l|l|l|l|l|l|}
\hline & $\mathbf{2 0 0 7}$ & $\mathbf{2 0 0 8}$ & $\mathbf{2 0 0 9}$ & $\mathbf{2 0 1 0}$ & $\mathbf{2 0 1 1}$ \\
\hline $\begin{array}{l}\text { Total Eggs } \\
\text { Not } \\
\text { Marketed }\end{array}$ & 516,043 & 622,710 & 621,282 & 493,362 & 702,214 \\
\hline $\begin{array}{l}\text { Total Eggs } \\
\text { Marketed }\end{array}$ & $3,993,800$ & $5,278,800$ & $3,399,800$ & $2,511,400$ & $3,690,800$ \\
\hline $\begin{array}{l}\text { Total eggs } \\
\text { retrieved }\end{array}$ & $4,509,843$ & $5,901,510$ & $4,021,082$ & $3,004,762$ & $4,393,014$ \\
\hline
\end{tabular}

Source: ADIO et al. (2012)

Furthermore, only ADIO members can legally harvest the eggs. The harvest of turtle eggs that nest solitarily and outside the arribadas is prohibited. Once collected, the eggs are packed in plastic bags and printed with the logo of the ADIO and other specifications (see Figure 2.13). The eggs are sold in the domestic market in supermarkets, seafood bars, restaurants and farmers markets in different parts of the country. The net product sales of the eggs, which make up for $70 \%$ of the income is distributed among the members of the ADIO (260 in 2012). $30 \%$ of this money is locally used, for operating expenses, research, scholarships, contributions to environmental education training (throughout the schools of the entire region), grants to various committees and organizations, sport, school, college, community works and social assistance. Senior citizens, and chronically sick are not required to work and receive $100 \%$ of the incentive. Also, mothers receive the same benefit two month before and after giving birth (Morera, 2013). 
Figure 2.13: ADIO egg harvest and packaging

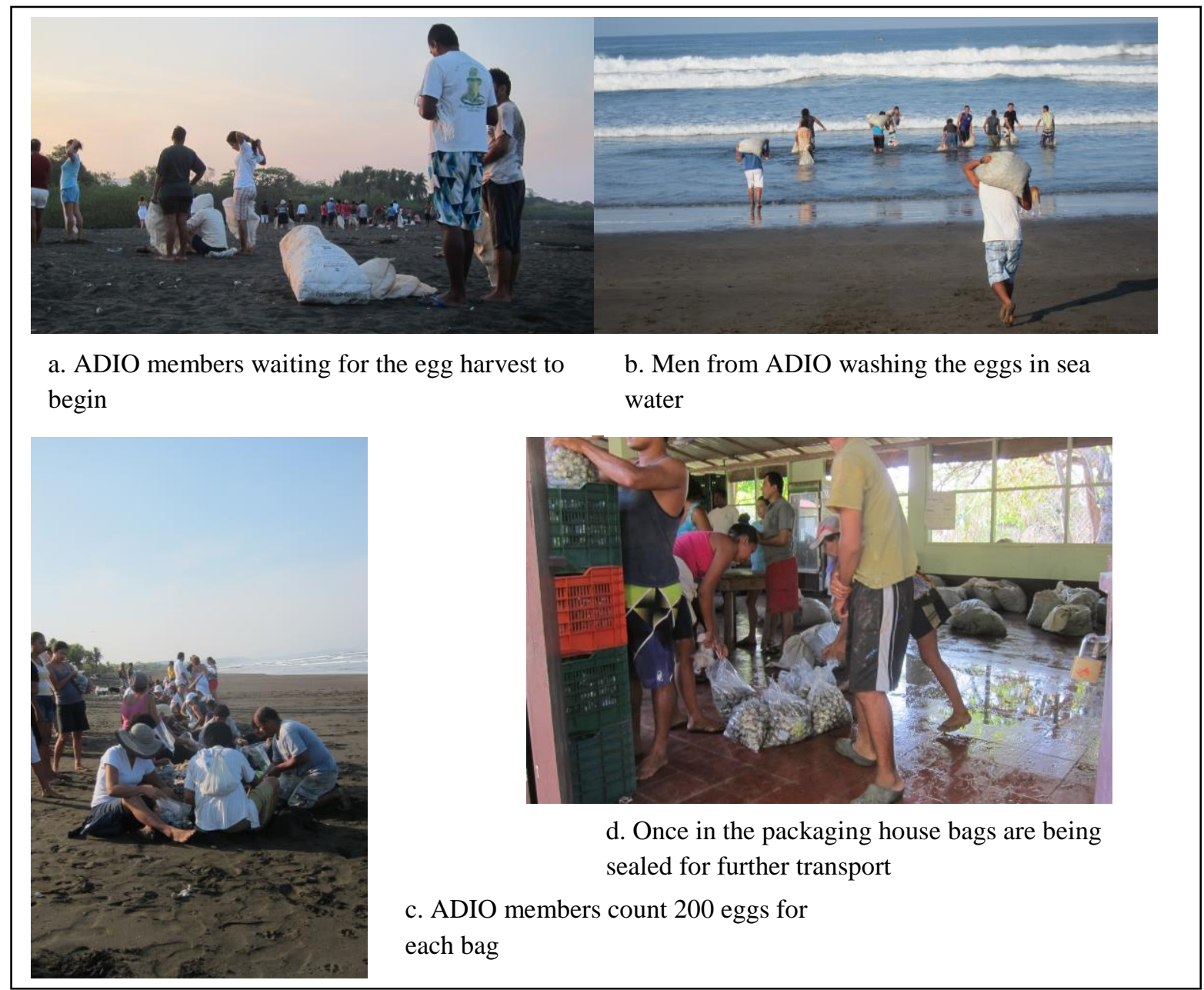

Source: The Author

Additionally, ADIO is running a Volunteer rotation scheme. The scheme rotates volunteers amongst 22 families who are ADIO members and want to be involved. This ensures that socio-economic benefits from volunteering are equally distributed throughout the families. MINAE runs a separate volunteer scheme, which has access to more resources and subsequently attracts more volunteers. A volunteer I met during my stay explained that she got to MINAE through the Global Volunteer Network which works with 'in-country partners' in Costa Rica and is an organisation called Maximo Nivel. Other MINAE volunteers came to Ostional through International Student Volunteers (ISV) and International Volunteer HQ (IVHQ). MINAE volunteers usually stay at the accommodations of the MNAE station. Only when spaces at the station are filled, volunteers are sent to a few selected families who work with MINAE. I was the only ADIO volunteer due to a lack of volunteers coming to the Project. I organised my stay with a local family through Green Life Volunteers, which distributes volunteers to sustainable projects around Costa Rica. I was told by a community 
member that the lack of ADIO volunteers during my time in Ostional might be the result of insufficient resources to advertise the ADIO scheme and to attract volunteers as well as bad publicity due to conflicts with the government in the past.

Furthermore, ADIO and the extraction of eggs as part of the Project of Sustainable Use, Management and Conservation is entirely locally organized, promoting the development of community services through an alternative economic scheme. ADIO's board of directors is made up of a president and an executive committee of eleven persons including the president. In terms of membership, as of 2012, ADIO had approximately 260 active members.

The Project resources have become the main source of income of the residents of Ostional, as well as a source of community development. ADIO has shown to be an indispensable initiative for a vast number of community members and has withstood, and evolved out of, various internal and external challenges. Internal conflicts are related to membership restrictions (only Ostional-born people can be ADIO members), noncompliance with regulations, the illegal extraction of eggs and tension with MINAE associates. External problems are primarily related to a conflicting situation with the government, due to legal issues related to the creation of the Wildlife Refuge and matters of social justice (this will be further discussed in my findings and discussion).

ADIO is entirely committed to conservation, protecting the turtles, cleaning the beach, controlling the growth of vegetation on it, helping the baby turtles when they hatch and patrolling the beach. As a result of establishing ADIO and the volunteer programme, the growth and proper management of the turtle populations and the socioeconomic status of the entire community have increased. Moreover, it can be argued that the population of Ostional would have mostly disappeared if not for the economic security and opportunities the turtle project offers (Vargas-Sánchez et al., 2011).

This chapter has attempted to deliver an overview of relevant information about Costa Rica and a detailed description of the location and organisation of the case study for this thesis. Information provided in this chapter is given for a better comprehension of the findings of my fieldwork and will reappear in the discussion (Chapter VI). Together with the following chapter on the academic framework, this chapter was designed to help place the research theme of this thesis into a wider academic context. In the next chapter I will provide a review of the relevant literature for this thesis. 


\title{
CHAPTER III
}

\author{
LITERATURE REVIEW
}

This chapter provides a review of the relevant literature in relation to sustainable community development and the case study of this thesis. Themes relevant for this thesis include sustainable development, conservation, ecotourism, community participation and community sovereignty and are elaborated in this chapter. The chapter aims to situate my research within the current debates and demonstrates the contribution of my research to the academic literature. Connections between concepts are made and their relevance for my case study is discussed. This chapter, therefore, outlines the theoretical and empirical foundations for the local development framework of my case study. Finally, it explores the significance of this study and outlines reasons for using ADIO as a case study in light of aforementioned debates.

\section{1 Contextualisation of Relevant Concepts}

Most of the key terms in the field of sustainable community development are as contested as they are popular, because they are based on individual ideologies and are context-specific. This section therefore defines and discusses relevant key concepts and relates them to each other as well as to the focus of the study.

The vast discourse on sustainable development makes it a difficult and abstract concept to define. More than 80 different, often competing and sometimes contradictory definitions, have been identified (Fowke \& Prasad, 1996). Connecting to the definition given in the introduction, what seems to be the best known definition, has been given in the Brundtland Report in the mid-1980s, published under the UN system by the intergovernmental commission to report on environmental issues of "development that meets the needs of the present without compromising the ability of future generations to meet their own needs" (Van Marrewijk, 2003, p. 98). Trevor (1999) adds that sustainable development in the wider sense, as originally formulated in the Brundtland report, is and should be about the broader issues of ensuring social justice, while, at the same time, improving quality of life. Another definition of ecological sustainability is useful in the context of the case study for this thesis and considers the sustainable harvest of species. According to Robinson (1993, p. 23), "the only 
requirement for ecological sustainability is that harvest from the population must not exceed the potential yield, meaning the total production subtracting natural mortality”. D. W. Pearce et al. (1989, p. 3) take this a step further and argue that "each generation should leave the next a stock of assets at least as great as that which they inherited themselves". Along with the rapid rise of these concepts has come a recognition of the "scope for local involvement in planning and implementing sustainable development solutions" (Selman, 1996, p. 1).

The idea of the scarcity of the Earth's resources is not new, nor is the conception that people should be involved in the planning and management of their own area. Yet, terms such as 'sustainability' and 'sustainable development' are widely debated in the academic literature. To understand what brought about today's extensive discourse on sustainability it is necessary to recognise the starting point of much of the sustainable development literature, and what is called the 'environmental paradox'. The term suggests that there is a mismatch between what is demanded of the earth and what the earth is capable of supplying (Cahill \& Fitzpatrick, 2001). In recent years, there has been considerable apprehension around environmental trends that concern all of humanity because they are global in scope; the Rio Earth Summit and the Kyoto Summit are only two examples of this trend. It has become evident that human activity has damaged important ecosystems on every continent, threatening the security of the societies that depend on these ecosystems (Vitousek et al., 1997).

Many scientists have pinpointed reasons for the current global dilemma. Roseland (2000) for instance suggests that, at present, communities in the global North and in many industrially growing countries are not developed sustainably. It is particularly unsustainably developed cities of the world that account for most of the world's pollution and consume most of the world's resources. Correspondingly, current scientific data suggests that "global resource depletion and pollution are forcing recognition that existing patterns of development and resource use are not sustainable" (Roseland, 2000, p. 75). With the intention to confront this problem, many agree that, if global agreements on environmental sustainability are to show success, action at the local level is required (Agyeman \& Evans, 2003; Brugmann, 1996; Ghai \& Vivian, 1992; Roseland, 2000). Still, fairly little attention has been given to examining small scale local incentives within the global context.

Scientists agree what also is required is either a reduction in societal demands or an increase in the earth's resources, so the gap between demand and supply can at its least be bridged to 
some extent (Hotelling, 1931; Lubchenco, 1998; Vitousek et al., 1997; Wackernagel, 1996; Williams \& Millington, 2004). A moderate view on how demands and resources can be balanced combines two core schools of thought and seeks to both expand the amount of resources, and reduce demands for those resources (Williams \& Millington, 2004). For others the answer lies in the local knowledge and small scale handling of resources while, at the same time, making use of existing resources more efficiently (Blaikie et al., 1997; Fischer, 2000). Proponents of the deep ecology paradigm argue that the demands we make on the earth need to be revised in order to reduce consumption. Following this view, rather than adapt the earth to suit our demands, we adapt ourselves to meet the finitude of nature; something which indigenous communities around the world have acknowledged and were forced to do for centuries (Williams \& Millington, 2004).

In order to understand 'sustainability' or the balance between natural resources and human interaction, the terms of natural capital and social capital have been defined as key features of sustainable community development and are described in the following paragraphs.

\subsubsection{Natural and social capital}

This sub-section defines key concepts of 'natural capital' and 'social capital', which are important concepts in the discourse around sustainability and participation, and relates them to each other as well as to the cross-cutting concept of the focus of the study.

Even conservative neoclassical economists are recognizing that the 'sustainable' component of development requires that human activities today do not deplete what can be termed 'natural capital'. Natural capital refers to any stock of natural assets that yields a flow of valuable goods and services into the future. For example, a forest, a fish stock, or, in the case of Ostional, the abundance of sea turtles can provide an egg harvest that is potentially sustainable year after year. The turtle stock is 'natural capital' and the sustainable harvest of eggs is 'natural income'. A minimum necessary condition for sustainability is the maintenance of the total natural capital stock at or above the current level. While a lower stock of natural capital may be sustainable, a community cannot risk a further decline in natural capital given the ambiguity and the consequences of estimating incorrectly (Costanza \& Daly, 1992). "This 'constancy of total natural capital' rule can thus be seen as a minimum 
condition for assuring sustainability, to be relaxed only when solid evidence can be offered that it is safe to do so." (Costanza \& Daly, 1992, p. 40).

Furthermore, the sense of connectedness and formation of social networks comprises what has become known 'social capital' (Putnam, 2000). Networks are usually informal groups of people who know each other personally, such as villagers in Ostional who help each other at harvest time or friends and neighbours who help each other cope. Social capital is the shared knowledge, acquired skills, patterns of interactions and understandings that people bring into a specific productive context (Coleman, 1988; Falk \& Kilpatrick, 2000). It is formed consciously through training and education and unconsciously through experience and participation (Ostrom, 2000). The first significant appearance of the concept of social capital was in the work of Jacobs (1961), where she used it to describe a norm of social responsibility, a corresponding atmosphere of social trust and interconnecting networks of communication (Coleman, 1988).

Additionally, social capital refers to the organisation, structures and social relations which people build-up themselves, independently of the state or large corporations. It contributes to stronger community ties, and, often as a by-product of other activities, builds "bonds of information, trust, and inter-personal solidarity" (Coleman, 1988, p. 95). Social capital is created when individuals learn to trust each other so that they are able to make reliable commitments and "rely on generalised forms of reciprocity rather than on narrow sequences of specific quid pro quo relationships" (Roseland, 2000, p. 73). Social capital is created by the individuals who form social networks, in order to produce goods and services, nonmonetized as well as monetized (Roseland, 2000).

Social networks can provide many informal types of social security and health care to individuals within a collective 'caring' network, as exemplified in the case of ADIO, through the social-caring network the Project provides for community members who work with the Association. Social capital can also add to natural capital, for example, by enhancing the use of natural resources, such as the sea turtle population, through participation and collective action. Another significant point about social capital is that, because it is located in relationships with specific individuals, social capital that is mobilized for one purpose can be readily appropriated for other purposes, such as standing in unity in political situations or when the sovereignty of the village is under threat (Roseland, 2000). 
Social capital is an important feature in the pursuit of social sustainability. "Social sustainability occurs when the formal and informal processes; systems; structures; and relationships actively support the capacity of current and future generations to create healthy and liveable communities. Socially sustainable communities are equitable, diverse, connected and democratic and provide a good quality of life" (Woodcraft et al., 2011). Social sustainability is important in the context of Ostional and intra-community conflict as well as in the context of mobilising social capital for extra-community conflict and in order to increase natural capital, as discussed in chapter VI.

In light of the literature on the above concepts and what we know about ADIO, we can say that the Association has been successful in preserving Ostional's natural capital and has strengthened social capital (as will be further explained later. Through the constant monitoring of the sea turtle populations, the detailed data collection of nests and their survival or destruction through predators or poachers, and respective data analysis by the University of Costa Rica, ADIO can demonstrate the consistency of turtle numbers at the Ostional beach. The data provided by the five-year management plan of the Ostional Wildife Refuge suggests that the harvest, of less than $1 \%$ of turtle eggs by ADIO, is sustainable. Information on the scientific monitoring of the turtle populations suggest that Ostional's natural capital is not being compromised for future generations, given that the community can minimize constant threats to the Project such as the illegal extraction of eggs and tourism development pressures in the area. According to Campbell (1998, p. 320), thus "Ostional is one of the only documented cases of a commercial, consumptive use of sea turtles that appears to fulfil the objectives of both sustainable use and community-based conservation".

Also, in Ostional, social capital is well developed and has helped the fortitude of ADIO and the community of Ostional through many challenging and threatening situations. The fact that ADIO has created or has emerged from a collective 'caring network' provides the community with social security and infrastructure for healthcare, education and capacity building. At the same time, protecting and managing the natural capital of the sea turtles that arrive at the Ostional beach fills people with pride and purpose. The notion of social capital in Ostional and the 'social caring network' ADIO has established in the community will be further analysed and discussed in chapter five of this thesis. 


\subsubsection{Community Participation}

A further key concept of my research is 'community participation'. The definitions of 'community' and 'participation' are a matter on which there is considerable disagreement among development scholars and practitioners. According to Palomino Schalscha (2011), the term 'community' remains problematic, because it overlooks the diversity among heterogeneous groups of people. Nevertheless, following the notion that community is a group of people living in the same place or having particular characteristics such as language, cultural values and practices in common (Garcia, 2011), the term 'community' is useful in describing Ostional and its residents. Agrawal and Gibson (1999) also suggest a more political approach: community must be examined by focusing on the multiple interests and actors within communities, on how internal and external actors influence decision-making.

Furthermore, some authors use the term 'participation' to describe active participation in political decision making. For certain activist groups, 'participation' has no meaning unless the people involved have significant control over the decisions regarding the organisation to which they belong (Dahl, 1994). Development economists, amongst others, tend to define 'participation' by the poor in terms of the equitable sharing of the benefits from these projects. A definition of 'community participation' that is most fitted to the case study of this thesis has been outlined by Cloete (2006, p. 5), as the "active involvement of local communities in development initiatives, where specified groups, sharing the same interests or living in a defined geographical area, actively pursuit the identification of their needs and establish mechanisms to make their choice effective". Peters (2000) adds that this form of involvement requires the ability of people to share, influence, or control, planning, decision making, and execute authority in development projects and programs that affect their lives and resources. High levels of community participation are usually a sign of good leadership and progress that benefit the whole community (Flora et al., 1997).

From a community perspective, participation also means contesting the top-down approaches which are often imposed on communities by outsiders. Furthermore, it has been argued that if stakeholders are included in decision making, they will become more self-reliant; meaning that dependency on outside actors is diminished. (Burkey, 1993; R. Chambers, 1997). Therefore, the argument that participation in collective decision making is a necessary condition for equitable and sustainable development outcomes (Alsop \& Kurey, 2005) is the baseline of this thesis. 
As much as most of the academic literature mirrors the importance of community participation in development, it is not as clear about the shortfalls of their notions. For instance, some writers criticise the conception that communities are portrayed as homogenous and having the same aspirations, values and perceived needs, when in reality they are diverse, can have different opinions and conflict amongst members and contain hierarchies around aspects including class and gender and marginalised groups (Crissman, 1967; Rifkin, 1986; Takano, 1997). Other deficits of the concept of community participation have been identified as the inclusion of some social groups at the expense of the others, which leads to conflicts, and that it causes experiences of disempowerment, inequality and inefficiency (Kellert et al., 2000; McFarlane, 2000; Taylor, 2007). It has also been stated that mechanisms of inclusion versus exclusion in community participation might result in antagonism as priorities and ideologies are contested (Hussein, 2003; Narayan et al., 2000); and "it can also be perceived to be elitist" (Davids et al., 2005, p. 20).

Nevertheless, participatory development, particularly community participation, can have important benefits. Davids et al. (2005, p. 20) outlines the following benefits: "Participation gives people the feeling that they 'belong' to the Project, thereby allowing people to develop a sense of ownership which can promote sustainable development". Further, participation motivates people to accept responsibility for their own development, thus promoting selfreliance and participation which also leads to capacity building and empowerment especially at an organizational level. It is also argued that community participation enhances efficiency and effectiveness, sustainability of development projects, and strengthens democratisation and empowerment (Cleaver et al., 2001). In that vein, participation is an useful aspect of development and poverty alleviation as it "lowers cost, helps better target (Kleemeier, 2000, p. 929). Community participation regards people' needs, it incorporates local knowledge and it ensures that benefits are equitably distributed" (Kleemeier, 2000, p. 929). Community participation is regarded as important, as the best way to address the perceived needs of the local people and when these needs are met, people's commitment and confidence in the local governance institutions and their own capacity is enhanced. Chinsinga (2003, p. 132) adds that for a project to be sustainable it must address those problems and aspirations that are identified by the people themselves. ADIO in Ostional relies on community participation for the successful implementation of the Turtle Project and the wellbeing of the whole community. In this regard, meaningful community participation can 
enhance social capital, and increases the likelihood of successful project implementation because it is perceived as beneficial to the community.

\subsubsection{Conservation, environment and development}

Other important concepts for this thesis are debates around conservation, environment and development. The pace of global ecological degradation suggests that human activity is already undermining essential ecological functions. Given the threat to societies around the world associated with irreversible degradation of the ecosphere, and the increasing probability of a worsening of the situation under current development approaches, the world is confronting a catastrophic risk. To recall, sustainability requires maintaining an adequate stock of environmental resources for future generations and avoiding irreversible damage to any single significant resource (Roseland, 2000). The idea of environmental conservation goes hand in hand with this concept of sustainability, with the aim of protecting the world's biodiversity, and ecosystems from excessive rates of extinction and degradation (Sahney \& Benton, 2008; Soule \& Wilcox, 1980). The economic benefits of destroying natural capital stock or the social costs of conservation may seem large, but "only as a function of our inability to adequately assess such costs and benefits" (Rees, 1991 in Roseland, 2000, p. 192). In short, if the potential benefits of conservation can be shown to secure the future, the costs are irrelevant limits (Rees, 1991 in Roseland, 2000). This suggests that it is time for a different kind of framework for planning and decision-making, guided by the understanding that natural capital stock should not be destroyed.

Some attempts to connect sustainability, environment, conservation and development have been made, as Campbell (2002, p. 29) points out: "Over the last decades, nature and wildlife conservation policies have shifted away from promoting approaches that exclude local people from parks and protected areas and prohibit their use of resources, towards attempting to reconcile conservation with development needs". Campbell (2002) has further distinguished two types of narratives that exist in regard to the management of parks and protected areas. First, a common traditional approach supports the "protection of parks and protected areas from human exploitation, habitat degradation and fragmentation from increased human populations, their unsustainable development and their demands on local resources" (Campbell, 2002, p. 30). This approach is supported by the argument that "local people do not value wildlife, at least not in the same ways that outside and often 'Northern' people do" 
(Campbell, 2002, p. 30). In this vein, people are seen as a hindrance to efficient and 'rational' organisation of resource use. This 'rational' logic supports the belief that the goals of conservation and the interests of local communities are in opposition: Conservation requires protection of threatened resources, and members of local communities, who rely on these resources, exploit them without restrictions. Efforts by biologists and governments to solve this dilemma have resulted in detailed wildlife protection strategies to create spaces protected from human impact and exploitation. One strategy is the relocation of local people which often meets resistance from the local population, due to unsatisfying conditions and poor arrangements. Hence, this traditional approach is often too simplistic when put into practice because it does not meet the needs of local populations who have often lived in a place for generations and are emotionally attached to their homes (Campbell, 2002).

There is however a counter narrative that emphasises the concepts of 'sustainable use' and 'community-based conservation' (Campbell, 2002). The concept of 'sustainable use' relies on the assumption that wildlife and biodiversity conservation is valuable, often resulting from the utilisation of the resource (Freese, 1994, Swanson and Barbier, 1992 in Campbell, 2002). On the other hand, the concept of 'community-based conservation' indicates "at least some of the following: local-level, voluntary, people-centred, participatory, decentralized, village based management" (Little, 1994 in Campbell, 2002). In 'community-based conservation', "local involvement in and sometimes control over conservation undertakings is critical to their success" (Campbell, 2002, p. 31). The narrative identified, emphasises the potential 'sustainable use' and 'community-based conservation efforts' hold when applied together and as alternative to the traditional way of dealing with the enforcement of wildlife conservation. This approach also represents an inclusive, rather than exclusive, approach to conservation, while, at the same time, attempting to satisfy both the environment and often much needed community development. The case study of this thesis, ADIO and the Ostional community is an example of what 'sustainable use' and 'community-based conservation' might look like, keeping in mind that complex local dynamics may impact on the complete success of the discussed concepts.

In the wider context, and on the current development agenda, it seems as if communities are now becoming the focus of conservationist thinking. Agrawal and Gibson (1999, p. 629) point out that "international agencies such as the World Bank, IDRC, SIDA, CIDA, Worldwide Fund for Nature, Conservation International, The Nature Conservancy, The Ford Foundation, The MacArthur Foundation, and USAID have all adapted 'community' as 
conservation strategy". They direct their funds and work toward community-based conservation and resource management programs and policies. Agrawal and Gibson (1999) have also identified a flood of scholarly papers and policy-centric reports that feature community-based management (e.g., Arnold, 1990; Clugston and Rogers, 1995; Dei, 1992; Douglass, 1992; Perry and Dixon, 1986; Raju, Vaghela and Raju, 1993; Robinson, 1995). In addition, the increasing prominence of the idea of participation, indigenous and ethnic claims about the stewardship for nature by local populations assists those who advocate a central role for community. In this vein, non-government organisations (NGOs) have helped to amplify the voices of local, indigenous, and community groups (Clay, 1988; Redford and Mansour, 1996 in Agrawal \& Gibson, 1999, p. 629).

Historical ecologists emphasise that environments have histories from which humans cannot be excluded and that humans have modified ecosystems greatly for millennia (Agrawal \& Gibson, 1999; Bailey \& Headland, 1991; Brookfield \& Padoch, 1994; Vitousek et al., 1997). If human populations have shaped and used their environments in sustainable ways for thousands of years, it may be possible to establish sustainable coexistence with the same results today. Much literature has shown communities to be successful and sustainable alternatives to governmental and private management of resources (Berkes, 1989; Berkes et al., 1989; McKean, 1992; Ostrom, 1990). Scholars have emphasised the important time and place and specific knowledge that members of communities hold and the arrangements they establish to achieve successful local resource management. Communities have a long-term need for the renewable resources located where they live, and furthermore, they hold more knowledge about these local resources than other external actors. They can, therefore, be seen as the best managers of their local resources. In the case of Ostional the community uses a mixture of local traditional knowledge, relationships of caring and long-term investment alongside modern western science. This is interesting in moving beyond imaginaries of 'traditional' communities and how these can comprise different traditional and modern approaches to 'ways of knowing'.

Therefore, as Ball and Ormerod (2000) argue, without reshaping the approaches to development and poverty alleviation, "biodiversity will pay the price for development yet again" (Ball \& Ormerod, 2000, p. 389). Said this, it is not to be assumed that communities are always the solution to sustainable development and conservation (Berkes, 1989). Nevertheless, knowledge about sustainability can be obtained and changes according to 
natural and social elements and processes. Therefore, communities display potential, and have often been successful in managing their local resources sustainably.

Furthermore, different positions on the topic of conservation and poverty alleviation are revealed the literature. This is as exemplified in the 'parks and sustainable use debate'. According to Adams et al. (2004), four positions can be identified: First, advocates of strictly enforced protected conservation areas in developing countries who are treating biodiversity and poverty as separate problems. Second, advocates of programmes to improve the situation of people living around parks, in order to locally create awareness about conservation, perceiving poverty as a constraint on conservation. Third, advocates of equal distribution of revenues from parks to all stakeholders and for compensation, attempting to ensure that conservation does not increase poverty. And lastly, "those who propose conservation strategies building on the needs of local communities for sustainable harvest of wild species resources, interlinking conservation strategies and sustainable use as a means to reduce poverty" (Adams et al., 2004, p. 1148).

\subsubsection{Sustainable tourism}

Another important area of my research encompasses sustainable, ecological and volunteer tourism. One feature which stands out in the review of recent research and development is that tourism is a major agent of transformation. Tourism development places new values on local resources and new strains on existing infrastructure. Wherever it occurs, tourism development changes a society and its environment (Murphy, 1983).

While using tourism to promote community development sounds like an ideal concept in principle, case studies from the literature show the practice to be more challenging (Scheyvens, 2002). The literature identifies a range of factors that lead to resident's dissatisfaction, including local planning, environmental management and tourism impacts such as "traffic and parking conditions, local crime, and local inflation rates" (Pearce, 1980, p. 225). Belisle and Hoy (1980) reveal in a case study of Santa Marta, Colombia that tourism is blamed for seasonally inflated food prices. A different approach of Scheyvens (2002) has articulated that negative experiences of 'traditional' communities with outsiders have fostered the perception that the tourism industry may undermine their cultural integrity and sense of self-esteem, thus only indirect involvement in tourism was preferred. 
Nevertheless, more optimistic approaches focus on "tourism which supports sustainable livelihoods and aims to minimise negative effects and maximise positive effects for local people" (Scheyvens, 2002, p. 8)

Therefore, sustainable tourism is tourism that is economically viable, but does not destroy the resources on which the future of tourism will depend, notably the physical environment, and the social fabric of the host community (Swarbrooke, 1999 as cited in Gran, 1987, p. 36).

Furthermore, according to Palomino Schalscha (2011, p. 16), "in a neoliberal context, tourism has been seen as an activity that can enhance economic activity and foreign revenue and has been supported as a strategy for poverty alleviation by national and global institutions". Therefore, alternative tourism, such as community, eco, and volunteer tourism can be viewed as a resource industry that returns benefits back to the community while extracting a livelihood from it (Murphy, 1983). A destination community provides the community assets such as landscape and heritage or in the case of Ostional the turtle arrivals, public goods including parks and institutions, and hospitality such as welcoming smiles, are the backbone of the tourism industry (Murphy, 1983).

Criticism to sustainable tourism acknowledges that it is more appropriate to describe destinations as being "indicative of sustainable tourism than to state that they are definitely sustainable" (Weaver et al., 2000, p. 7) and encompasses that implementation is subject to a variety of problems at all stages of the procedure. These include the "definition of goals, the establishment of temporal and spatial parameters for the planning and management process, political realities, and the existence of competing resource users" (Weaver et al., 2000, p. 37).

Furthermore, within the tourism industry, ecotourism is often considered to be both a set of principles based on environmentally and socially responsible actions (Hay-Smith \& Hunt, 1995). The UNEP-WTO Quebec Declaration on Ecotourism states:

Ecotourism embraces the principles of sustainable tourism, [...a set of $]$ principles, which distinguish it from the wider concept of conventional tourism (UNEP, 2014)

According to Honey (1999), ecotourism is defined as responsible travel to areas with relatively high degree of natural values, which might sustain exclusive biodiversity and local 
people welfare. (Honey, 1999) continues that ecotourism strives to be at low impact and, usually, at low scale, it helps educate travellers and provides funds for conservation which in turn, directly benefits the economic development of local communities, and fosters respect for different cultures and human rights.

Therefore, ideally, ecotourism contributes actively to the conservation of natural and cultural heritage. It includes local communities in its planning, development, and procedure, contributing to their well-being and interprets the natural and cultural heritage of the destination to visitors (Campbell, 2002).

However, on another note, limitations of ecotourism have been outlined by Agrawal and Gibson (1999, p. 629) "conservation and local economic development is limited by factors such as the small areas and few people involved, limited earnings, weak linkages between biodiversity gains and commercial success, and the competitive and specialized nature of the tourism industry". Hence, many ecotourism initiatives provide only a small improvement to local livelihoods, and sometimes remain dependent on external support (Agrawal \& Gibson, 1999). Therefore, the impacts of tourism on a host community result from a complex process of interplay among tourists, the community, and destination landscapes (Farrell \& TwiningWard, 2004; McMinn, 1998; Page et al., 2001; West, 1993). Nevertheless, as Gutierrez et al. (2005, p. 23) point out, "both, ecotourism and sustainable tourism have the potential to link the conservation of nature with the well-being of local communities through a number of positive benefits including revenue generation, cultural preservation, and capacity building”.

Likewise, a number of academic writings have acknowledged the phenomenon of volunteer tourism as an alternative to conventional tourism and beneficial tool for development (Barbieri et al., 2011, 2012; Brown \& Hall, 2008; Lyttleton \& Allcock, 2002). Following Wearing (2001, p. 1) popular definition, we understand volunteer tourism as "involving those tourists who, for various reasons, volunteer in an organised way to undertake holidays that might involve aiding or alleviating the material poverty of some groups in society, the restoration of certain environments or research into aspects of society or environment". These travellers interact with local and community development organisations in ways said to capacitate the organisations and contribute to development as a whole (West, 2011). Often it is not just economic benefits of volunteer tourism that are seen as valuable, but a reciprocal exchange of knowledge from the encounter fosters the basis for good relationships amongst people. 
Therefore, in the field of 'volunteer tourism' it is assumed that volunteering is an alternative to conventional tourism and leads to the increased development of host-communities and its people. Other than in conventional tourism, volunteer tourism is said to foster cultural interaction and sympathy between volunteer and 'voluntourd'. For instance, Wearing and Lyons (2008) advocate volunteer tourism as a development strategy leading to sustainable development and benefits for both locals and the volunteers. This said and taken into account direct benefits from volunteer programmes, volunteer tourism seems to create a basis of reciprocal exchange.

However, the literature also indicates that volunteer tourism benefits only some residents of a community (Harrill, 2004), as volunteers might only be distributed to selected residents. Furthermore, processes of volunteer tourism have also been criticised to be volunteer-centred and imposing neo-colonial power structures (McGehee, 2012). The tendency of prioritising tourist needs and desires (and epistemologies), over the needs and desires of host communities in volunteer programmes directly leads to questions of ownership and equality in the process. Additionally, issues around ownership have emerged to be a key debate in volunteer tourism. In this respect, emphasis lays on the empowerment of local organisations and communities to manage their own development work in the field and to 'own' the development strategies in the process (Organisation for Economic \& Development, 2005). Other writers have criticised volunteer tourism in a post-colonial context, arguing that it reinforces structures of dominance and a centre-periphery relationship (Mustonen, 2007). Others again argue that volunteer tourism does not lay enough emphasis on participatory development or local ownership and that the process does not respect locally expressed visions for development (McGehee \& Andereck, 2009a).

The focus of volunteer tourism in regards to this thesis is, however, on volunteer tourism that takes place within development projects in low-income countries. In the case of Ostional there have been two different local approaches to volunteer tourism. One approach which has been established by ADIO distributes volunteers equally amongst the local families, through a rotation scheme which has been explained in Chapter II. The second approach is run by MINAE who get their volunteers mainly from overseas based organisations, which means that benefits are distributed to only some community members who are involved with MINAE. 
Discussed alternative forms of tourism such as ecotourism and volunteer tourism feature prominently in development policy and literature. In Latin America in particular, pro-poor, community-based and ecotourism have been the focus of much attention, as these initiatives came to be viewed as improved options for pursuing development and combating global inequalities. Volunteer tourism as form of 'tourism with a development agenda' has become increasingly popular among young people from developed countries, appealing to the desire to affect a positive change abroad. Although some forms of volunteer tourism have been criticised as a neoliberal approach to development practice, where development can be privatised and packaged as a marketable commodity (Vodopivec \& Jaffe, 2011), particularly volunteer tourism has become a feasible alternative form of tourism and has been positively linked to a range of development projects in low-income countries. It is argued that volunteer tourism both reflects and contributes to a new logic of development. Furthermore, there are alternatives to 'volunteer tourism as a commodity' if it is implemented by communities themselves as worked by ADIO in Ostional, which distributes volunteers through a rotation scheme, so that benefits go directly into the community.

\subsection{Significance of Research and Reasons for using ADIO as a Case Study}

Currently, there is limited research on sustainability of community-driven development projects despite being advertised as the best way to scale up poverty reduction through sustainable development interventions. The literature reviewed has tried to identify the linkages between the main study concepts and the challenges of sustainability.

Community participation has been discussed as the active involvement of communities in development initiatives and as a way of contesting top-down approaches to development. Community participation can play a crucial role in conservation and project sustainability as it reconciles conservation with development needs and as alternative to the traditional way of dealing with the enforcement of wildlife conservation. Similarly, sustainable tourism, including approaches to eco- and volunteer tourism are viewed as improved options for pursuing development and sustainability and often also rely on community participation. The notion of community power and control over local resources has been of particular interest in the context of my case study and reflect common struggles related to community-run development approaches. 
The concepts of conservation, environment and development, community participation, sustainable tourism and the literature on community power and control over resources are predominant in the academic literature about sustainable community development. These concepts helped me to bring sustainable community-run development into perspective and were most relevant in the context of my case study.

The concepts discussed above are crucial to understand the context and the significance of ADIO as local initiative of the community of Ostional towards sustainability and conservation. Discussed debates build the framework for the assessment of the Association's situation and help to unpack the dynamics around ADIO and Ostional. I chose these concepts to tell a particular story about ADIO and Ostional from the community perspective because of their fundamental relevance in the case study context. Therefore, the emphasis of this thesis lies in identifying key elements for the success of ADIO and to contribute to current debates around sustainability, community-run conservation and development. My research will help to understand discussed concepts and relationships more realistically by analysing a real life setting and involving first-hand experiences. Findings from my research aim to contribute to the overall literature on sustainable community development by sharing experiences from a community approach that aims for balance between natural resources and human interaction. 


\section{CHAPTER IV}

\section{APPROACH AND METHODOLOGY}

This chapter explores the epistemological approach of this research. It also discusses the methodology used and approaches undertaken in this research, particularly the processes of data collection and data analysis of my investigation. Finally, the chapter discusses ethical concerns and limitations I confronted while conducting this research.

\section{1 Epistemological approach}

The methodology of this thesis is grounded in the belief that local knowledge has an important role to play in understanding the dynamics between local management systems and people's physical environment on which they depend. Further, my research adopts a constructivist epistemological stance. A major focus of social constructivism is to uncover the ways in which individuals and groups participate in the construction of their perceived social reality. It involves looking at the ways social phenomena are created, institutionalized, known, and made into tradition by humans. The social construction of reality is an on-going, dynamic process (Kim, 2001). Constructivism assumes the relativism of multiple social realities, recognises the mutual creation of knowledge by the viewer and the viewed, and aims toward interpretive understanding of subjects' meanings (Charmaz, 2003; Guba \& Lincoln, 1994; Schwandt, 1994). Social constructivism emphasizes the importance of culture and context in understanding what occurs in society and constructing knowledge based on this understanding (Kim, 2001). In Ostional, the existence of multiple social realities reflects the different stakeholders who are involved in the Wildlife Refuge. Therefore, the advantage of integrating social constructivism with my case study for the purpose of my research is that it acknowledges multiple social realities, aims toward interpretive understanding of peoples' meanings and constructs context-specific knowledge based on this understanding. 


\section{2 Research Design}

\section{2. 1 Case Study}

With my research I aimed to generate a case study that adopts a south-centric, local community focus. Through the intensive examination of a sustainable development project in a particular community, my study aims to show how things occur in practice. Siggelkow (2007) argues that a single case analysis can be a very powerful example and can be used to fill in the gaps in existing theories. Yin $(2009$, p. 4) summarises:

As research method, the case study is used in many situations, to contribute to our knowledge of individual, group, organizational, social, political, and related phenomena. In brief, the case study method allows the investigators to retain the holistic and meaningful characteristics of real-life events - such as individual life cycles, small group behaviour, organizational and managerial processes, neighbourhood change $[\ldots]$.

According to Yin (2009) the case study is a suitable research method when the research focus lays on contemporary events and control of behavioural events is not required. As indication, the research questions, 'how' and 'why' determine the suitability of a case study as research method. Yin (2009, p. 19) further states that, "a case study can be on any topic, but it must [use] some empirical method and present some empirical (qualitative and/or quantitative) data". What distinguishes case studies from other research approaches is that a case study method would be used in order to gain in-depth understanding of a real-life phenomenon, but such understanding is context-specific (Yin, 2009)

The case of ADIO is a unique situation which has been formed by its specific history and contextual conditions. The effectiveness of sustainable community-run development depends on a number of place-specific factors including levels of participation and a functioning organisational framework. Communities are not to be viewed as homogenous networks, but as places with complex unique conditions and therefore need to be viewed on a case to case basis. The specific conditions of Ostional such as community size, levels of participation, numbers of actors involved in ADIO and the extensive experiences the Association and its members have related to sustainability of the Project make it an ideal case study for my research about sustainable community-run development. 


\section{2. 2 A hands-on approach with ADIO}

My aim was to apply a practical and hands-on approach to my research, in order to better understand sustainable community-run development and how it is done by ADIO. Visiting Ostional as researcher and volunteer for one and a half month helped to familiarise myself with the community and its unique situation. My goal was to participate in an extended experience and become part of the community as much as possible, rather than writing about the Association as complete 'outsider'. Therefore I was able to explore the context of ADIO from a standpoint of 'betweenness' of being an 'outsider' but still working as an 'insider' within the context of the community (as discussed further in section 4.2 about my 'positionality' in the research). I wanted to have the opportunity to observe, build relationships and trust with community members and learn first-hand about the processes, local perspectives and power relations surrounding the Project. I also wanted to be able to reflect upon my own volunteer-research experience, and gain access to additional voices such as other volunteers and host-families on site.

Thus, before my departure to Costa Rica, I organised my stay as a volunteer/intern in Ostional, with the help of Green Life Volunteers. I volunteered from the end of April until the beginning of June 2013 and was mentored by Rodrigo Morera Ávila, the resident biologist and a legal representative of the ADIO Project, who I was in email contact with prior to my arrival in Ostional

During my fieldwork I stayed with the former president of ADIO Gilberth Rojas Araya, and his wife María. Gilberth stepped down from his role as president in 2003 after a tragic incident in which his house and livelihood was destroyed in a fire. Gilberth and María helped me to get to know the local culture and important contexts, which we often discussed in hour long conversations and in great detail. During my fieldwork I was working with the resident biologist Rodrigo Morera Ávila, some members of ADIO during an arribada, and sometimes joined volunteers and staff from MINAE e.g. at beach cleaning activities.

I had the chance to participate in community life and Project activities of ADIO. The latter included helping with processes during the monthly turtle arrivals. Other activities involved cleaning the beach (burning off driftwood), and helping with scientific data collection and ADIO documents. Being accommodated by Gilberth Rojas Araya, the ex-president of the association, his wife María who is a founding member of the ADIO tourism organisation 
Associación de Guías Locales de Ostional, and her father, who is founding member of the Association, turned out to be a great source of information about ADIO.

On a few occasions groups of university students and tourists would come to our house and receive an introduction to the Project, including watching a video and a follow-up discussion where questions were addressed (see Figure 4.1). These discussions opened new areas of thought for me and were inspiring for my research. Additionally, these group visits gave me the opportunity to share and reflect on the knowledge I had already gained during my stay. At times, I was able to help clarify matters and sometimes functioned as a translator in the process.

Figure 4.1: Introduction to a group of University students visiting the Project

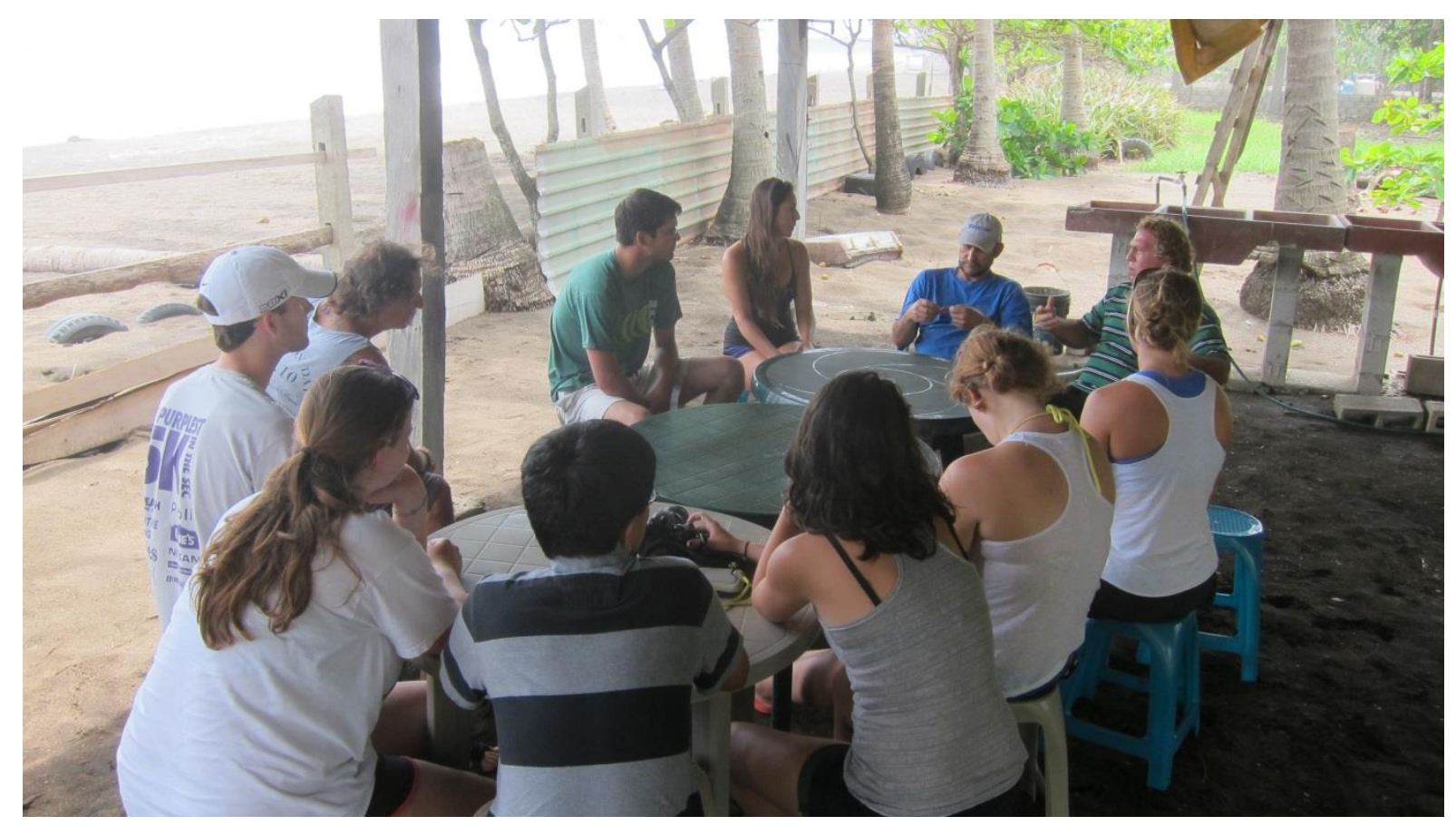

Source: The author

\section{2. 3 Research methods}

I decided on the research methods for my fieldwork prior to my departure and prepared the questionnaire survey, workshop and interview questions as much as possible in advance. After my arrival in Ostional, new questions came up as I gradually learned more about the specific situation of Ostional and ADIO. Therefore, I allowed for flexibility within my research methods while in the field. This section introduces the methods used for data 
collection during my fieldwork and discusses how and why they were beneficial for my research.

\section{2. 4 Purposeful sampling: choice of participants}

In qualitative research, the reliability and the value of the results are related to the richness of the information gathered, not the sample size (Hay 2000, Patton, 1990). The most important concern is assuring the representativeness of possible viewpoints, to understand the range of variation of experience and perspectives (Suzuki et al., 2007). Surveys are commonly conducted on a sample of the whole population (Gutierrez et al., 2005). A 'sample' is a portion of people who represent a larger population. According to Gutierrez et al. (2005), surveys are conducted on a sample size because it is often too costly and time consuming to survey the whole population. Therefore, a sample population is usually chosen through random selection and to avoid bias (Gutierrez et al., 2005)

With the choice of participants for my questionnaire survey, interviews and workshop I aimed to generate a purposeful sample. The underlying principle of purposeful sampling is to select "information-rich cases, that is, cases that are selected purposefully to fit the study" (Coyne, 1997, p. 627).

Therefore, an anonymous questionnaire survey was conducted with 50 community members of different age groups, of which 25 were women and 25 men, including members and nonmembers of ADIO. Furthermore, in-depth and semi-structured interviews were conducted with 3 people, who consented to their names being used in this thesis: The current ADIO president Máxima Magdalena Vega Figueroa, the resident biologist and ADIO coordinator Rodrigo Morera Ávila, and the former ADIO president Gilberth Rojas Araya. Also, approximately 10 Ostional community members of mixed gender and age participated in a reflective workshop. These methods will be discussed in detail further along in this chapter.

\section{2. 5 Mixed methods}

My research uses both, qualitative and quantitative methods for data collection. In qualitative research, not only the content, but also the context is important (Miller \& Glassner, 1997). 
My overarching aim was to get a feel of the research context, its culture and the relationships between people, so as to build a trusting relationship between the participants and myself.

Qualitative research assumes that variables and multiple understandings coexist in a given social context. According to Rossman and Rallis (2011), qualitative research requires awareness of the position and powers of the researcher and the politics of doing research. For my research, it has been important to continuously reflect, especially when my own personal positionality shape the ways I interpreted the data collected.

Seale (1999) points out that qualitative methods are ideally suited for research answering questions about meanings, interpretations and explanations people associate with particular phenomena. According to Snape and Spencer (2003, p. 7) "interrelatedness of different aspects of people's lives is a very important focus of qualitative research, and psychological, social, historical and cultural factors are all recognised as playing an important part in shaping people's understanding of their role". Therefore, and as embedded in social constructivism theory, qualitative methods can uncover how people participate in the construction of their perceived social reality. Thus, qualitative research can bring powerful insight, and is essential to understanding what makes the world meaningful for people (Scheyvens \& Storey, 2003).

To gain such insight, and to achieve profound and positive interviews with different community members from Ostional, I interviewed people face-to-face and in private. I was able to do so by integrating in people's daily routines during my stay in my host family and my volunteer work with the community. Thus my research also adopts an ethnographic approach, as it includes "empirical data on human societies and cultures" (Ball \& Ormerod, 2000). Therefore, participant observation helped me to witness the world from the point of view of the participants and record observed behaviour in order to make a substantial contribution toward the understanding of the social life and reality of participants.

Methods used in qualitative research attempt to provide a "holistic understanding of research participants' views and actions in the context of their lives overall" Snape and Spencer (2003, p. 7). Therefore, my research used qualitative methods as described by Patton (2005, p. 1), as "qualitative research that analyses data from direct fieldwork observations, in-depth, openended interviews, and written documents". He continues that "qualitative researchers engage 
in naturalistic examination, studying real-world settings inductively to generate rich narrative descriptions and construct case studies" Patton (2005, p. 1).

Furthermore, quantitative data played a significant role in my data collection as I used, analysed and interpreted questionnaire data. According to (Simon, 2006, p. 163), "if used appropriately, the different formats of questionnaire represent potentially invaluable tools for ascertaining a wide range of factual information and subjective views and perceptions from a representative sample of a particular population". In other words, the information from the questionnaire survey conducted in the field helped me to obtain a broad spectrum of participant perceptions. After analysis, this variety of views resulted in visible trends which helped me reaffirm interpretations and added to the information obtained through interviews, observations and the reflexive workshop.

\section{2. 5. 1 Participant observation}

I engaged in participant observation as part of my research approach. According to Kearns (2005, p. 195), participant observation is an approach that is "seeking to understand more fully the meanings of place and the contexts of everyday life. The goal of participant observation is, to develop understanding through being part of the spontaneity of everyday interactions". The success of my observational approach depended upon constant reflection as the researcher as I described in a journal entry:

People get together a lot socially and naturally talk about ADIO. I can usually just join in and it is straightforward to ask questions if I don't understand parts of the Project. Themes often concerned ADIO and the recent news on theft, or theft of eggs in general. I always told a bit about myself, because people are very interested, and I usually said that I am a student and work with Rodrigo and that I would like to write about $\mathrm{ADIO}$, because it is such a unique and special project in the world and people should know about it, as it might help and provide an example for other community-run projects around the world (Author, field journal, date 26/5/13).

I had to constantly reflect on my experiences in relation to my research objectives. Participant observation played a supporting role in my research. It aimed to add to information obtained 
through interviews. Hence observations I made in the field often confirmed or questioned the information gained through interviews, questionnaires and the reflective workshop.

During my fieldwork, I aimed to consciously place myself in the daily life activities of community members. This helped to facilitate relationships with the residents and members of ADIO, which was essential to build trust and gain permission to conduct questionnaires and interviews. Participant observation activities included: living with my host family in the community, helping community members, from both MINAE and ADIO with activities including cleaning up the beach, protection efforts for the sea turtles and participation in meetings and other social community activities. I used a fieldwork journal to record my observations of my experiences. Casual conversations and attendance at social events helped me learn more about the community, the Association, its unique Project and people's lives in the rural Costa Rican context.

\section{2.5.2 Interviews}

My aim was to collect primary data, partly through in-depth, semi-structured interviews. Dunn in Longhurst (2003) suggests that semi-structured interviews employ an interview guide and are organised around ordered but also flexible questioning. Interviews commonly focused on personal perceptions and personal stories and are informant-focused. Informants determine personal accounts of significant events and perceptions in their own words. In fact, interviews in which everyone feels at ease usually generate more insightful and more reliable information (Longhurst, 2003). I used audio recording and note taking as the two main techniques for recording my interviews.

The interview is a social encounter. Thus, the participants' answers depend upon the relationship of participant and interviewer. Prior to conducting an interview, it is important to consider potentially difficult situations that might arise during the interviews. There are power issues that I, as a researcher, had to be aware of, such as balance of dialogue, research agenda, and societal hierarchies; each interview is a special unit of work on its own (Cotterill, 1992). Therefore, I treated interview participants with respect and adapted to local customs like formally introducing myself and asking for permissions so as not to be disrespectful in any way. The interviews I conducted lasted between 1.5 and 2 hours and followed a set of 
questions that allowed participants to express themselves accordingly. Interview locations were chosen for the convenience and comfort of the interviewees (see Figure 4.2).

Figure 4.2: Interviews

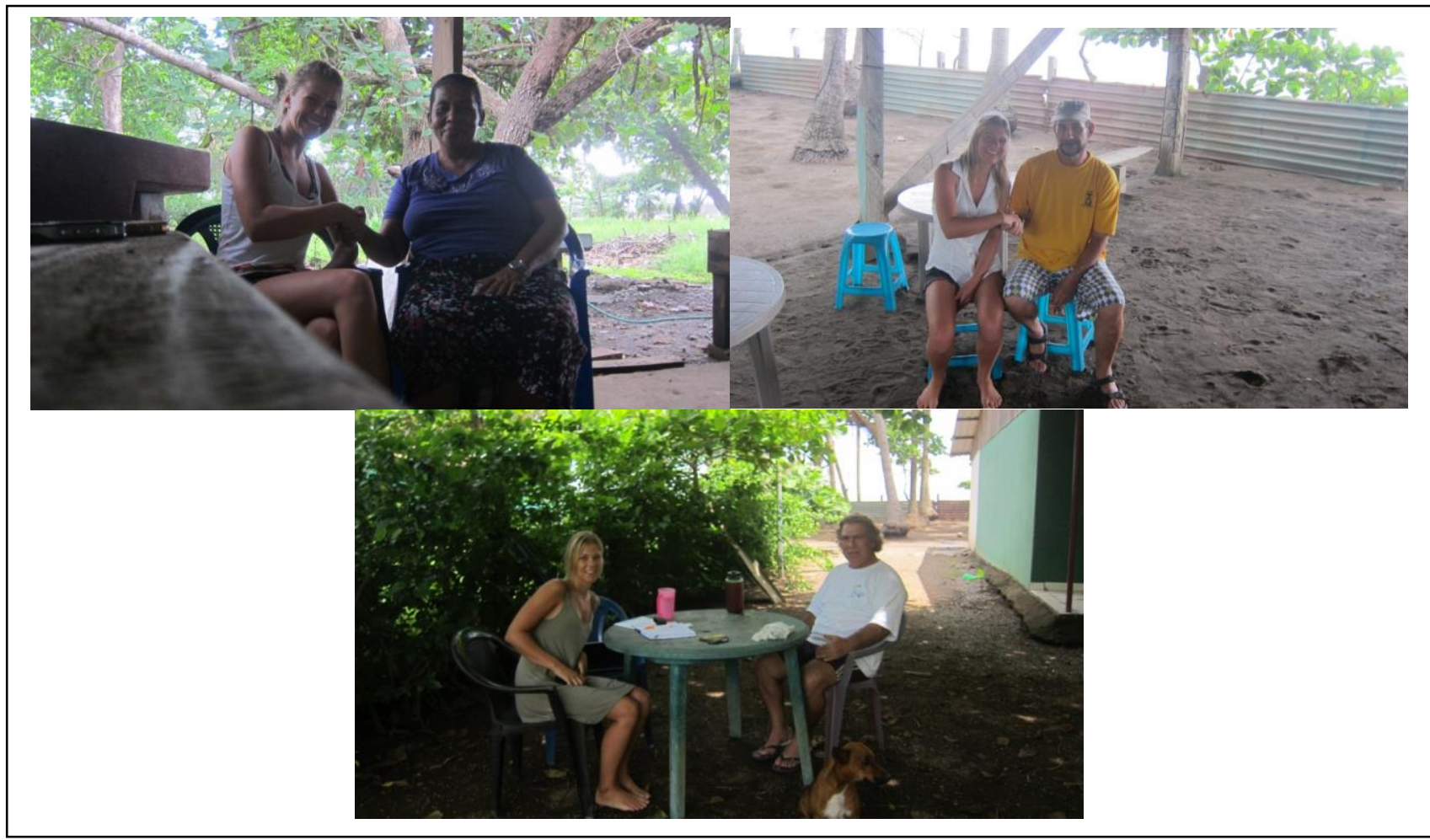

Source: The author

A flexible list of key questions shaped the framework for my interviews (see Appendix 8). This interview format enabled me to ensure that all participants would address certain topics. This was essential for comparison of answers in order to obtain an unbiased picture of the situation. All the interviews were conducted in Spanish and recorded and transcribed, in order to ensure complete data collection, and to avoid the disturbance of note taking (Hill, 1993). I ensured that no one but me had access to the recorded dialogues. I gave every participant the choice of where and how long they would be interviewed. Sometimes an interview naturally became a relaxed conversation when all questions had been answered.

\section{2.5.3 Questionnaire survey}

I conducted an anonymous questionnaire survey as one part of my data collection. This section outlines the characteristics of questionnaire participants and explains the processes of 
conducting the questionnaire survey in the field. Results from the questionnaire responses are further analysed in chapter $\mathrm{V}$ of this thesis.

I designed an anonymous questionnaire (see Appendix 7) to seek additional information from community members. The questionnaires were conducted with as many community members as possible in the limited time of my fieldwork. The majority of times I conducted questionnaires directly with people either by going from house to house, asking people I met through the family and friends and by choosing frequented areas such as the small shop, and asking people to answer my questionnaire.

The questionnaires included open questions in order to enable participants to express their views freely. The questionnaires focused on participants' views about the Project and the ways they are affected by it, along with their connection to volunteers. The questionnaires, written in Spanish, consisted of uniform questions that were easy to understand. The questionnaires used simple questions such as: age, education, marital status, occupancy and involvement with the volunteer programme. Further questions included: What aspects of the volunteer programme do you perceive as beneficial? And which aspects could be improved?

The average age of participants for this survey was 40.8, including 25 women and 25 men from the Ostional community. Most of them are active members of ADIO and 12 participants are former members, not currently active for other reasons or not Ostional-born which is a requirement to be a member of ADIO. I intended to do a meaningful sample of community members' perspectives, paying attention to create a diverse spectrum of responses from community members in different situations and with different occupations. Some of the occupations of female participants include: housewives (18), students (5) and chefs (2). Male participants' occupations include: farmer (2), professor (2), ADIO (3), MINAE (2), maintenance (2), merchant (5), security (1), research assistant (2), pensioner (3), administration (1), guide (1), pastor (1).

After conducting a number of questionnaires it became apparent that answers started to repeat themselves and a tendency towards common perspectives established itself. I identified main themes across responses which are outlined and analysed in Chapter V of this thesis. Often responses crossed thematic areas and were interwoven with and related to each other. 
In a journal entry I reflect upon my data collection with questionnaires:

Questionnaires are going well. In social occasion I could quite comfortably conduct questionnaires with people and my guest mother always called me when visitors come around. It had usually already come up what I am doing and people were willing to participate in the questionnaire survey. Today one participant compared me to other people that have conducted questionnaires before and he liked my questionnaire and how I conducted it. He said sometimes researchers come around and ask very scientific questions that are too hard to understand because people sometimes have a very low level of education and often cannot write or read. After I conducted questionnaires with friends and family I made them give me feedback about, if questions are easy or too hard to understand, and if they are too long. They seemed okay, although I noticed that people have very different abilities to answer the questions. Most people can't or don't want to write, especially the older generation. A few people did not know how to respond, sometimes because they are not very interested or are not involved in the Project. In these situations I try to guide the conversation and start giving some examples. Participants then usually pick the example that most reflects their opinion.

It has been a bit harder to go from house to house and ask people I don't know if they want to participate in the survey. I am very lucky because I had great help so far, from my host family and my Ostional friends. Some friends came with me and introduce me to people in order for me to do my questionnaires. Also the shop has been a good point to 'hang out' as I have friends who work there and they have usually time to sit outside in front of the shop and help to connect me to people who come in, to do my questionnaire.

The questionnaires started showing a general direction in peoples' answers, in terms of what people like about what ADIO has done so far, what should be continued and about what people generally think should be improved. I also asked people about a specific example of what they desired to be improved. A small issue I came across while conducting the questionnaires was that women were usually a bit more reluctant and shy to respond and they would usually try to send their men to do the questionnaire. A couple of women said things like "I don't know much about those things". Often I would do a questionnaire with 
both, man and woman in the household. Sometimes another person sat around but issues around ADIO seem to be quite openly discussed here, so people were not shy to word their 'criticism' or desires for improvements. Older people usually had a lot to contribute and were very pleased to be asked about their opinion and to share their wisdom. Tomorrow I will go to 'el golfo' (a part of Ostional) and look for more participants. (Author, field journal, date 26/5/13)

\section{2.5.4 Reflexive workshop}

My aim was to integrate a reflexive workshop into my research. During the last days in Ostional I invited friends and community members I met during my stay to participate in a reflective workshop as part of my thesis and join in for a subsequent barbecue and music. I invited people personally when visiting them in their houses or when seeing them on the street.

Workshops may be appropriate if working in a smaller destination (Gutierrez et al., 2005). The reflexive workshop I hosted involved around 10 young community members. I aimed to invite as many 'young' community members because their perspectives seemed particularly important for the long-term sustainability of the Project. As the researcher, I facilitated, moderated and guided the workshop. A local friend helped me to take pictures, and recordings of participatory activities. This way, I was able to focus more on the facilitation of the workshop. The aim of the reflexive workshop was to provide information that can be used in my data analysis and to complement the interviews. The collective reflection over community themes created a safe space for collective knowledge production, as participants were able to freely share ideas and different perspectives on what was discussed.

According to Cameron (2000) in a reflective workshop, interaction between members is the key characteristic of the research method, as people respond to the contribution of others. The interactive aspect of the workshop provided an opportunity for the participants to explore different viewpoints, formulate and reconsider their own ideas and understandings. I aimed to facilitate a workshop that is interactive and lively, and a safe place for participants to share their thoughts together. I tried to encourage equal participation to ensure no one was left out. It was important for me to stay neutral in the interaction and remember my role as researcher. 
Figure 4.3: Reflexive workshop

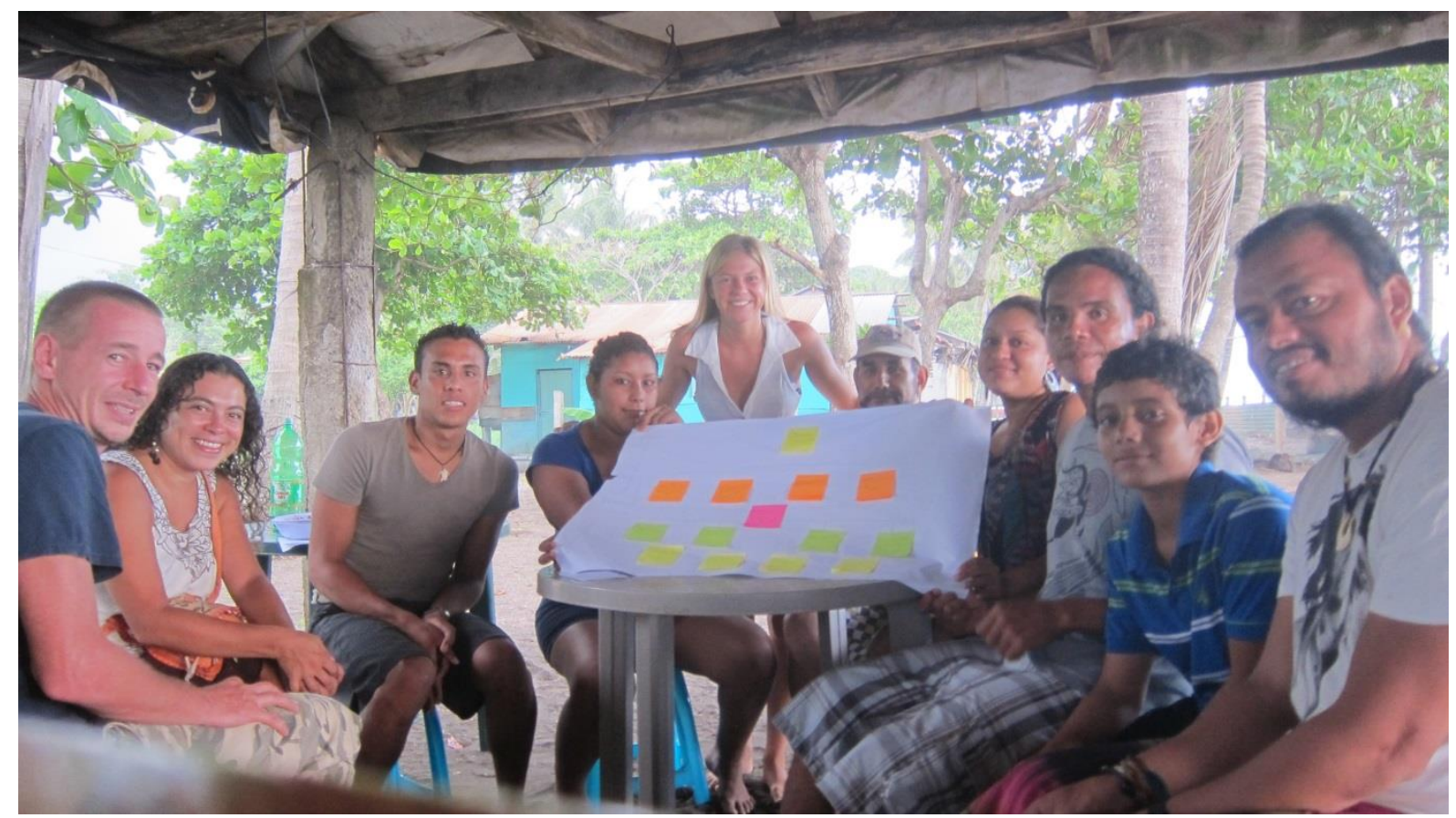

Source: The author

The 'casual nature' of Ostional led to some people arriving at different times of the workshop. I asked the members to join in and talk to each other about the current situation of ADIO, how they would imagine the Project in ten years and what kind of changes need to be done in order to improve the Project. During the workshop, we also discussed issues related to new projects, relationships with MINAE, and the association's organisational framework.

The highlight of the workshop was the creation of a problem and solution tree (see Figure 4.3) about the issue 'poor organisation and management of the Association', which we had defined as most important. The problem and solution tree focused participants' attention on the positive and negative aspects of the Project. Everyone seemed to enjoy the process of visualising problems and solutions. I had the feeling that the group reflection and exploration of ways in which members have benefitted from the Project, made participants more aware about future possibilities and the changes the Project has brought to their lives and the lives of the other participants. The discussions among participants stimulated exchange about problems and achievements. The discussions provided a good opportunity for me to ask 
participants about previous trend as well as about possible opportunities to resolve current problems. I had the feeling that the workshop helped to organize the range of opportunities for the community to consider.

\section{3 Positionality: working in a rural Costa Rican community}

My positionality, and aspirations to place myself in a suitable research context determined my research design from the very beginning. My aim was to find a research context I felt comfortable with while applying my skills in development research. I decided to place myself in a volunteer/intern setting to generate a basis for information gathering, reciprocal exchange and, at the same time, be proactive in my endeavour. I expected volunteer tourism in my case to be beneficial and perceived as 'positive' by the local community. Green Life Volunteers functioned as the distributor of me as a volunteer to the ADIO volunteer scheme. The Green Life organisation stands for the promotion of sustainable volunteer programmes throughout Costa Rica, and assured me that the benefits of my stay would go directly into the community. I later found, that one of the main reasons families accommodate volunteers is to enhance their livelihoods economically and culturally.

Being fluent in Spanish was a key factor when looking into doing research in Central America. My language ability was crucial during my fieldwork and transcription phase. I learned most about the Project and community members' viewpoints in profound conversations in Spanish and by following up on complex matters.

As a young researcher it can be challenging to establish the networks and connections needed to gather required information and conduct good research, especially if the time in the field is limited. Arriving as an 'outsider' in a set of well-established connections in a new social context can be challenging and restrictive, due to hierarchical power relationships and sociocultural differences. Nevertheless, the 'outsider's view' (or third party observation) might help the neutrality of the research and can bypass boundaries that might be blurred by different parties' emotions. In this vein, Gutierrez et al. (2005, p. 23) argues that it can be beneficial if someone from the 'outside' conducts a survey, because "if local people do this, the results may be less objective due to personal interests".

I was able to establish networks with various members of the community, of which some became friends and joined me to go from household to household in order for me to collect 
my questionnaire responses. The connections I formed during my stay were also the basis for participation at the reflexive workshop at the end of my visit.

I put in effort to blend in as much as I could, constantly aware of my difference and the power relations that came with it. Nonetheless, many aspects of my positionality, such as my nationality, ethnicity, gender, clothing and ability to engage in regular conversation in the local language shaped the research process and opened and closed certain conversations. For instance, having learned Spanish mainly in a Chilean background, conversations related to my accent were usually humorous, which I engaged and sometimes used to loosen up the atmosphere.

The clear difference in class was perhaps the most striking difference of my positionality. I was from a wealthy and educated background and had a laptop, camera and an iPhone, which immediately put me in a different location, and often in one of hierarchy, where "people in rural areas have come to respect and be deferential to urban, educated elites"(Sultana, 2007, p. 378). Also, although people are used to foreigners and volunteers, my blonde hair and fair skin generally created most interest.

Therefore, it would be naïve of me to assume that I became an complete 'insider' or that the relationships in the field were fully equal, but I believe that my personality and the way I interacted with people helped in forming "relations of trust that are important in fieldwork" (Sultana, 2007, p. 378). I was aware of that I was only able to partially access the lives of the people I met in the field. The important thing, however, for me was to be authentic in building relationships with people and respectful to the knowledge that was produced and shared in the research.

\section{4. Data analysis}

The first step for the assessment of the data collected in the field was to transcribe information from my interviews, questionnaires and workshop. I compiled the data from the questionnaire survey I conducted by using the computer program Excel to generate themes along responses and turn them into bar graphs in order to visualise my findings. Analysis of questionnaire data by hand is relatively simple. Since the questionnaire I designed was easy to interpret and analyse, hand tabulation of the data was not a problem. The three semistructured interviews followed the same loose set of questions which enabled me to compare 
responses in order to extract areas of agreement and differences. These methods were also the base line to open up for the key themes discussed in chapter V and VI.

Furthermore, coding qualitative material helps data reduction and organisation (Cope, 2005). Therefore, I used descriptive and analytic codes to structure the information gathered in the field. Cope (2005) states that descriptive codes or category labels, reflect themes or patterns that are obvious on the surface, while analytic codes reflect themes the researcher is interested in. After transcribing the information gained from aforementioned methods, I identified key themes in my research. I compared these themes and tried to find connections, similarities and divergences, which are discussed in the following chapters.

When evaluating results from the mixed methods used in the field, I had to consider the following questions: What are the characteristics of those surveyed? Are participants all active ADIO members? What is the general response of the people surveyed? Is there a tendency in their responses? Are there any questions that generated responses that are overwhelmingly positive or negative, or are all the responses somewhere in between? Are there any obvious connections between different questions? Are the themes and responses interconnected; and, how might the different abilities to answer questions affect my results? The following sections integrate these questions together with the findings and analysis of key themes and questionnaire results.

Thematic analysis is the most common form of analysis in qualitative research. It emphasizes identifies, examines, and records patterns or 'themes' within data (Guest et al., 2012). Themes are patterns across data sets that are important to the description of a phenomenon. The themes become the categories for analysis (Muir-Cochrane \& Fereday, 2006). Thematic analysis uses process of coding in six phases to recognise meaningful patterns. According to Braun and Clarke (2006), these phases are: familiarization with data, generating initial codes, searching for themes among codes, reviewing themes, defining and naming themes, and producing the final report. 


\section{5. Ethical concerns}

This research involves asking about not only how to realize the goals of development research, but also, what the ethical limits in their pursuit might be (Luhtanen \& Crocker, 1992). The nature of my research focuses on ethically desirable development. Nevertheless, directing my research from a south-centric focus, questions arise over my own positionality and use of methods in the process. I needed to reflect upon the fact that I am a young, welleducated German-born woman, and that I was part of the ADIO volunteer scheme opposed to MNAET, staying with the ex-president of the Association, and how this might have influenced interactions, relationships, the research process as a whole, and consequent knowledge produced. Knowing of conflicts between ADIO and MINAE in the past, I was concerned that this might perhaps affect responses or access to people working with MINAE. As I had volunteer friends at the MINAE station, and after asking MINAE staff for permission, I ended up spending a reasonable amount of time at the Station and build relationships with volunteers and staff. Therefore, I managed to build good relationships with people from both institutions. This was important for my objectivity as a researcher and to gain unbiased information.

Furthermore, I was concerned about, how being a volunteer, might determine how community members relate to me. However, I was able to represent myself as working together with, and being mentored by Don Rodrigo, who is well known and respected in the community. Participants accepted that I was working together with the organisation and generally saw the questionnaires as an opportunity to have their voices heard, and to eventually help the Association improve, by sharing their experiences and opinions.

Some challenges appeared when asking for participation in the questionnaire survey. The women in the household often tried to get their men to do the questionnaire. Therefore, it was generally more difficult to gain access to female opinions. Whenever possible I encouraged women to answer for themselves and highlighted that their opinions were equally important to me. Also, when conducting the questionnaire survey, I often got told to read the questions out loud and write the answers myself. I sometimes had to explain questions in easier terms because the ability among participants to answer questions varied.

Furthermore, I needed to question myself if I actively embraced the local ways while participating in respective volunteer tasks and conducting my research. I was aware of 
possible unexpected circumstances where my own behaviour and perceptions might have affected the research or the people I am working with. Also, I had to take into account cultural differences which might have impacted on the research process and the personalities involved. My respectful and friendly attitudes, as well as my fluency in Spanish, were crucial and very helpful attributes, which overall, enable me to conduct and transcribe my research in Costa Rica effectively. I informed participants about the purpose of my research and what I was going to ask in my questionnaires and interviews. I also contributed to and participated in various community activities. I complied with my volunteer duties and went for early morning walks with Rodrigo in order to documenting turtle tracks and collect scientific data. Next to helping in the household, I participated in community activities such as cleaning the beach, burning piles of driftwood, help during the arribada process and help when groups arrived. Furthermore, I helped young community members with their English (see Figure 4.4) and translated and edited a flyer that the ADIO guides can give to tourists. Also, other ways I might have contributed to ADIO and some people in Ostional is that I created space for individual and group reflection, through questionnaires, interviews and the workshop. Sometimes it became clear that people take pride in their achievements and that they felt that their stories and perspectives are important. Beyond my thesis, I am aiming to return a report on my findings back to ADIO. I would like to continue supporting the community by giving talks and showing the film made about Ostional and will continue fostering the relationships with the friends I have built in Ostional.

Figure 4.4: English study group

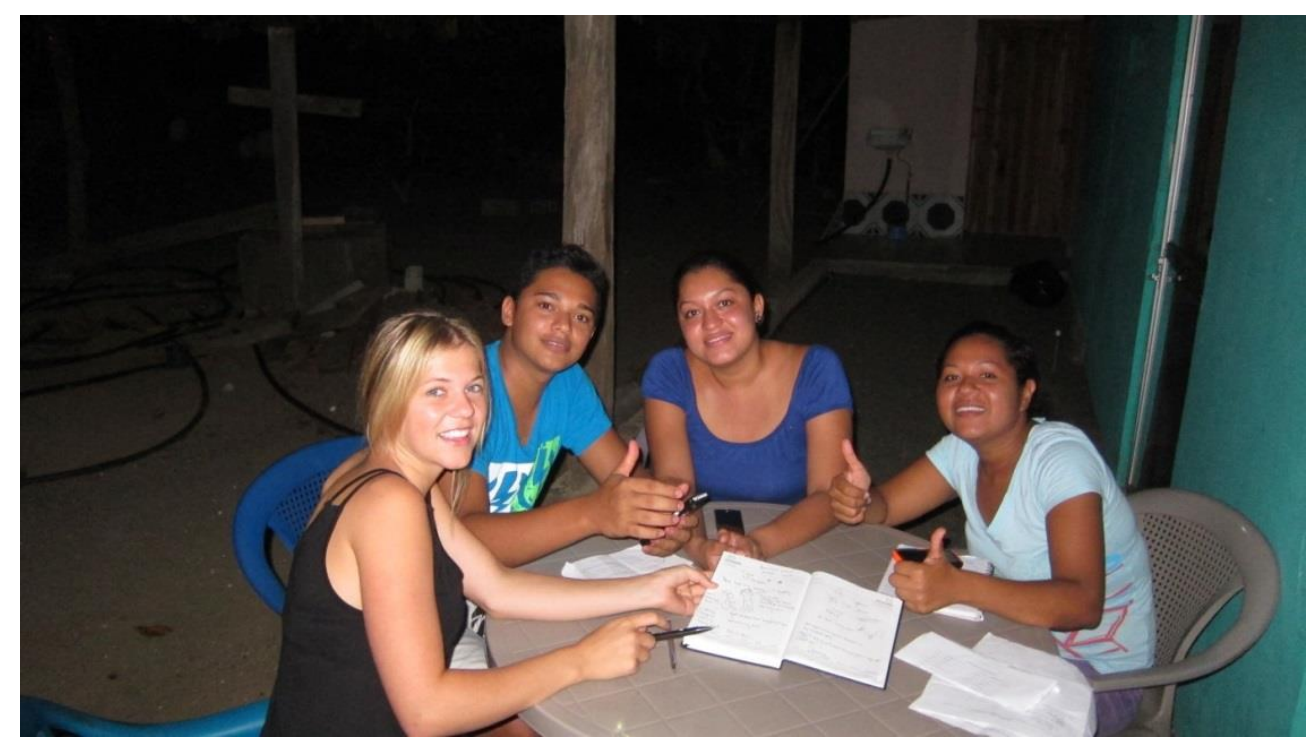

Source: The author 


\section{6 Success and limitations}

Overall, I found that the aforementioned methods and how I applied them in the field were successful for my research. I had the chance to live and work with key figures of the Project that were most knowledgeable about ADIO and its story. I gained vast knowledge about Costa Rica and the humble lifestyles of the Ostional community, but foremost, I gained thorough understanding of ADIO and its unique Project of Conservation and Management of the Olive Ridley Sea Turtle.

Furthermore, the feedback I got from the participants was throughout positive. Informants were very helpful and interested in my work. I built great relationships and supported their initiatives, innovations and local customs. Therefore, my research is not only 'extractive' but also 'generative', because it expresses experiences from within the community using community voices.

Furthermore, as a researcher from 'outside', I was aware of the need to protect participants' privacy. I kept personalities confidential unless consent was given otherwise. Confidentiality in my questionnaire survey and workshop was provided and showed respectful behaviour from my side. The three interview participants agreed on having their names identified in this thesis. Also, I followed the Victoria University ethics guidelines throughout my research. The Human Ethics Approval (see Appendix 2), as well as information sheets for each relevant group (see Appendices 3 and 4), and consent forms for interview and workshop participants (see Appendices 5 and 6), built the official ethical framework for my research.

This research also faced a number of in-field and post-field limitations. First, the time I was able to spend in the Ostional community was limited, due to the financial obligation of participating in a volunteer experience. Therefore, in-field limitations might have been a result of general time constraints. Second, originally aiming for a volunteer tourism focus, I soon realised that Ostional is much more than a tourist destination. I found that volunteer tourism is a rather small aspect of the Project and moved my research focus to the Project as a whole. Being in the field was a process of learning and trusting, changing my preconceptions, understanding what was really important. Having shifted my focus while in the field is a limitation, but it also speaks of my awareness and high level of reflection while in the field. It also shows engagement and flexibility of my side and reflects my true interest in what was 
relevant for the local community. Third, as mentioned before, being an 'outsider' can limit access to information and, in my case, participants' perspectives. There are various reasons for this: limited time and the differences of backgrounds and cultures make it almost impossible to get to know the whole community and become a complete 'insider'. That is why it was useful to have a mentor, who has experience with my type of research and who could point me into the right direction when needed. Post-fieldwork, I had some difficulties transcribing due to background noises during interviews and the workshop, blurring the words of participants, such as bird and ocean noise. This might have led to a loss of data in the audio record during transcriptions.

This chapter has outlined the approach and methodology of my research carried out with the community of Ostional and ADIO. In the following chapter, I will discuss my findings and analysis. 


\section{CHAPTER V}

FINDINGS AND ANALYSIS

This chapter presents the findings and analysis of my research. The processes and tools for data analysis have been outlined in Chapter IV. This chapter first presents my findings about the story of ADIO and the Ostional community, beginning with what people shared with me about the foundation and structure of ADIO. It exposes what it is like to be living in a rural area of Costa Rica, and discusses what it means to be ADIO member and part of the Ostional community. This is followed by an analysis of the community members' perspectives about the Project and a discussion about members' relationships, interactions and spaces. I then discuss the achievements and strengths of ADIO, along with some of its limitations and challenges, by engaging the views and opinions of community members. Finally, this chapter concludes with a discussion of why ADIO is a good example of sustainable development, placing my findings in the context of the broader literature, while also stressing the reasons and problems that are on-going within the association. By overcoming these problems, the Project could be even more successful and beneficial for the community as well as the turtle populations. Furthermore, findings reinforce the literature on community participation and community-run initiatives as being beneficial for sustainability and conservation if organised well on an intra-community as well as an extra-community level.

\subsection{Research Results:}

During my time in Ostional, I had the chance to talk to various people from the community. Whenever I had the opportunity, I asked people about their relationships with ADIO and the history of the organisation in relation to their own past. A number of topics recurred and seemed to be of particular importance for the people I spoke with. These topics are the history and foundation of ADIO, ADIO's organisational and legal framework, the tourism initiative and issues related to the separation of tourist guides into ADIO and MINAE-run tourism, peoples' personal survival and livelihood stories, challenges and issues around power relationships, issues of community resistance in the context of the TECOCOS law and struggles with the government. These themes helped me to explore the story of Ostional and 
ADIO and will be analysed and discussed in the following two chapters, using information gathered through the mixed methods of participant observation, interviews, questionnaires and reflective workshop, which have been explained in Chapter 4 of this thesis.

\section{1. 1 History and Evolution of Ostional and ADIO}

The first human settlement in Ostional dates from the 1940s (Arauz, 1992 in Campbell, 1998), but an actual village had not evolved until the 1950s (Bonilla, 1990 in Campbell, 1998). While residents of Ostional were first to experience arribadas since the 1940s, this phenomenon was unknown to the outside world until 1969. According to Arauz, (1992) in Campbell (1998), until the 1970s, the population of Ostional grew slowly with only six resident families living in Ostional practising subsistence agriculture. There was a special attraction for people moving to Ostional: the nesting of Olive Ridley turtles and the, then illegal, egg harvest (March, 1992 in Campbell, 1998). Agricultural production was reportedly good and residents say that there was no distinctive dry season as there is today. However, According to Campbell (1998, p. 308) "population growth slowed in the 1990s, possibly due to restrictions on participation in the egg harvest". These restrictions were the result of the establishment of The Ostional Wildlife Refuge in 1983, which was set out mainly to protect nesting marine turtles, principally the Olive Ridley species which is most abundant in Ostional. Since the establishment of the Wildlife refuge in 1983 the Ostional community has had limited possibilities of land use and infrastructural development due to legal restrictions (Figueroa, pers. comm, date 28/05/13).

After the validation of the arribada phenomenon in 1970, by Richard and Hughes via an aerial survey, a research station was set up a in Ostional by the University of Costa Rica (Cornelius \& Robinson-Clark, 1981 in Campbell, 1998). However, when nesting at Ostional was officially discovered, egg collection was already a "time honoured tradition" (Cornelius 1981 in Campbell, 1998, p. 309). Villagers were harvesting eggs for sale on the black market, and domestic pigs were being fed on the eggs on the beach (Rojas, pers. comm. date 30/5/13). Many people I talked to during my time in Ostional in interviews and in private conversations refer to the pig-story in this context. Gilberth explained in an interview:

Previously, there were low-income families but people worked in agriculture and had livestock on a small scale as part of their livelihood. An important aspect in 
the history of Ostional is that, in a place like this people had many pigs and people brought them to the beach [to feed of the turtle eggs and for transport]. For the families it was an additional income when they killed and sold pigs. They were brought up to Punta Arenas by boat, which was 12 hours from Ostional, to be sold so people were able to buy and bring back food, clothes and shoes. One of the most important aspects of the Project is that they managed to eliminate the pigs when the Project was defined. There were families that had maybe 100 pigs or 80 pigs. The people did something very important, which was not to return damaging activities such as the pig farming due to the commitment that was formed to protect the turtles and their hatchlings. That commitment has so far been maintained with the same level of importance to protect the resource of the turtles (Rojas, pers. comm. date 30/5/13).

Initially, and following the arribada discovery, attempts to stop the illegal extraction of eggs in Ostional were made; however, the dependency on the turtle eggs as a livelihood strategy for the people from Ostional, the extreme poverty of the region and the insufficient law enforcement, made attempts unsuccessful. In 1979, under the government of Rodrigo Carazo Odio, members of the civil police force began to interfere by patrolling the beach, which had no effect on the illegal extraction of turtle eggs, but led to the beginning of a long conflict with the Ostional residents (Rojas, pers. comm. date 30/5/13). Corruptive activities such as guards poaching eggs themselves and accidentally shooting an elderly woman from the community, led to a tipping point in the history of Ostional. Residents were seeking a solution that did not involve outside law enforcement and that would put a stop to the unequal distribution of benefits and the chaos the illegal extraction of eggs had brought to Ostional.

A journal entry I had wrote on the $19^{\text {th }}$ of May, after a very insightful conversation with a founding member of the Project describes the starting point of the Association and summarises the chaotic situation from a first-hand perspective:

Today I talked to el abuelo (grandpa). He is one of the founders of the Project and came here in 1958. At this time there was nothing much in Ostional. He said that the people would have left if they wouldn't have created new opportunities in the village. A crucial event for him was when they killed a family member. He said people from outside and inside the village use to steal the eggs and they don't know who exactly killed the member of his family in her home in bed, but that 
they had to do something. His vision was to create more security for the people of Ostional and protect the beach with people from the village. It was always important for him that the people work together. Also the beach would have been lost so they started to do cleaning efforts of the 'rubbish' - mainly beach wood and vegetation in the summers. This is how the first conservation efforts begun. The turtles had already arrived back then and the idea formed to turn the sale of the turtle eggs into a business so that people could stay, survive and grow in Ostional. This was the start of a sustainable livelihood for the founding families of Ostional. (Author, field journal, date 20/5/13)

I was told that in 1981, as a result of the various pressures related to the turtle resource, a small group of community members created a committee aiming to find a rational and scientific argument for a legalised harvest of turtle eggs. At the same time, Ostional was designated a protected area in 1981 and declared a Wildlife Refuge in 1983 (Author, journal entry. Date 26/5/13).

In 1984, international marine turtle biologists' opinions on Ostional were sought and "almost all who responded were in favour of a regulated harvest" (Pritchard, 1984 in Campbell, 1998, p. 309). Hence, Law 6919 allowed for a limited extraction of turtle eggs, and commercial sale of animal products from the refuge on two conditions: First, scientific evaluation and monitoring was used to justify and control the harvest of the turtle resource; Second, community members formed a development association in order to create a legal framework for the harvest (Ávila, pers. comm. date 29/5/13).

Later in 1987, the Association extended its responsibilities to include all development issues to reduce economic dependence on egg harvest, and changed its name to the 'Integrated Development Association of Ostional' or ADIO (Alvarado 1987 in Campbell, 1998). It became evident that the legal framework ADIO was granted was crucial to the community's sense of confidence regarding the Project and the security of people's livelihoods through the steady income opportunity the Project presented. This feeling of consistency allowed for a "reinvestment of profits into both community development and marine turtle conservation" (Campbell, 1998, p. 309), marking the beginnings of a project which is set out to be a unique win-win example of resource sustainability and community development. 


\section{1. 2 How do community members perceive ADIO?}

This section discusses how some community members perceive ADIO and how it affects their lives. I analyse and visualise the results from the questionnaire responses and my other methods and opens up relevant themes for discussion.

The general perceptions of participants about ADIO were exceptionally positive. Although, when asked, respondents could all suggest areas of improvements, the overall importance and usefulness of ADIO and the Project for the community was perceived as very high (see Graph 5.1)

Graph 5.1: Usefulness of Project for community

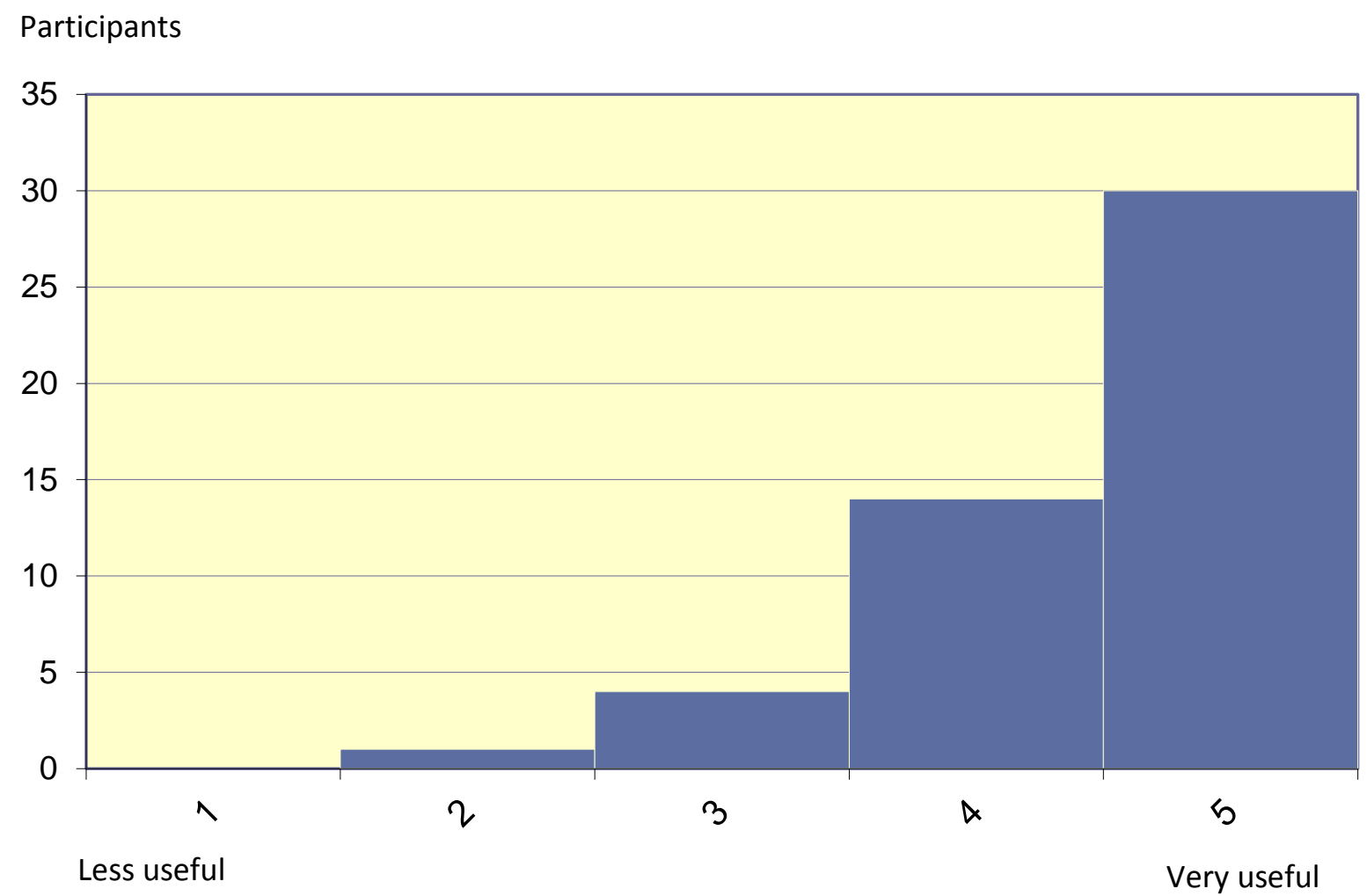

Source: The author

I asked participants to rank the usefulness of the Project for the community from one to five, where one is less useful and five is very useful. Answers were dominantly at the top end of the ranking with an average of 4.489 out of five. 30 out of 50 participants gave the Project the highest possible ranking, followed by the second highest with 14 out of 50 participants. Only 
5 participants ranked the Project lower than four and no one ranked the Project on the lowest possible level 'one'. If 4 or less was elected, some people added that this is because there is always something to improve, but that they think it is generally a very useful project for the community, if not essential for its survival. Results from a previous study conducted by Campbell in 1989 showed similar results (Campbell, 1998).

There are a number of overarching explanations why the Association is perceived as highly important by community members. First, the Project creates regular economic opportunities and socio-economic security for members. Second, the legal framework of ADIO increases the legitimate status and sense of security of the whole community. Third, the whole community benefits from community development including infrastructure and capacity building opportunities. Further benefits of the Project are discussed in more detail in Section 5.1.4.

\section{1.3 Organisational and Legal Framework}

In Costa Rica turtle egg extraction is prohibited, except as agreed on at Ostional beach. The legal framework of the Association regulates the actions related to the management and use of eggs in the National Wildlife Refuge Ostional and is based on the Law No. 7906, approving the Convention for the Protection of Sea Turtles (Morera, 2013). The convention aims to:

[...] promote the protection, conservation and recovery of sea turtle populations and the habitats on which they depend, based on the best scientific evidence available and considering the environmental, socioeconomic and cultural rights of the parties (ADIO et al., 2012).

The Law provides that:

Each party may allow exceptions to satisfy economic subsistence needs of traditional communities, provided that such exceptions do not undermine efforts to accomplish the objective of the agreement (Ley de Protección, 1993)

This legal framework considers the standpoint of the parties who live amongst turtle populations, as well as the impacts on turtle populations at the regional level, and the methods used to take the turtle resource to meet local needs. For ADIO this means that, for 
the extraction and resource use of the marine turtle it is on exemption allowed to establish a management program that includes limits, planning and annual reporting (ADIO et al., 2012).

Wildlife Conservation Law 6919 is the principal law guiding egg harvesting in Ostional and in Costa Rica. Once the two criteria outlined in it were met, other laws had to be adjusted to allow for the legalised egg extraction and sale and to distribute profits from the egg harvest. Justification of use was gained through the scientific monitoring and evaluation of data by the resident biologist and the University of Costa Rica, which suggests that the harvest is sustainable. Thus, the first entirely legal harvest in Ostional was in October 1987 (Salazar, 1991 in Campbell, 1998). Since then, the legal framework for the egg harvest by ADIO has increased and functions to protect environmental, economic and social benefits of the Project.

Furthermore, on an organisational level, the daily tasks of running the Project are managed by a Board of Directors of the Association. ADIO members elect ten board members at the Annual General Assembly. Gilberth Rojas Araya, the former president of ADIO explains:

The roles of the Board of Directors are president, vice president, secretary, treasurer, three vocals, and three advisors which make up ten people who act as Junta Directiva or Board for the Association. The Association for Rural Economic Development (DINADECO) is our master organization at the national level and is part of the government. On an organisational level the administrative tasks of the Board are very clear. Each person of the Junta has well established roles. In fact, the role of the Junta is the management of the whole community. They say that ADIO is like the mother of the community. It is the predominant authority of the community. Hence it orders other associations who are like children. The president is the legal representation, the person who is authorised to represent ADIO in any criminal court in the country, regarding crimes or similar issues. The president directs meetings, and the formal activities of the association. The role of the vice-president is to act when the president is unable to attend. The secretary documents all meetings. The treasurer organises all the financial areas including inputs and outputs of the Project. The three vocals are like replacements, if the president and vice president cannot attend. They have a voice and vote. The three advisors have a voice but cannot vote. They are the facilitators who make everything around the Project work. Hence, of the ten 
people in the board there are seven with voice and vote (Rojas, pers. comm. date $30 / 5 / 13)$

Furthermore, I was told that any ADIO member can run for a Junta position regardless of age or sex. Men and women of different ages have filled these positions successfully in the past. The Junta is elected for a four-year period. However, a new election can be called annually if co-workers are unhappy with the leadership situation. During my stay I heard many stories of favouritism of certain family lines in the Junta, and accusations of misuse of finances throughout the Association's history and in various positions of the Project. This has led to continuous conflict within the community. It seemed that the topic of dissatisfaction in the leadership of the Project is recurring. This issue holds the risk of people getting used to an unsatisfying situation or lose interest in the Project, as a result of incapability and inadequate management of some people involved. Campbell (1998) adds that before, as a result of mentioned issues, the Junta was frequently re-elected on an annual basis.

A number of other limitations were mentioned in the responses to the questionnaire. To the question 'What aspects of ADIO are not working so well for the community and could be improved' some responses addressed issues on the organisational level. Some participants perceived the Board of Directors as not industrious enough. Corruption in the Junta and in other processes, and money lost to pockets of individuals was also commented on. Community members would like to see that the Junta members work for the people rather than for their own agenda. This was said could help the community benefit more. Also, some participants perceived that the training of the board of directors and the main figures running the Project could be better. This perception reflects the idea of the need for capacity building and the wish for more knowledge and education in technologies including computer training, and in other areas such as 'social relationships' leading to generally more professionalism, and higher education amongst members.

Further, a lack of communication from the Junta to ADIO members and the community as a whole was identified. In this vein, a better handling of the leadership role, better distribution of information and more ability for community members to speak with the Junta was wished for. An issue that came up in the context of lack of communication was the divide of Ostional into different 'sides', which are basically ADIO and MINAE. Some people mentioned that 
they would like the 'misunderstandings' to be fixed and to see the conflict to be resolved. According to this, some people complained about a lack of unity amongst the population, due to differences and unresolved issues between some of the community members. In this context, better communication by the president was seen as important - through more awareness and meetings and through dialogue with different groups such as the government and other institutions - in order to create better relationships on different. It also seemed important to some participants to present a good image including good infrastructure and tourism management and a united picture of Ostional for visitors.

On a different note, the regulations of ADIO were perceived as 'badly handled' by a few. For example, people who work for the government can't work with ADIO and there are strict rules on what people call 'fines' or sanctions. A member of ADIO explains:

Everyone gets the same part. If some do not come to the beach at times they get their money amended accordingly, because it is the right thing to do. If someone is sick for example, they only get half of the money but if they just don't want to come they get nothing. Jocelyn Correa, ("EraVerde," 2009a)

The legal framework of ADIO, although there is scope for improvements - in areas of 'transparency of funds', 'work ethics', 'capacity building' and 'communication' - is successful in the way that it has been created out of the social capital of the local community, through participation and for the benefit of both the turtle populations and the community. Furthermore, it increases the community's sense of confidence regarding the Project and the security of people's livelihoods. Overall, the legal and organisational framework in place for the turtle conservation and egg harvest by ADIO increases and protects environmental, economic and social benefits of the Project.

\section{1. 4 Benefits from ADIO}

One of the key objectives of my research was to explain aspects of ADIO that work well and are perceived as beneficial for community members. Perceptions about the benefits from the Project are important for community participation and project sustainability, which were useful in order to identify key elements for the success of ADIO (research objective 3). 
In my questionnaire survey, when participants were asked what they believed to be the most beneficial aspects of the ADIO Project of Conservation and Management of the sea turtles, I received 129 responses out of 50 participants. Three areas stood out significantly (see Graph

Graph 5.2: Participants perceptions on beneficial aspects of ADIO

\section{Number of responses}

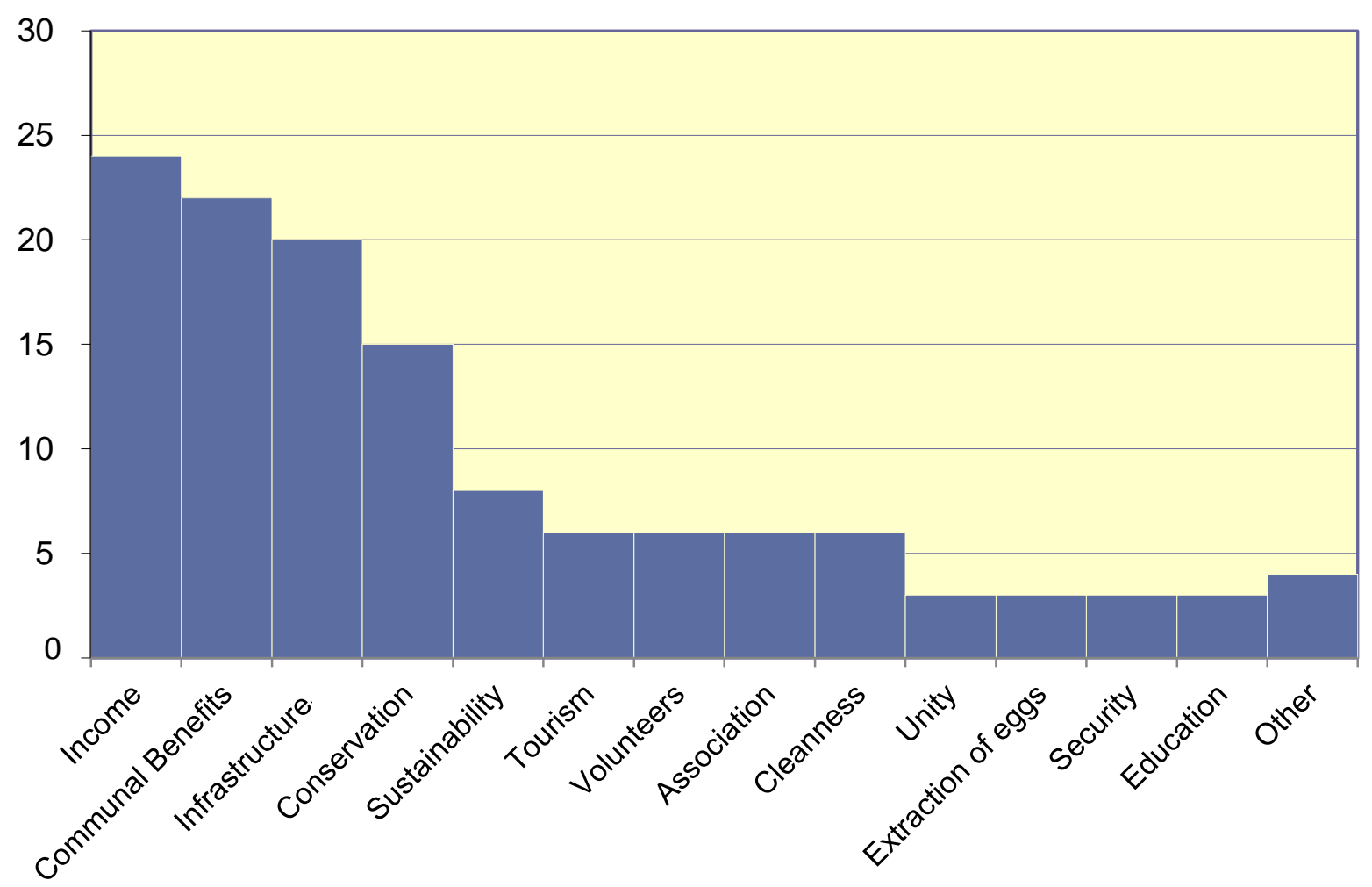

Source: The author

First, out of 129 responses to this question, participants perceived the income opportunity and salaries from ADIO and from tourism related activities as being most beneficial. In casual conversations beyond the questionnaires I found that, for some, the monthly income from the participation in the Project which include, cleaning the beach, helping in the extraction and packaging process and tourism activities, presents their only opportunity to earn money. Nevertheless, the seasonal fluctuations in turtle numbers (many turtles arriving in the rainy season, but hardly any arriving in the dry summer season) is perceived as challenging as income decreases over the summer months. 
Second, respondents found that the assistance and support that the Project offers to members in different areas such as sports, school and university education, support for older people, pregnant women and help for the sick with chronic diseases is highly beneficial.

In discussion about improvements during the reflective workshop, there was a general consensus on what a participant said:

It would also be good to have a place to go for the young people. It would be good to have a place to 'hang-out' and play games where we can share and teach the younger kids, so the young people are off the street and don't get dragged into bad things like drugs. (Pers.comm.,workshop, date 31/5/13)

Third, the infrastructure improvements that have been financed through the Project, such as the plaza (sports place), the surrounding bridges (used for crossing the rivers when the water levels rise in the rainy season) casa de salud (house of health), centro de nutrición (nutrition centre), planta de empaque (packaging facility), and activities such as programmes and courses that these facilities have enabled, were seen as highly valuable. Some of the infrastructure improvements are summarised in more detail below and were financed from ADIO money through the egg harvest (Table 5.2):

Table 5.2: Investment in community infrastructure and materials for the development of the Project, conducted by the ADIO during the period from 2007 to 2011.

\begin{tabular}{|c|c|c|}
\hline Year & Entry & Value in Colones \\
\hline 2007 & $\begin{array}{l}\text { - Construction of hammock bridges over the } \\
\text { Río Montaña, Rio Ostional and Quebrada } \\
\text { Ray (creek). } \\
\text { - Placement of sewers for channelling water } \\
\text { in the community. } \\
\text { - Construction of the local cemetery chapel }\end{array}$ & 44.780 .000 \\
\hline 2008 & $\begin{array}{l}\text { - Repair and refurbishment of classrooms in } \\
\text { the School of Ostional for operating a } \\
\text { Computer Centre } \\
\text { - Equipment of Computer Centre (purchase } \\
\text { of computers, furniture and air conditioners) }\end{array}$ & 42.420 .000 \\
\hline
\end{tabular}




\begin{tabular}{|c|c|c|}
\hline & $\begin{array}{l}\text { - Repair of casa multiusos (multipurpose } \\
\text { building), purchase of furniture and fans for } \\
\text { it. } \\
\text { - Purchase of sealing machines of plastic bags } \\
\text { for packing of eggs. } \\
\text { - Purchase of egg packing material (plastic } \\
\text { bags and other). } \\
\text { - Purchase of work tools for maintenance } \\
\text { activities of the habitat of nesting turtles }\end{array}$ & \\
\hline 2009 & $\begin{array}{l}\text { - Contribution in fuel and other materials for } \\
\text { channelling Rio Ostional, such as } \\
\text { alimentation and housing of the machinist } \\
\text { and dredging assistant. Compensation of } \\
\text { labour used in specific tasks for the } \\
\text { canalisation of this river. } \\
\text { - Construction of the CENCINAI building or } \\
\text { Nutrition Centre. } \\
\text { - Purchase of work tools for maintenance } \\
\text { activities of the habitat of nesting turtles } \\
\text { - Repair of building District Police } \\
\text { Delegation. } \\
\text { - Fitting of the site for construction of bridge } \\
\text { over Rio Rosario. } \\
\text { - Purchas of sewers and placement on the } \\
\text { Quebrada Cuyuza. }\end{array}$ & 28.156 .300 \\
\hline 2010 & $\begin{array}{l}\text { - Termination of the repair of the } \\
\text { infrastructure of the District Police Station. } \\
\text { - Installation of canals for water within } \\
\text { community and repair of sewers }\end{array}$ & 5.043 .000 \\
\hline 2011 & $\begin{array}{l}\text { - Channelling of Quebrada Seca. } \\
\text { - Repair and construction of checkpoints on } \\
\text { the beach. }\end{array}$ & 4.500 .000 \\
\hline & Total & 124.889 .300 \\
\hline
\end{tabular}


Source: ADIO et al. (2012)

Other perceived beneficial aspects of the Project were related to the conservation of natural capital and the resulting sustainability and the symbiosis between turtles and community. Furthermore, tourism and the opportunity for guides and the community economy were related to volunteers that the Project attracts, and were also perceived as beneficial. Further participant voices can be grouped around the benefits for Ostional through the establishment of a legal framework for the Association as was noted down by a participant:

The existence of an Association that protects the turtles, organises the community and creates a legal framework and representation of the community (Pers.comm.,questionnaire survey, date 1/6/13)

Furthermore, the benefits of a clean beach and village were mentioned six times, followed by benefits of working together as a unity, the general security through the organisation of the resource, and management, education and awareness through the Project.

Under 'other' in Graph 5.2 fall perceived benefits which were once or twice related to equality in gender and equal distribution of income, the survival of the village through income otherwise people would have to leave due to a lack of economic opportunities; and the potential of the Project if managed well. Particularly, equality of gender is an aspect of the Project people are proud of as it creates equal opportunities for women and men to benefit and learn from the Project.

Furthermore, when participants were asked in my questionnaire about their motivations in participating in ADIO I received 48 responses from a total of 50 participants (see Graph 5.3). 
Graph 5.3: Motivations to participate in the Project

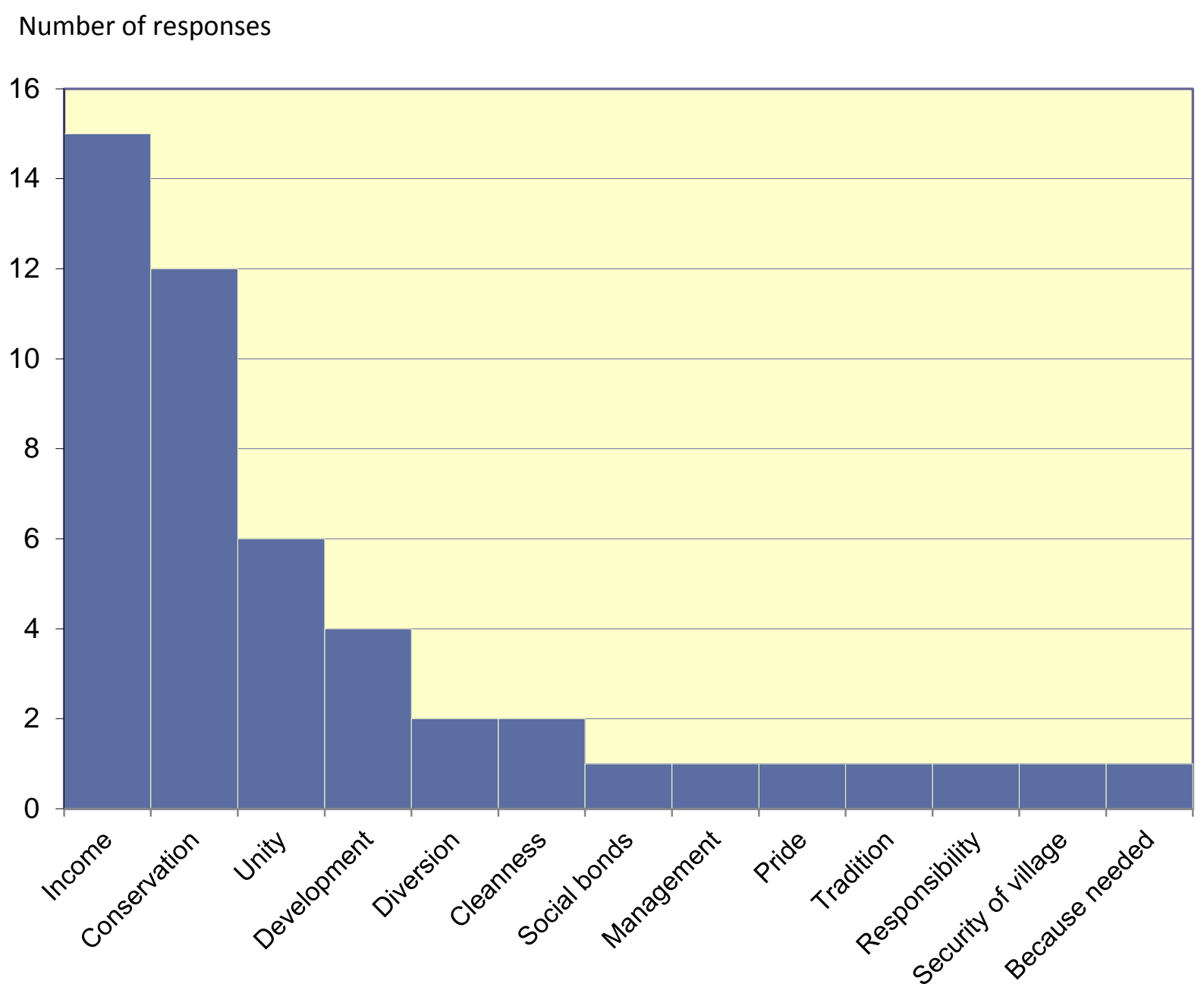

Source: The author

Out of 48 answers to this question, approximately one third stated that income and the economic help the participation in the Project offers to families was the main motivation for their participation. This was followed by the importance of the conservation of the resource and sea turtle species that arrive at Ostional beach, the protection of turtles in order to increase their existence and the sustainability of the Project. Further, an important motivation for participants to work with ADIO was the feeling of unity the Project creates for the community, the sharing of ideas, relationships with the people and the idea of everyone's participation. Other motivations were noted as: increased development through the Project, more income for the community and general benefit for the community, diversion and a chance to 'untangle', keeping the beach and village clean, better social relationships, better management and organisation of the extraction of eggs, pride of being part of a unique model in the world, tradition, responsibility as a founding member and the responsibility towards 
family which has continued across generations (some family member was may be killed due to theft of eggs), security of the village and the people.

However, on a different note, a lack of motivation of the people has also been seen as impairment to the Project. Mostly 'the young' mentioned here who were seen as lacking motivation to work and participate in the Project. Some comments on this included 'they only come to pass the time' and 'many socios (partners) and members of the Junta have lost the love they had for the Project in the beginning'.

Whenever participants were not active members of ADIO I asked politely why they did not participate. Some participants commented why they are not involved in the Project. Some answers included; other obligations, other or permanent job, not being Ostional born, no desire of involvement, 'they don't like me', lack of good will or misuse of money, conflict in the past and the handling of fines. In the study of Campbell (1998) it was expected that nonmembers would be more critical of the Project's impacts than existing members. However, this was not the case in both studies, and all non-members and non-active members ranked the impacts of the Project as positive and useful for the community (Figure 5.1). The primary reason mentioned for this was the income flow in the village, as a result of the Project, supported the economy.

Overall, economic benefits and the awareness about the importance of conservation to preserve the natural capital of Ostional made up for a big part of people's motivations to actively participate in ADIO. Income, communal benefits, infrastructure as well as conservation can be seen as the four main pillars of perceived benefits of ADIO. In the context of community participation, conservation and sustainable development discussed in the literature it is important to know what people perceive as beneficial and why they participate, in order to reinforce the successful aspects of the Project and secure its survival in the long run.

\section{1. 5 Impact of ADIO in livelihoods}

Ostional is a rural community and livelihood strategies are limited by access to jobs and educational opportunities. Nevertheless, the people of Ostional have managed to subsist in and develop the community, largely through the initiatives of ADIO, which have created an 
important and sometimes sole income opportunity for community members. In one journal entry, I reflected on my observations and on what people have told me in regards to their livelihoods:

Men in the Ostional region I was told, work mainly in construction, in for example close by communities of mainly foreigners. Some men make artesania, shape, sell and rent surfboards, house sit or maintain foreigners' houses. I met some women who go to the richer people's (mainly foreigners) houses in the neighbouring towns and work in housekeeping and nanny jobs. Some women from the neighbouring town came around on a motorbike and sold the fresh cheese their mother-in-law makes. I was told that, some years before, when the ADIO was founded, people did not have many of these employment opportunities and the salary from the extraction and sale of eggs was the only income. "In 1992, $60 \%$ of households identified egg harvesting as their most important economic activity and $31 \%$ identified agriculture" (March, 1992 in Campbell, 1998, p. 308). For many women I talked to, it still remains the only income opportunity. People, back then did, and still work their own small scale farming in order to sustain themselves, other necessities are bought from the bigger neighbouring cities. Not many people have a car so the bus serves as the main form transport. Other community activities have been baking cookies (with turtle eggs) and making ponche (punch) that is been sold in the domestic market (Author, field journal, date 20/5/13).

Therefore, the Project and its legal framework resulted in the greater distribution of the benefits of the egg harvesting and increased income security for the Ostional community. Growing up with, and being involved in ADIO, means that Ostional born residents have the security and the opportunity to be part of and benefit from the different aspects of the Project.

A community member stated with pride:

As long as the Project continues, members will always have the prospect of benefiting - the work with ADIO, including having a 'salary' as elder or student or being supported if chronically sick or before and after giving birth. (Pers. comm., date 27/5/2013) 
Resulting from the economic stability that comes with the Project, some member's choice to stay in Ostional instead of selling their land and moving to the city might also be affected. I could observe that the community had managed to build a small social welfare system, showing community sovereignty in a place where help from the government hardly reaches, while at the same time protecting the natural capital of the area.

\section{1. 6 The role of tourism}

Tourism activities in Ostional are mainly related to the arribada phenomenon. There is limited tourism infrastructure such as cabins or transport, nevertheless a number of families rent out rooms to tourists. Tourism was generally perceived as an opportunity, and something that was hoped for, that increased tourism might lead to more work and revenue for the community.

ADIO has established a tourism initiative to take visitors to the beach during arribadas. Guides provide tourists with information about the Wildlife Refuge, the turtles and their eggs, and the conservation and management work that ADIO does in order to preserve and utilize the turtle resource. A number of times people told me about issues related to the tour guides which emerged in 2004 when a small group from the ADIO tourist guides started their own tourism initiative. I was told that this happened in collaboration with MINAE which apparently suggested the move, with the condition that a certain percentage (\$6US) of each paying tourist goes to MINAE. This is apparently a legal requirement but ADIO has not done so in the past because of a number of reasons. An ADIO member explains:

MINAE does not do their job, but uses the government facilities such as cars, quad bikes and petrol money for their own benefit and to show volunteers and tourists around. But, when they are needed, when there is for example an incident with dead turtles through illegal fishing nets, they claim they don't have money or resources to do anything. (Pers. comm., date 18/5/2013)

Furthermore, I was told that:

The people who started an independent tourist guide initiative learned all their knowledge through ADIO and ended up taking ADIO resources like tables and boards - which MINAE has now. (Pers. comm., date 18/5/2013) 
I was surprised to hear that the tour guides who became independent from ADIO apparently also followed different rules and guidelines. For example, I was told that:

They took up to 20-25 tourists per guide during 'arribadas' which created a lot of chaos and is hard to oversee. Also, the money they earned did/does not benefit the community at all, but only the small group of guides and MINAE. Some of them didn't have the official papers to be a guide and did not do the training or course in order to call themselves 'turtle guides'. (Pers. comm., date 18/5/2013)

It was mentioned that a key event in the conflict between ADIO and MINAE and the tourist guides was that the guards from MINAE did not let the ADIO guides with their tourist pass through the main entry of the beach during an arribada. ADIO reacted and printed, with the help of a volunteer, hundreds of flyers and distributed them in the region and wider region, informing people about what is going on, in order for visitors to support the ADIO guides when they come to Ostional. Apparently, this minimized the number of tourists for the independent tourism initiative and tourism remained a minimal income for them.

However, the conflict between ADIO and MINAE goes long back, arguably since the establishment of the Refuge and mentioned stories are summarising key events that happened in the past. Said this, it actually seemed that the conflict between the two parties had calmed down in recent times and that various members I talked to - from both parties - seemed open for discourse and wanted to improve the situation. I interpreted the situation as one of a 'status quo' where both parties did not want more conflict but motivation to come and work together was not yet achieved.

Thus, although tourism is perceived as beneficial for the community it has also accentuated community division and conflicts. The literature on sustainable tourism reveals that "the development of sustainable tourism requires the informed participation of all relevant stakeholders [...]" (WTO, 2004). Thus it can be suggested that, in order to reach sustainable tourism, conflicts between tourism initiatives need to be resolved and stakeholders should participate equally in the development of the local tourism sector. 
On a different note, many participants in my questionnaire survey and workshop expressed their hopes, to extend tourism activities in Ostional. ADIO has many years of experience with volunteer tourism the prior explained volunteer rotation scheme and volunteer tourism in general were usually perceived as very beneficial. People I talked to mostly mentioned financial benefits through volunteer tourism. When I questioned the participants about their opinion regarding the reciprocal exchange of knowledge between volunteers and hostfamilies, it was often perceived that the volunteers learned more from families and not the other way round. This challenges dominant discourses that it is the volunteers the ones who teach locals. Most people agreed though, that there is reciprocal exchange between volunteers and community to a certain degree, particularly in regards to learning about cultural differences. I was told by a number of participants that they would like the ADIO volunteer rotation scheme to be continued and enhanced. A questionnaire participant mentioned that:

The regulation of the guides is not organised well and that the organisation of volunteer tourism is not the best as ADIO does not receive many volunteers anymore, and MINAE now owns most resources in this area. (Pers.comm., interview, 26/5/2013)

However, during my stay, most volunteers arrived at MINAE through bigger overseas based volunteer organisations and had usually no involvement in or knowledge about ADIO and community activities. On this note, a few MINAE volunteers I talked to brought out their wishes for more involvement with the community, or to be more involved with ideas for organising independent study groups or sports teams with community members.

\section{1. 7 Other issues to be improved}

There were perceived issues on almost all levels of ADIO, but mainly on the reinforcement of regulations regarding the illegal extraction of eggs, money administration and the general management of the Association as discussed in this section.

When I asked participants in my questionnaire survey about aspects of ADIO that do not work so well for the community and could be improved (Objective 2), I got 104 responses from 50 participants (see graph 5.4). 
Graph 5.4: Participants perceptions on aspects of ADIO that do not work so well for the community and could be improved

\section{Number of responses}

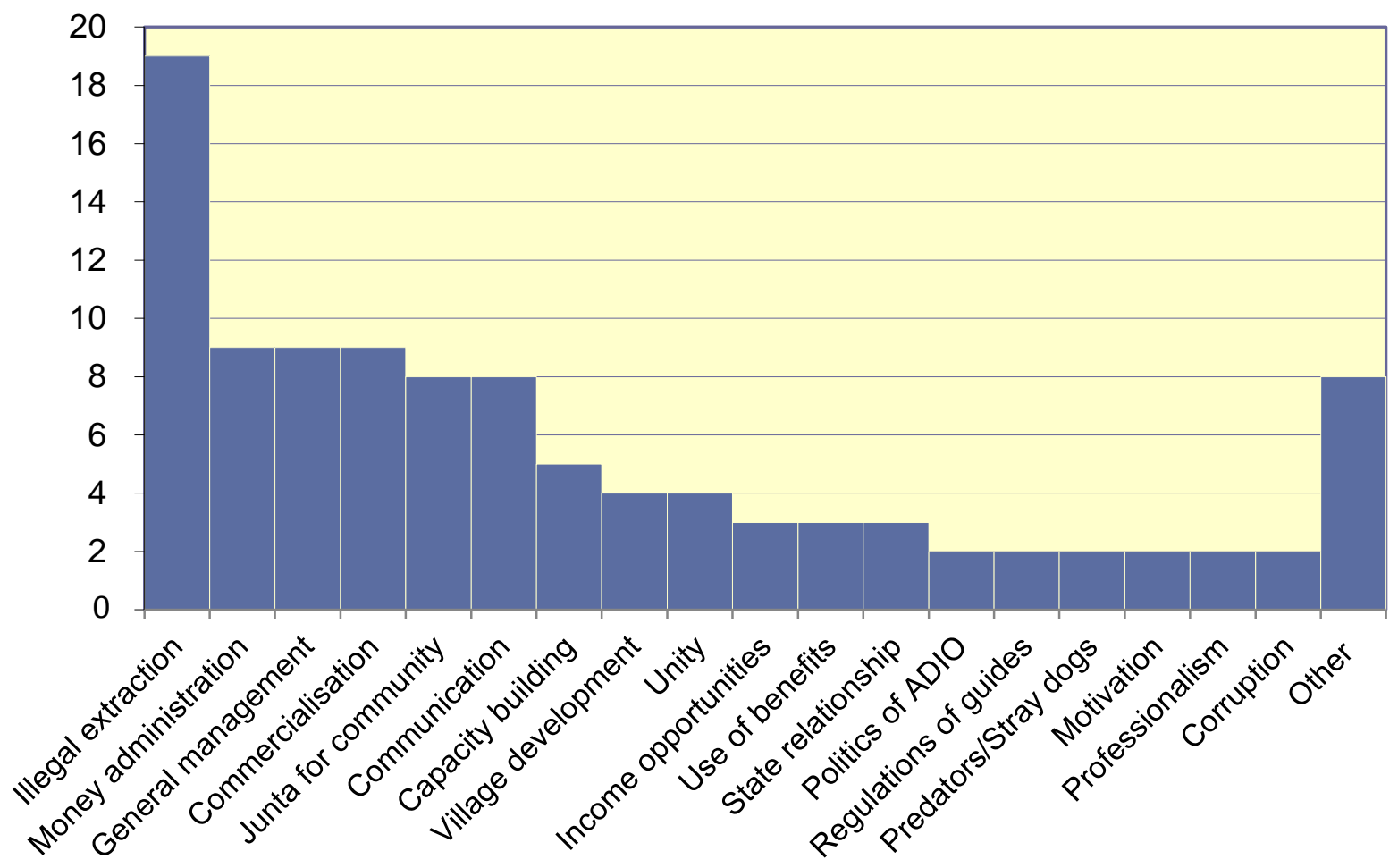

Source: The author

When participants were asked about their perceptions on aspects of ADIO that do not work very well for the community and could be improved, one issue stood out: Out of 104 responses to this question, the illegal extraction of eggs and related lack of security at the beach made up 18 per cent of participants' answers. People referred to guards, who at the beginning of the Project were exclusively ADIO members, but now consist of a mix of partners (socios) and non-partners. One questionnaire stated that:

The surveillance of the beach does not work very well and that the group of 18 guards is badly coordinated. (Pers.comm., questionnaire survey, 26/5/2013)

Also, the theft and smuggling of eggs, in order to sell them, was said to be badly handled by guards. Consequently participants would like the guards to be more responsible. 
Complex issues arise from this need for control and reinforcement of regulations which involve kinship connections. Many people who extract eggs illegally were said to be from the same family. Apparently, the Junta is aware of this but would not act because of these kinship connections and the issue of the poorly managed illegal extraction of eggs now poses a significant danger to the Project. The noncompliance of some people in the community towards the regulations of the Project and the Wildlife Refuge reflects the importance of informed participation of all community members and stakeholders, in order to reach project sustainability, as discussed in the literature. Although, the regulations applied in Ostional since the Association's foundation has led to immense improvements regarding the theft and monitoring of turtle eggs, I was told that the association has gone through different phases in which the amount of illegal extraction of eggs has varied, often related to the strictness and the execution of regulations by ADIO. It might be beneficial to consider returning to a more strict leadership and prosecution of poachers. Keeping in mind, that complex family and community structures make it difficult to execute certain tasks, such as prosecution of poachers, objectively.

Hereafter, three issues were criticised uniformly in the sum of questionnaire responses. First, the administration of money, which was said to be 'not very well handled', because there is no money for 'other things' when needed. These things were mentioned as: Salaries and infrastructure maintenance. Secondly, the general management, organisation and leadership role of the Junta was criticised. Specific poorly managed areas were noted as 'the organisation of groups', 'the unresolved status quo of theft' and the organisation of the cleaning of the beach'. Lastly, the commercialisation of eggs was not at an optimal level or was perceived to have decreased. In this context, a community member explained and suggested:

The commercialisation of eggs is not optimal because intermediaries make most money in the process. It would also be beneficial to conduct a study of the market and search for new markets to open up the trade of turtle eggs from Ostional. (Pers.comm., questionnaire survey, 26/5/2013)

Other points were referred to as the lack of work and other economic opportunities, the dependency on the egg harvest, and the financial instability across seasons. Some people did not feel that there was an assuring security for income if the turtles for some reason should not come anymore. In this context, a wish for diversification of egg products, including 
creams and shampoo was also mentioned. Hereafter, it was said that the utilisation of benefits and money from the Project could be improved because it not often beneficial for the community.

Other less frequently mentioned limitations include the 'issue of the stray dogs', 'lack of awareness of courses and programmes' which was related to a lack of discipline to go to them if people signed up, and 'lack of resources to enhance the Project' such as trucks for the commercialisation of the eggs.

Also a lack of democracy in the Association was noted by two participants for the reason that sometimes the community does not agree with what the Junta does. Furthermore, one MINAE staff noted a lack of respect for conservation rules as an impairment of the Project. This participant referred to rules including the use of only red light on the beach in order to not disturb the turtles arriving at the beach. Other impairments that were mentioned once but no more, ant they were the 'poor access to Ostional' because of rivers and bridges that need to be repaired or built, the 'lack of capacity building in languages' and the 'issues surrounding drugs' in the region.

When I asked participants in my questionnaire survey about ideas how ADIO could be improved, I received 62 ideas from 50 participants (see graph 5.5). 
Graph 5.5: How could the Project be improved?

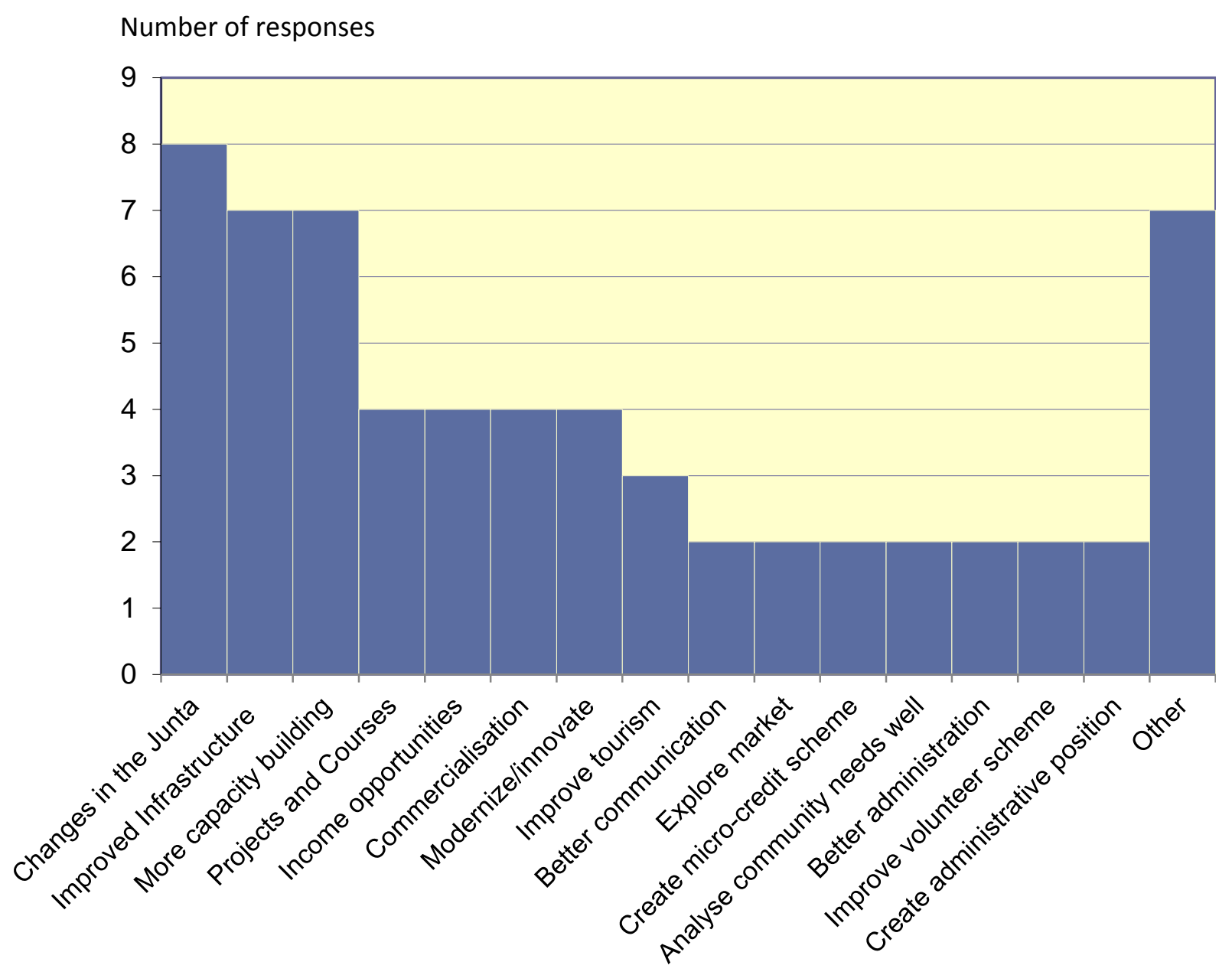

I could identify essentially two broad main areas for improvements. First, participants wished for changes and more capacity building amongst the Junta and capacity of the younger people of Ostional in particular. When discussing capacity building most people brought up the wish for change in the Junta and employment of more competent people for better administration, the desire for generally neutral leaders, and the avoidance of sympathy elections of friends or family members. Further, it was important for the people to motivate, involve and invest in the young because they are the future of the village. Areas mentioned for capacity building included computer courses, technology and sports and higher education.

Capacity building for all the residents and ADIO members in general was spoken of, to further the development in areas such as nutrition, computers, technology, English, the capacity to think about 'tomorrow' and to save and gain prosperity while overcoming 
imbalance in income between dry and rainy seasons. People wished for more projects in general, and for families to gain greater development through household courses on, for example, sewing, baking and sustainable living. Through a discussion about improvements in the reflective workshop, I realised that young people generally wish for more community development programmes for the 'young' (often sport's related), whereas older people are more concerned with the administration of the Project and the transparency of where the money goes.

Secondly, a key area for improvements was perceived around economic opportunities and infrastructure improvements.

One participant stated in detail:

[...] infrastructure with more benefits for the community, including good restaurants, cabins for visitors, businesses such as hardware, butcher, grocers shop, chicken and pig farm, animal shop, because people currently have to go to neighbouring towns or the city (Pers. comm., questionnaire survey, date 29/5/2013)

Furthermore, people emphasised the importance to repair bridges and installations of the ADIO, the community hall, to continue the project of the square, build sodas or snack bars, a nursery, a playground, improve the roads, improve the health clinic with better equipment, introduce organic fertilisers, create a garden with paths, gazebo, painted walls and make the village nicer in general which might stop people selling their land and attract more visitors.

Moreover, many participants expressed the wish for greater employment opportunities, to diversify livelihoods into alternative sustainable sources of income. Here, the emphasis laid on creating other income opportunities relating to tourism and more work opportunities related to the turtles, including making more egg products, and making cookies, tomato sauces and shampoo especially in the summer when the turtle numbers are reduced.

The above two areas of improvements were perceived as most important, according to the number of responses in my questionnaire survey (Graph 5.3). The following ideas were mentioned less frequently by all the participants. Nevertheless, they are important in order to identify trends in community perceptions about ADIO and to identify key aspects for the success of the Association. 
Other ideas proposed were to improve commercialisation by selling directly to supermarkets, as partly discussed in the prior section. Improvements in the commercialisation process of the eggs were hoped to make the Project more productive and profitable. In this context, the employment of a person who administers market sales was proposed which would eventually make the egg sale more efficient. A few people recommended exploring the market for turtle eggs further through research, to see where there were new routes for sales and to develop a new market strategy.

Furthermore, an improvement mentioned was to create a mentality towards innovations, especially in the administration of the Project. E.g. to elect a more modern and open Junta, generally modernise, have new and improved ideas about the Project and initialise new projects with the focus on a better organisation of the community.

A further enhancement was proposed regarding improved tourism and to reunite the divided tour guides; to start activities such as horse riding and boats trips for the mangroves with tourists and volunteers; to generally increase turtle tourism and create turtle nurseries to show tourists how hatchlings are born and educate them more; to improve the volunteer scheme from the ADIO side, and also improve the structure of accommodation available for both, national and international guests.

Furthermore, the administration and organisation of the Project could be improved by analysing what is most beneficial for the community and what the community actually uses. A Junta is wished for that is actively working towards achieving those desires. The participants had another idea to create the position of an administrator to guarantee good management and use of the resource of the sea turtles.

Last but not least, another area of improvement was to develop the financial part of the Project further and, for example, create a micro-credit scheme from ADIO money for community members who would like to start their own business, or who need a loan for other reasons. The two points that were least mentioned were to bring back projects like the Red Cross initiatives, which have been in Ostional in the past and, to further decrease the number of stray dogs and zopilotes (buzzards) as they are a major threat to the turtle population. 


\subsubsection{Land Ownership}

In light of the current debates on control over territories and power relationships between the coastal communities of Costa Rica and the government, and throughout my methods, I could identify a great wish of community members to secure the survival of the community and the Project. This wish reflects problems around land ownership of foreign investments in the region. Some people told me that they desired development but without the current extensive involvement of foreigners. A reflection from a journal entry clarifies:

I was told that it has been a common process that ticos sell their land cheaply to foreigners and move to the cities because of pull and push factors and the dream of opportunities in the city. However, six to eight years later the usually come back to their home towns without any financial assets. To buy back land from the foreigners is difficult. Due to expensive infrastructure foreigners build, the property value increases extremely. (Author, field journal, date 20/5/13)

On conservation and land ownership, one participant mentioned the example of the absence of lights along the beach side, which is important for turtles, and that there were no visible lights until the foreigners came. Again, much hope for improvement in this area lies in the proposed TECOCOS law to keep the coastal land in the hands of the local population. If the TECOCOS law passes, Ostional and other coastal communities will not be affected by the pressures of foreign landowners anymore as the land needs to stay in the families, and cannot be legally sold.

This chapter has presented the findings and analysis of my research. It has analysed community perspectives obtained from aforementioned methods, in regards to beneficial and not so beneficial aspects of the Project, which has led to a number of improvement ideas and areas for future research with ADIO. It also presents the baseline for themes discussed in the following chapter VI. 


\title{
CHAPTER VI
}

\author{
DISCUSSION
}

This chapter brings out the key findings and discusses them in a wider context of ADIO and community-run sustainable development. The objective of this chapter is to demonstrate how the research findings connect with the literature reviewed in Chapter III.

\subsection{ADIO and sustainable development}

In the context of the current global dilemma where communities around the world and in many industrially fast growing countries are not being developed sustainably, pressuring global ecosystems (Ulgiati \& Brown, 1998), it is important to search for sustainable alternatives for sustainable community development. In Ostional, awareness about sustainable actions seems high and views on sustainable development seem strong. The way Ostional has developed through its context specific circumstances has manifested itself in the idea to co-exist with nature in harmonious balance. This seems to be passed on from generation to generation. Therefore, through an environmentalist lens, in communities such as Ostional, resource use may be often more sustainable as a result of the successful application of a mixture of internal and external regulations.

Findings indicate that the controls established by ADIO in the Project appear to succeed in contributing to project sustainability. Going back to the broader definitions about sustainable development, ADIO has managed to create a project that fosters development of the local community, while "meeting the needs of the present without compromising the ability of future generations to meet their own needs" (Van Marrewijk, 2003, p. 98).

Furthermore, the case of ADIO shows the "scope for local involvement in planning and implementing sustainable development solutions" (Selman, 1996, p. 1), which supports the long-standing conception that people should be involved in the planning and management of their own area. Re-connecting to the discourse around natural and social capital, the 'sustainable' component of development requires that human activities do not deplete a place's 'natural capital'. In Ostional the turtle populations represent a stock of natural asset that yields a flow of valuable goods and services into the future. The strict rules ADIO has in 
place for the egg harvest and community protection efforts for the turtle species aim for the upkeep of the sustainability of the village's source of 'natural capital'.

Further, supported by the academic literature on social sustainability, the case of Ostional has shown that using 'social capital' for an initial purpose creates mutual understandings that can frequently be used to accomplish entirely different joint activities at much lower start-up cost. The different initiatives that have emerged out of the Association including the tourism initiative and the involvement of some community members in the proposal of the TECOCOS law are two examples of the mobilisation of social capital. ADIO members have acquired skills to form a productive context related to the unique natural capital of Ostional and have formed social capital through training, education, unique experience and participation (Ostrom, 2000).

\subsection{ADIO and community participation}

During my time in Ostional, ADIO had approximately 260 members who were actively participating in meetings and regularly working in Association and conservation tasks. This number has been slowly rising over the last few decades. Given that only Ostional-born residents can benefit from participation in the Project, and taking into account changes in motivation and community population through emigration, it is unlikely that complete community participation can be achieved. Nevertheless, participation in Ostional is crucial to the survival of the Project, and findings show that community participation is overall successful.

Following Dahl (1994), one signifier for successful community participation is that the people involved have significant control over the decisions regarding the organisation to which they belong. Findings from the questionnaire survey and workshop suggest that many residents would like to see improvements regarding communication and increased democracy within the Association. It is important for the people involved to keep control over the decisions made in the Association. Although improvements could be made, the foundation of the Association with aforementioned organisational framework in place is outlined for democracy within the Project.

Also, more widely, the capacity of rural people to participate in and manage resourcemonitoring, conservation efforts and implementation of educational programmes on the 
ground represent a vast human resource. This is why examples such as ADIO and the Ostional community are rather rare in the academic literature and, hence, make up important case studies with lessons to be learned for other communities around the world. If promoted, this 'untapped' human resource leads to greater empowerment of local conservation and management work, creating conservation-minded residents within the community. In Ostional the residents now discuss conservation issues with tourists, volunteers, students and researchers, promoting on-going dialogue about the concerns around use of natural resources.

The literature indicates that sustainability of community-run projects is largely dependent on collective action or local organizational capacity. Like-minded people come together to identify and work towards eliminating a common and shared problem as a community (Stewart et al., 2004). When a group of like-minded people come together to solve their felt needs, usually with the help of development agents, but in the case of ADIO, mainly selforganised, they form, collective action. The ability of the collective to achieve their goals reflects the local organisational capacity which is also largely influenced by community participation, empowerment of the people, people's partnership and social learning (Davids et al., 2005). Although the organisational capacity of ADIO has been criticised by some participants, the Association has done a great job in mobilising many people in the community to develop itself and work towards a common goal, particularly given the complex structures and power relations within the community and with external stakeholders.

I want to emphasise that the special conditions that have led to the foundation of ADIO might well be unique and that lessons learned from the Project might not be transferable to other communities. For example, one reason for the high participation of Ostional residents in the Project might be the lack of alternative economic opportunities in the region. Especially women are heavily dependent on the income from ADIO, whereas men are more likely to encounter casual work opportunities in construction and trade. As stressed by participants, Ostional would not exist without the Project as it presents most community members with their only stable opportunity for income.

This study has shown that local organisational capacity depends on public participation, empowerment of the people, and partnership with the other stakeholders in development and in social learning. If problems in one area persist, the Project as a whole is inevitably affected. In this vein, the struggles ADIO and the community have faced with the government in the past had a significant impact on the success of the Project in terms of the unity of the 
community, levels of participation and perceived democracy. This is also mirrored by participants voicing the wish for a resolution of conflict between different 'groups' of the community, which has been discussed in Chapter V.

\subsection{ADIO and conservation, environment and development}

From an environmental perspective, existing scientific evidence from the monitoring of the turtle populations and the extraction process supports the sustainability of the egg harvest. The focus of this study, however, lies also in the socio-economic aspects of the Project which contribute to the overall objective of environmental sustainability through sustainable development.

In sum, there are three key areas of the Project that lead to the aforementioned aims of conservation and sustainability. First, community members undertake and re-invest into conservation activities. Thus, there is a direct link between profits from the egg harvest and conservation of the marine turtle species. Second, members respect and are proud of conservation activities and link them to the long-term survival of the village and sea turtle population. Third, the Project's legal framework requires continuous scientific monitoring and evaluation of the turtle populations and the harvest impacts, allowing interruption if evidence suggests that the harvest is damaging the turtle populations.

Local pride is at the centre of villagers' conservation efforts to protect the sea turtles coming to Ostional. Through ADIO, the community has gained a sense of growing pride and recognition, mainly through the process of local empowerment and via public support for the goals of the Project, and in fostering project participation. The Project has created a sense of achievement in the local community, and has fostered widespread ecological consciousness and sense of a community work ethic.

More broadly, the emerging global strategy for biodiversity conservation has the central principle that biodiversity can be conserved only through efforts to promote and sustain human welfare (Blaikie \& Jeanrenaud, 1997). Ostional mirrors this strategy where conservation of biodiversity goes hand in hand with wider social and economic benefits. In the context of sustainable development, Ostional appears to meet major requirements for sustainable development as supported by the literature. Development has been identified by Ritchie and Crouch (2003), as a social change process that involves four elements: growth in 
material or service output; equity of benefits among participants; increase of organizational effectiveness; and capacity building toward sustainability. Democracy is an inherent part of the process. Development so defined is participatory development; for people to prosper anywhere they must participate as competent citizens in the decisions and processes that affect their lives. Development is thus about the level and quality of empowerment and participation of people (Schuftan, 1996). Development so defined is not the purview of neoclassical economists. In the context of Ostional, the 'development' component of sustainable development can be described as a process of fulfilling human needs, increasing social equity, increasing organizational effectiveness, and building capacity toward sustainability, which are all apparent in the ADIO framework.

Furthermore, the integration of local people's knowledge and practices is crucial for conservation and a sustainable environment (Cash et al., 2003). Ostional is a proof for the importance and benefits of local participation in conservation efforts presenting us with a scientific approach to conservation that is ecologically sound and economically beneficial. Additionally, the conservation of biodiversity in Ostional goes hand in hand with wider social and economic benefits, creating a win-win situation of sustainable use and management of the rare marine turtle resource.

\subsection{ADIO and tourism}

In Ostional tourism has been a major agent of transformation, shaping the community into a resource industry, with restaurants, shops, cabins, tourist guide initiatives and volunteer placement opportunities. Particularly ecotourism plays a significant role in Ostional, tapping into the high degree of natural value the area provides. Nevertheless, ecotourism in Ostional seems at low impact and follows the trend identified in the literature that ecotourism usually strives to be at low scale (Honey, 1999). In Ostional, tourists attracted by the arribada phenomenon provide funds for conservation and delivers direct benefits to the economic development of the community, while also encouraging respect for different cultures and forming beneficial connections across borders. The example of Ostional also supports the idea of limitations related to ecotourism outlined by Agrawal \& Gibson (1999), that local economic development is limited by factors such as small areas, and few people benefit due to limited earnings. Hence the ecotourism initiatives in Ostional provide only a small improvement to local livelihoods and dependence on income from the egg harvest and other 
economic opportunities persist. Nevertheless, ecotourism in Ostional has the potential to link conservation efforts with the well-being of the community, with benefits such as income and capacity building.

Similarly, volunteer tourism is said to be a beneficial tool for development with the potential to alleviate material poverty of some host-people, and can create reciprocal exchange of knowledge from the encounter (Zapata et al., 2011). Comments from many participants during my fieldwork made me question how reciprocal the exchange really is. Often participants emphasised the learning process of volunteers who come to the families with poor language skills and do not know much about the Costa Rican culture. I was left with the impression that host families could not quite pinpoint what they had learned from the volunteers that were staying with them. Although most agreed on reciprocal learning about different cultures. This might be because volunteers coming to Ostional are usually relatively young. Nevertheless, I heard of some volunteers who took the initiative and started e.g. a local (female) soccer team and who organised small gatherings to help students out with their English (including myself).

\subsection{ADIO and challenges around land ownership}

This section discusses ADIO and Ostional in the context of community sovereignity, conflict over land and struggle with the government. The resolution of intra- and extra community conflicts is crucial in the pursuit of social sustainability (Vallance et al., 2011). In the case of Ostional it is crucial for the community the survival of ADIO and

Some internal conflicts exist within the community of Ostional. These tensions are mainly between the people who are members of the Association and community members who cannot be members because they are not Ostional-born or decide not to participate for other reasons. A report from the Costa Rican channel UCR explains that, the regulations of ADIO seem to be very rigid. Because of this many people have been expelled from the Project. This has generated resentment and violence in the community, to the point of retaliation against the former director of the association ("EraVerde," 2009a). I was also told that membership in ADIO affects the behaviour of some people in the community. Particularly 'non-members' might not comply with the conservation regulations of ADIO and the Refuge, leading to illegal extraction of eggs. 
On the other hand, unequal power relationships and miscommunication between the government and the community has led to extra-community conflict in the past. Findings have shown that the separation of tourist guides into ADIO and MINAE-run tourism initiatives has created tensions on an intra-community level as well as putting pressure on the relationship between ADIO and MINAE as described in chapter V.

It should be clarified that the Project of Sustainable Use, Conservation and Management, and therefore ADIO, are embedded in the National Wildlife Refuge Ostional. The refuge was declared as such in 1983 when the ADIO Project had not started until 1987.

Thus, the egg harvesting Project began a few years after Ostional was declared a protected area. However, the village of Ostional has been established for more than a century. When the Refuge had created it was not taken into account that the people of Ostional who were living in the village were not reassured of their legal stay in the area of the Refuge. Neither was there a management plan to clearly define which activities could be performed in the area and which could not ("EraVerde," 2009b).

I was told that one of the problems resulting from the Refuge is that the Ostional people fear for being evicted. In theory, they are not supposed to live within the Refuge. Some community members also claim that, when MINAE first came to Ostional, their attitude was very confrontational and arrogant. Tomas Chavarria, a Project founder of ADIO explains:

When MINAE began to enforce the Refuge, they came pressuring the people, demonstrating their power as an institution of the state, saying that they are the only ones that have the right to preserve nature, but they are wrong ("EraVerde," 2009a)

Within MINAE there is recognition of these conflicts and that the MINAE's attitude toward the community had to change. Jose Pablo Baltodano a MINAE official acknowledges:

"Historically there have been conflicts between MINAE and the communities by creating refuges. The Refuge of Ostional was created and when the people realized that the Refuge comes with a lot of limitations this obviously created a conflict environment. This environment worsened at times because of the guidelines MINAE had to follow. However, MINAE has changed their policies recently, partly because it has been proven, over more than 20 years that people 
who live here do not affect the use of turtles. What is needed is a legal tool that allows individuals or communities to stay where they are, with obviously some limitations in place because people are inside a protected wildlife area. ("EraVerde," 2009a)

The search for greater consensus from MINAE is reflected in the creation of the interinstitutional commission called SIMACO, which involves MINAE, INCOPESCA and residents of nearby communities.

Jose Pablo Baltodano explains on SIMACO:

\begin{abstract}
"SIMACO is a commission where communities are integrated, to create awareness of what is being done with the Refuge, what the processes involved are, and to give advice. The idea is that the admin or MINAE does not take decisions alone as has happened in the past, but to have some kind of consensus to make those decisions, and to have a positive atmosphere between communities" ("EraVerde," 2009a)
\end{abstract}

However although it is assumed that everyone can participate in the Project, many people complain that they feel excluded. This is partly because of the very technical language that is being used which makes it difficult to take part in the discussions. Besides, MINAE manages the agenda of what is being discussed.

The community of Ostional has been living a situation of division at the community level. This division is directly related to the way that institutions have influenced the community. The community was excluded from the decisionmaking process, and, the regulations did not consider and were not aligned with the community. Therefore, there has to be an approach of the institutions that will be more inclusive with the community and work more in the area of social community living. Also the rules should be discussed in the language of the community and with the community within the community space, and not only with representatives within institutions ("EraVerde," 2009a).

At present, the relationship between ADIO and MINAE seems to have improved but certain grudges on both sides and a disjointed collaboration still persist. Finally the proposed use of 
turtle eggs at Ostional deserves all the recognition of the case to achieve sustainability and harmony between nature and local development. However, not paying attention to the social problems the community is facing could undermine the Project. Thus the inter-governmental organizations should get involved more in the social dynamics of the population to achieve a more balanced and fair participation.

In the interview with ADIO's president Maxima Magdalena Vega Figueroa, an important distinction became clear. It is of great importance for the Ostional people to be a community with a wildlife refuge 'inside' it rather Ostional being part of a wildlife refuge. She stressed that visitors principally come to a community and not to a refuge (Pers.comm., Interview, $1 / 6 / 2013)$. This is important because the community is older than the Refuge, and it is crucial that, community identity and the historical roots are not being lost or misunderstood.

Nevertheless, the establishment of the Wildlife Refuge has resulted in limitations of development efforts for Ostional due to infrastructure regulations. In 2009, the government ordered the creation of a management plan for Ostional. It ordered MINAE to evict all the people and businesses who came to Ostional after the Refuge was put into place, unless they are dedicated to conservation, capacity building, research or ecotourism. Therefore, tourism businesses within the Refuge do not have to leave, but the new generations of Ostional residents who created their housing within the Refuge boundaries have to move.

Much after my fieldwork I was in phone contact with a member of the community and was told:

The other day the government wanted to move the village again, because of the Refuge. Now, people of Ostional want to go protesting again in San Jose. They want to fight so that the people can live in harmony with nature and without having to worry to move. It seems that the government has some benefit of the coastal area of the country because they do not want the law to pass. Now our hopes lie with the election of a new government that will help to pass the coastal law (Pers.comm. 22/2/2014).

The members of Ostional assure that behind the eviction, there is an interest to grant the land to tourism-mega structure projects, because although, they cannot provide permission of use for those territories, the area of conservation tempisque (ACT) has actually provided permission. Laura Brenes, an administrator of the Refuge explains: 
They say that they are worried that we might bring mega-tourism structures to the area. You cannot create a mega project because the management plan that comes with the Refuge includes certain characteristics for buildings.("EraVerde," 2009b)

An example is the Hotel Playa Nosara which is foreign-owned, lies within the refuge in the Maritime Terrestrial Zone and has use permits. María Brenes complains:

They don't give us permission, there is no lights no water, everything is forbidden, but the foreigners get it all. They argue that they are not within 900 meters of the beach or that they have the right to use the land but if we ask for permission for the land use they don't give it to us. Because we are ticos, we are nationals ("EraVerde," 2009b).

Resulting from this conflict, the people of Ostional require a new law to grant them the rights over their land. Thus, initiated by the people of Ostional, and together with 60 other coastal communities the draft for Coastal Communities Territories Law (TECOCOS) has been introduced.

Figure 6.1: Ostional present in the fight for TECOCOS

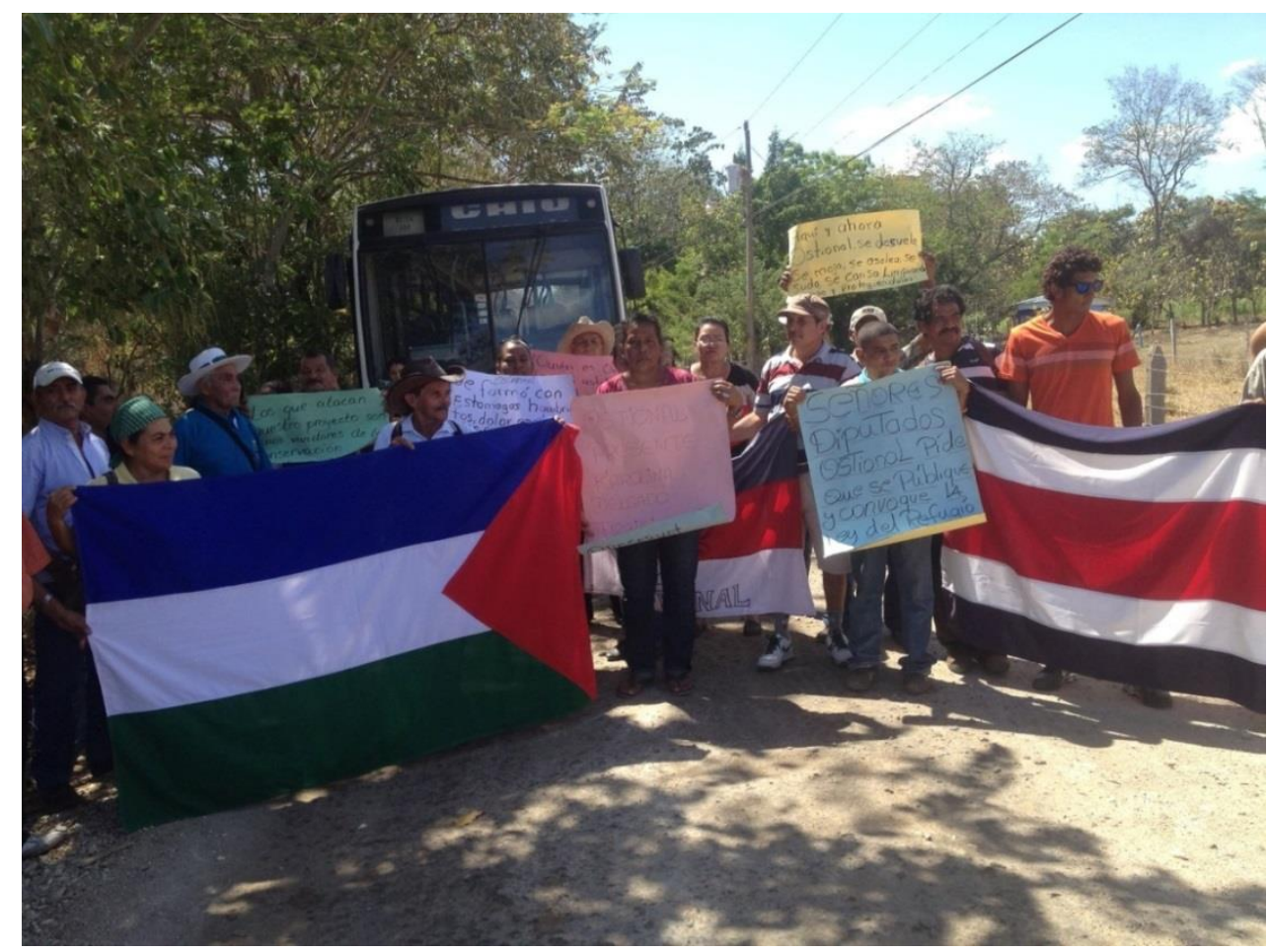

Source: (Avilés, 2014) 
As initiators of TECOCOS, people from Ostional and ADIO, have provided a model of private land ownership that holds benefits for community conservation and coastal community development in the whole of Costa Rica. If passed, the law would secure the Ostional community legally, so that people cannot be forced to move from the Refuge, sell their land or have to make space for tourism mega structures. The law would set a new, higher legal status for the community of Ostional and is said to be an important step to solve existing conflicts between the community and the government.

\subsection{Conclusion}

Overall, this chapter has demonstrated how the research findings connect with the literature on sustainability, conservation, tourism and community participation. Lessons learned from Ostional concern the importance of participation in sustainable development, conservation and tourism, and areas of social tensions from protection efforts, land ownership, restrictive resource use and community resistance and power over resources. Often, protected areas have been created without prior consultation with the local people, as in the case of Ostional, leading to tensions between stakeholders. Furthermore, increased levels of private land ownership have led to people selling their land and encroach on protected areas (Agrawal \& Gibson, 1999). As in the case of Ostional, unequal restrictions in refuges work against local people as long as foreign investments and tourism infrastructure persists.

Therefore, the legal framework of ADIO has been a crucial step for the community to gain power and control over their resources. The TECOCOS law project has emerged out of communities that fight for equal power relationships in order to be the stewards of their territories. Projects such as ADIO concentrate communities' efforts in the pursuit of local sustainable development and bring about a sense of ownership within natural resource management. Local people are empowered to make decisions and to take action to secure their future. Ideally, such an approach, integrated under a national planning structure, promotes a controlled but flexible approach to sea turtle management. This is crucial to longterm viability of the Project as it does not simply absorb local knowledge, but allows the community to take action and be responsible for their own future. 


\title{
CHAPTER VII
}

\author{
CONCLUSIONS
}

In this chapter, I first summarise the aims and findings of this thesis along with its contribution to the field of development studies. I then reflect upon my research by drawing upon my personal insights and learning regarding this field of work, and addressing the limitations of my study. Lastly I will identify areas of gaps for future research.

\subsection{Summary of my findings}

The goal of this thesis was to present a case study of sustainable community-run development by using a mixed range of methods to gain nuanced insight about the Project. By analysing community perspectives from questionnaires about benefits and impairments of the Project and participants' ideas for improvement, this thesis aims to reveal a local community assessment of the situation.

At the beginning, the objectives of my research were to:

1. Understand some community members' experiences of being involved in, or affected by, ADIO in Ostional, Costa Rica.

2. Explain aspects of ADIO that work well and are perceived as beneficial for community members, and unpack aspects of ADIO that do not work well for community members and could be improved.

3. Identify key elements for the success of ADIO

4. Contribute to current literature around sustainability, community-run conservation and development.

After completing my research, my responses to these objectives are the following:

1. ADIO has managed to organise and improve a chaotic situation of illegal extraction of turtle eggs and subsequent conflict in the village. The Association has shown to be crucial for the livelihoods of men and women from Ostional. The legal framework of 
the association creates a feeling of security and confidence that peoples' future livelihoods and living space will be safe. The community has also been benefitted from the Association's development efforts which including infrastructure, educational programmes, and income opportunities for the community.

2. The areas of economic and communal benefits, infrastructure as well as conservation were perceived as most beneficial, by community members who participated in my research. In economic terms, some of the biggest perceived strength are the financial help for the elder, students, mothers and people with for example chronic diseases, making the small-scale social welfare system aspect of the Project a major achievement of ADIO. This facet of the Project grants the community a certain independence from the help of the state, as the community has managed to 'help itself'.

Related to tourism, the Association and turtle arrivals attract visitors, volunteers and scientists from around the world, which bring about benefits and new experiences to the village. This interest of visitors in the Association and turtles is connected with a feeling of pride for many Ostional community members. A distinctive aspect of the Project is the participation of most community members in a united cause, which is the conservation of Lora sea turtle. As the literature on participation has revealed, this level of community participation also creates scope for other projects and missions such as the initiation of the TECOCOS law project has exemplified.

However, there were also perceived issues on almost all levels of ADIO, but mainly on the reinforcement of regulations regarding the illegal extraction of eggs, administration of money, commercialisation of eggs and the general management of the Association. For instance, there was pressure to engage and motivate members with the Project, there was some mentioned inequity in distribution of profits, and there was a constant reappearance of the issue around intra and extra community conflict. Furthermore, a major issue, which seems to have been present since the discovery of the turtle population, is the illegal extraction of eggs. According to participants, administration of money and transparency of funds by the Junta needs to be improved. The commercialisation of turtle eggs and egg products in domestic markets and a widening of the market for these products have been perceived as a 
promising area of expansion, reflecting the aspiration of members to enhance their livelihoods economically and to create more job opportunities along way. Another issue is the perceived 'personal agenda' of the board of directors and how their own perspectives might dominate the way of issues being approached. A number of participants mentioned that they would simply like to see a Junta that works for the people rather than for their personal benefit. This issue is interwoven with the wish for better communication and transparency which, if increased, might have a very beneficial impact on the relationship between Junta and community.

Improvement in mentioned areas will lead to generally greater management, as wished for by numerous contributors. Further areas of improvement to consider are the scope for community participation. Increasing differentiation and aspirations within communities is making it more difficult for all-inclusive participation. This is due to a decline in traditional value, especially among young people and a greater engagement with the outside world, especially through the pull-and-push factors of rural-urban migration. Nevertheless, these identified problems with the Project were overpowered by the overall and overwhelming support for it.

3. The handling of identified issues and the factors that determine ADIO's success in the future can be summarised as follows:

- The key issues regarding strengths, weaknesses, opportunities, threats and how their might balance or exceed each other.

- The community's ability to voice their opinions and communicate with the Junta, fellow residents and external stakeholders.

- The overall attitude and levels of motivation of the local participants. The ability to building capacity, adapt and innovate.

- Their capacity to work together and mobilise social capital in order to achieve common goals including capacity building of young community members for leadership

- The ability of ADIO to reflect on the general situation and local perceptions for improvement on the organisation and administration level of the Association. 
- The ability to work with the government and within the political structure, to create a beneficial relationship between the community and national authorities.

4. Some key elements for the success of ADIO identified in relation to the themes discussed in the literature are:

In terms of conservation and sustainability:

- The Project contributes to environmental conservation through conservational activities organised by the community and volunteers. Community members undertake and re-invest into conservation activities. Thus, there is a direct link between profits from the egg harvest, tourism and conservation of the turtle species'

- Members respect and are proud of conservation activities, use them as survival strategy and link them to the long-term survival of the village and the sea turtle populations.

- The Project's legal framework requires continuous scientific monitoring and evaluation of the turtle populations and harvest impacts, and allows for interruption if evidence suggests that the harvest is damaging the turtle populations.

In terms of the power, control over resources and the legal framework:

- Unequal power relations for issues of sustainability are ultimately intersects with environment and economics

- The legal framework for ADIO and the Project has been created out of the initiative of the local community, through participation and for the benefit of both the turtle populations and the community.

- The legal framework for the egg harvest by ADIO increases and protects environmental, economic and social benefits of the Project.

- The legal framework ADIO that was granted was crucial to the community's sense of confidence regarding the Project and the security of peoples livelihoods through the steady income opportunity the Project presented. 
- The legal framework of ADIO increases the legitimate status and sense of security of the whole community.

- The legal framework considers the standpoint of the parties who live amongst turtle populations, as well as the impacts on turtle populations at the regional level, and the methods used to take the turtle resource to meet local needs.

- The legal framework of ADIO has been a crucial step for the community to gain power and control over their resources.

On a participation level:

- Findings reinforce the literature on community participation and community-run initiatives being beneficial for sustainability and conservation if organised well on an intra-community as well as an extra-community level.

- Sustainable development and community participation can go hand in hand, and actions at the local level need to be consistently nurtured by their host communities in order to be environmentally and socially sustainable

- Economic benefits, to be gained through appropriate community-run local participation in sustainable conservation projects holds the potential to further enhance local community's desire to be better stewards of resources. Community participation in the case of Ostional is crucial for the continuation of the sea turtle programme, as the Project is mainly community-run, and people's concern about their own 'backyard' drives their efforts.

- Tourism development and community participation are interlinked. Conflict resolution and informed community participation of all stakeholders in Ostional is an essential step to ensure tourism development is sustainable.

- High levels of community participation are usually interlinked with good leadership and progress that benefits the whole community.

- Participation gives people the feeling that they 'belong' to a project, thereby allowing people to develop a sense of ownership which can promote social sustainability and sustainable development.

- Participation motivates people to accept responsibility for their own development, thus promoting self-reliance which also leads to capacity building and empowerment, especially at an organizational level.

- Income and the economic activities at the local level are a main driver for motivation and participation. 
- Through ADIO, the community has gained increased pride and a sense of recognition, mainly through the process of local empowerment, and via public interest in the Project, and by fostering Project participation

In conclusion, I have found that the National Wildlife Refuge Ostional has good conditions of convergence between the dynamics of the Olive Ridley population and the social conditions of the Ostional community. Findings suggest that ADIO is meeting most of the criteria for sustainable development which we have discussed in prior chapters. Some local perspectives have indicated deficits in this endeavour. However, the majority of participants is highly fond of the Project as a whole, and ranked its utility for the community as very high.

The community of Ostional is at present an example of community-driven development that is using its local resources in a sustainable way. However, a range of special circumstances in the history of Ostional has led to the foundation of this unique Project of conservation, management and use of the sea turtle resource. The overall legal framework in which the harvest takes place and the organisational framework of the Project together build a good basis for environmental protection, at the same time producing economic and social benefits for the local community.

Overall, the Project of Sustainable Use, Conservation and Management of the Olive Ridley sea turtle eggs has helped not only economically develop the community of Ostional, but also develop it socially. Lastly, it can be argued that research conducted with ADIO and Ostional is a positive and useful example for issues around community-run sustainable development. The success of the Association is being promotional for Costa Rica's high levels in ' human development' biodiversity, and its status of being a 'poster child' for ecotourism and sustainability.

\subsubsection{Final reflections on this research}

Reflecting on my own approach with ADIO, I felt that my contribution to the association and the community was positive. Community members welcomed me and I enjoyed meeting people from the community in return. For my research, it was helpful to have a number of contact persons such as my host-family who have experience with ADIO and a mentor who is 
a member of the Junta. I felt that this affiliation gave me the necessary 'authority' to conduct my research. It was also helpful to assist with Association tasks as a volunteer/intern, in order to participate in and learn about the scientific monitoring and the harvest.

In general, participants felt important to be questioned about their opinions. I hope that my presence and genuine interest in the Project and peoples' perspectives added to their feeling of pride as being part of the Project. I enjoyed learning, researching, and experiencing the full development process. This experience taught me how to collect, analyse and interpret information as a researcher. I really enjoyed talking to men and women in their homes and connecting with people while learn more about their experiences with the Project. Perhaps, it would have been desirable to have more time in the field in order to collect more perspectives from community members. Nevertheless, in the limited time I was also able to make strong friendships and connections in Ostional, which continue to persist after my fieldwork.

In order to understand better how sustainable community development works in practise, it was important for me to visit and study an Association and integrate with the local community to see the pros and the cons of community-run development: what aspects of the Project worked well, what aspects did not, and to identify possible improvements in collaboration with participants. This work enabled me to gain a wider perspective on what is going on within Ostional and Costa Rica, particularly for communities that organise themselves in order to develop sustainably and enhance their livelihoods. Therefore, this research has provided key areas of success, and lessons learned from a context-specific and effective approach to sustainable community-run development.

\subsubsection{Areas for future research}

In terms of possibilities for future research, there could be more studies and experiences from community-run sustainable development projects, to compare and learn from different approaches to sustainable development. Scope for further research in this topic area also indicates the need for investigations, uniting and comparing sustainable community projects on a global, national and local level. 
It would be desirable to continue or to return to the study with ADIO to see changes over time, and see if the Association can stay successful, overcome discussed issues and resolve intra and extra community conflicts. Areas to consider regarding further research with ADIO are: a study of the market which would be helpful to increase the efficiency of the Project for members. Also, in order to further develop the turtle 'product' and attraction it would be helpful to analyse what is needed. Some factors of consideration are how to provide more work opportunities for both men and women from Ostional and other coastal communities who might be in similar situations. Lastly, in light of the issues of community power and control over territories and resources, this study has opened up for further research into processes related to the proposed TECOCOS law and the resistance movement of coastal Costa Rican communities. 


\section{APPENDICES}

1. Letter from the association ADIO, Costa Rica

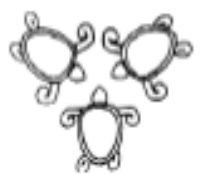

ASOCIACION DE DESARROLLO INTEGRAL DE OSTIONAL, SANTA CRUZ, GUANACASTE, COSTA RICA.

Cédula Jurílica: $300-208-7421$

Telefax: 26820470 - E-mail: adiotor@gmail co.cr - Web: ostionalcr.tripod.com

\section{TO WHOM IT MAY CONCERN}

The Association for Integral Development of Ostional (ADIO, la Asociación de Desarrollo Integral de Ostional) puts on record that Katja Klopfer (Passport GERMAN: C8993KHPP) worked as a volunteer on the project Rational use, Conservation, and Management of the Eggs of the Lora Marine Turtle (Lepidochelys olivacea), developed by the Ostional community through ADIO within the Silvestre National Wildlife Refuge of Ostional. She participated in various activities within the turtle conservation project from 29 April through. June 03,2013 . Katja showed responsibility, punctuality, and enthusiasm in all of the activities in which participated. Our association is pleased that other people from the NEW ZEALAND may come to collaborate with our project.

Katja also took this time to perform in Ostional many interviews with community residents, which will serve to complete his master's thesis.

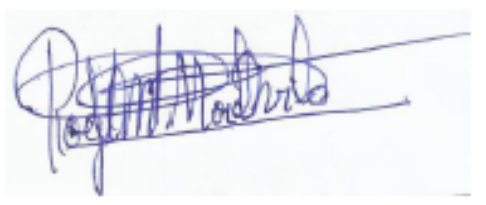

MSc. Rodrigo A. Morera Ávila

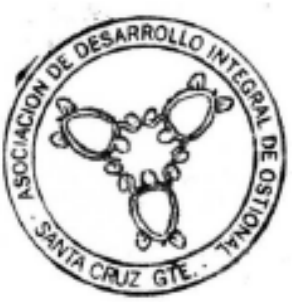

Managing biologist, Racional use,

Conservation And Management of the

Eggs of the Lora Marine Turtle

(Lepidochelys olivacea) project, ADIO.

Archive. 


\section{Human Ethics Committee approval}

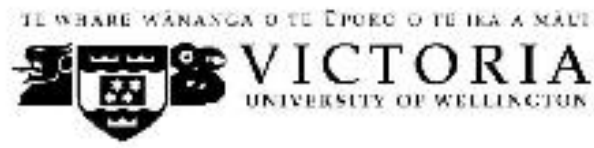

MEMORANDUM

Phone $0-4-4635676$

Fax 0-4-4635209

Email Allison kirkmanêvuw.ac.nz

\begin{tabular}{l|l}
\hline TO & Katja Klopfer \\
\hline COPY TO & $\begin{array}{l}\text { Marcela Palomino-Schalscha } \\
\text { Sara Kindon }\end{array}$ \\
\hline FROM & Dr Allison Kirkman, Convener, Human Ethics Committee \\
\hline DATE & 27 May 2013 \\
\hline PAGES & 1 \\
\hline SUBJECT & $\begin{array}{l}\text { Ethics Approval: 19820 } \\
\text { Local community perspectives from a Green Life Volunteers } \\
\text { project in Ostional, Guanacaste, Costa Rica }\end{array}$ \\
\hline
\end{tabular}

Thank you for your application for ethical approval, which has now been considered by the Standing Committee of the Human Ethics Committee.

Your application has been approved from the above date and this approval continues until 28 February 2014. If your data collection is not completed by this date you should apply to the Human Ethics Committee for an extension to this approval.

Best wishes with the research.

Allison Kirkman

Human Ethics Committee 


\section{Participant Information Sheet: Interviews with Project Managers}

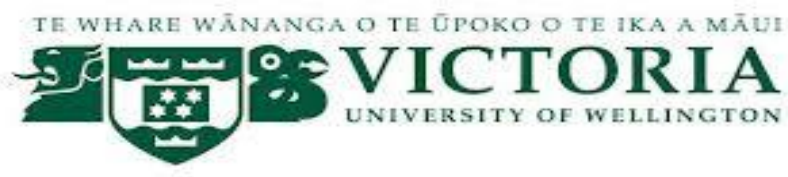

Participant Information Sheet

Interviews with Project Managers

\section{Local community perspectives from the ADIO project in Ostional, Guanacaste, Costa Rica.}

Researcher: Katja Klopfer: School of Geography, Environment and Earth Sciences, Victoria University of Wellington.

I am a student in Development Studies at Victoria University of Wellington, in New Zealand. As part of my Master's degree I am undertaking a research project leading to a published thesis. The project I am exploring focuses on experiences of being involved in, or affected by, sustainable community-run development.

As well as being academic research, I hope that this study will be of use to ADIO, community members, and people involved in volunteer tourism, and contribute to a better understanding of the perceptions and positions of the local community in the project. I hope to use this work to inform Costa Rican community organisations, NGOs, development practitioners and academics about local views of community-run development.

This research has been approved by the Human Ethics Committee of Victoria University of Wellington.

I am inviting community members from Ostional and ADIO staff to participate in this study. I will talk to and work with participants over the course of 6 weeks (May 2013 to June 2013) in Ostional.

I expect to conduct some interviews, a questionnaire survey, a reflexive workshop, and observe and take notes while working with the community as a volunteer/intern. Information obtained from interviews in Spanish, conversations, and general observation will be translated into notes which I will use for my subsequent analysis. I would like to interview you once, between one and two hours, at an appropriate place to be decided with participants. 
If you agree, interviews will be audio recorded in order to transcribe and translate information correctly. Otherwise I will take written notes during the interview.

Responses collected will be the basis of my research project and will be put into a thesis on confidential basis. This means that no individual names will be used in my published work, unless agreed on otherwise. All material collected will be kept confidential to me and my supervisors Marcela Palomino-Schalscha and Sara Kindon for further research if needed and for a period of two years. Afterwards, all material collected will be destroyed. No other person besides my supervisors and me will see my research material. The thesis will be submitted for marking to the school of Geography, Environment and Earth Sciences, deposited in the University Library, might be published or presented in conferences.

Should any participants feel the need to withdraw from the project, they may do so without question at any time, up until the end of data analysis in August 2013.

If you have any questions or would like to receive further information about the project, please contact me at Klopfekatj@myvuw.ac.nz or at the project office under (506) 26820400, or contact my supervisors, Sara Kindon at Sara.kindon@vuw.ac.nz and Marcela Palomino-Schalscha at Marcela.palomino-schalscha@vuw.ac.nz at the School of Geography, Environment and Earth Sciences at Victoria University, Wellington, New Zealand.

\section{Katja Klopfer}

Signed: 


\title{
4. Participant Information Sheet: Reflexive Workshop
}

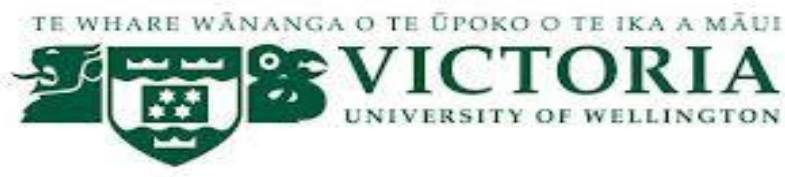

Participant Information Sheet

\author{
Reflexive Workshop
}

\section{Local community perspectives from the ADIO project in Ostional, Guanacaste, Costa Rica.}

Researcher: Katja Klopfer: School of Geography, Environment and Earth Sciences, Victoria University of Wellington.

I am a student in Development Studies at Victoria University of Wellington, in New Zealand. As part of my Master's degree I am undertaking a research project leading to a published thesis. The project I am exploring focuses on experiences of being involved in, or affected by, sustainable community-run development.

As well as being academic research, I hope that this study will be of use to ADIO, community members, and people involved in volunteer tourism, and contribute to a better understanding of the perceptions and positions of the local community in the project. I hope to use this work to inform Costa Rican community organisations, NGOs, development practitioners and academics about local views of community-run development.

This research has been approved by the Human Ethics Committee of Victoria University of Wellington.

I am inviting men and women of the Ostional community to participate in this study. I will talk to and work with participants over the course of 6 weeks (May 2013 to June 2013) in Ostional.

While I expect to conduct some interviews, a questionnaire survey and a reflexive workshop, the majority of my observations and notes will be made as working with the community as a volunteer/intern. Information obtained from the reflexive workshop, conversations and general observation will be translated into notes which I will use to identify community 
members' perceptions of volunteer tourism. I am planning to host one reflexive workshop, for one to two hours. I aim to record the workshop and take some photos of participatory activities, in order to transcribe and translate information correctly.

I hope that the community members, ADIO staff and volunteers, will actively participate in this research.

Information collected will be the basis of my research project and will be put into a thesis on a confidential basis. This means that no individual names will be used in my published work, unless agreed on otherwise. I also want to ask participants of the workshop to keep other participants responses and personal information confidential. All material collected will be kept confidential to me and my supervisors Marcela Palomino-Schalscha and Sara Kindon for further research if needed and for a period of two years. Afterwards, all material collected will be destroyed. No other person besides my supervisors and me will see my research material. The thesis will be submitted for marking to the school of Geography, Environment and Earth Sciences and deposited in the University Library.

If you have any questions or would like to receive further information about the project, please contact me at Klopfekatj@ myvuw.ac.nz or at the project office under (506) 26820400, or contact my supervisors, Sara Kindon at Sara.kindon@vuw.ac.nz and Marcela Palomino-Schalscha at Marcela.palomino-schalscha@vuw.ac.nz at the School of Geography, Environment and Earth Sciences at Victoria University, Wellington, New Zealand.

Katja Klopfer

Signed: 


\section{Consent Form: Interviews with Project Managers}

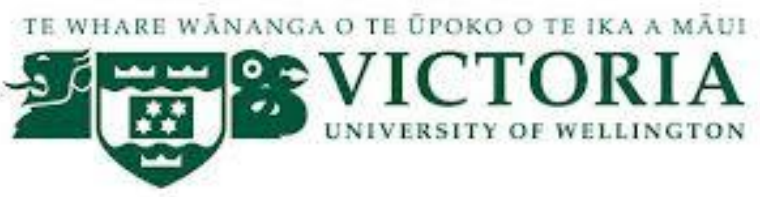

\section{Consent Form}

\section{Interviews with Project Managers}

Consent to participation in research

Title of the project: Local community perspectives from the ADIO project in Ostional, Guanacaste, Costa Rica.

I have been given and have understood an explanation of this research project. I have had an opportunity to ask questions of the researcher and have them answered to my satisfaction. I understand that I might withdraw myself (and/or any information I have provided) from this project without having to give reasons before August 2013. I consent to information or opinions which I have given, being attributed to me in any reports of this research.

I understand that the data I provide will not be used for any other purpose or released to others without my consent.

I would like to receive a summary of the results of this research when it is completed.

\section{Tick here}

I understand that the interview will last for 1-2 hours in a location of my choice. I understand that the participation in this interview is voluntary, that I can refuse to answer any questions without having to give reasons and that I can request the recorder be turned off at any point.

I agree to take part in this research.

Signed:

Date: 


\section{Consent Form: Reflexive Workshop}

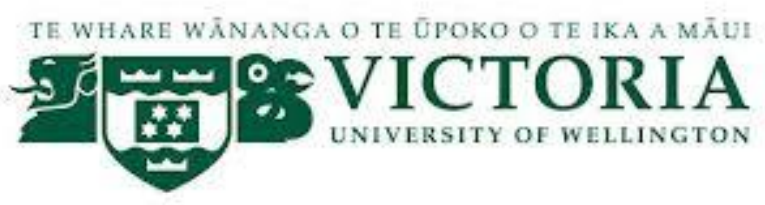

Consent Form

Reflexive Workshop

Consent to participation in research

Title of the project: Local community perspectives from the ADIO project in Ostional, Guanacaste, Costa Rica.

I have been given and have understood an explanation of this research project. I have had an opportunity to ask questions of the researcher and have them answered to my satisfaction. I understand that I might withdraw myself (and/or any information I have provided) from this project without having to give reasons before August 2013. I consent to information or opinions which I have given being attributed to me in any reports of this research.

I understand that the data I provide will not be used for any other purpose or released to others without my consent.

I agree to keep participants' responses and personal information, mentioned in this workshop, confidential.

I would like to receive a summary of the results of this research when it is completed.

$\square$ Tick here

I understand that the participation in this workshop is voluntary.

I agree to take part in this research.

Signed:

Date: 


\section{Anonymous Questionnaire Survey: Ostional Community Members}

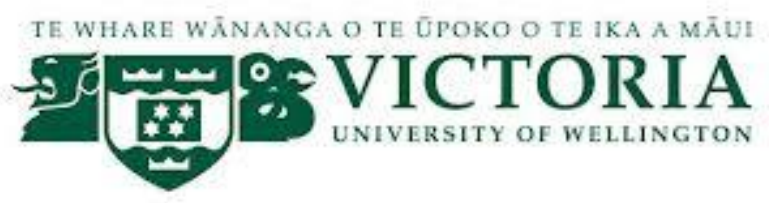

\section{Anonymous Questionnaire Survey}

\section{Ostional Community Members}

Information about this research:

I am a student in Development Studies at Victoria University of Wellington, in New Zealand. As part of my Master's degree I am undertaking a research project leading to a published thesis. The project I am exploring focuses on experiences of being involved in, or affected by, sustainable community-run development. I am interested in community members' experiences and perspectives linked to ADIO.

Contact Information:

Katja Klopfer

$$
29 \text { Devon St. }
$$

Aro Valley, Wellington

New Zealand
Email: Klopfekatj@ myvuw.ac.nz

Phone: 00642102629482

By taking part in this anonymous questionnaire you are agreeing to take part in this research. Information may also be used to inform other publications and feedback to ADIO staff. This research has been approved by the Human Ethics Committee of Victoria University of Wellington. If you have any questions or would like to receive further information about the project, please contact me or my supervisors, Sara Kindon at Sara.kindon@vuw.ac.nz, and Marcela Palomino-Schalscha at Marcela.palomino-schalscha@vuw.ac.nz at the School of Geography, Environment and Earth Sciences at Victoria University, Wellington, New Zealand. 


\section{Questionnaire Survey:}

Please read each question carefully and take your time to answer.

Where required, answer simply by putting a tick $\checkmark$ in the box next to the answer you want to give.

Age: ......

Sex:

\section{Male}

Female

Education (highest qualification):

Occupation

What is your relationship to volunteers?

Host family

Work together

Social

none

Other (please specify):

Are you a member of ADIO? Yes/No

If you have no connection to the ADIO project, what are your motivations for this?

What do you think are the three main aspects of ADIO that are beneficial and work well for community members?

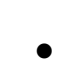

What do you think are the three main aspects of ADIO that don't work well for local community members and could be improved? 
How could ADIO be improved?

If you are involved in ADIO, what are your main motivations or reasons to participate?

Do you think there is an exchange of knowledge between community members and volunteers? Yes/No

What kinds of local knowledge do you commonly share with volunteers?

What things have you learned from volunteers?

On a scale from 1-5, how useful would you rank the ADIO project for the local community?

$\begin{array}{lllll}1 & 2 & 3 & 4 & 5\end{array}$




\section{Interview Guide}

Interview Questions

Semi-structured interview themes:

- History and vision of the project, and interviewee's role

- Situation of the community before the foundation of the association

- Organisational framework of ADIO: Income and distribution, commercialisation, tourism, volunteers, memberships

- Sustainability of the resource 'turtle egg'

- Relationship to other involved organisations

- Board of directors and their election

- Legal vs. illegal extraction

- Positive impacts on ADIO members and problems (hierarchical)

- Best and worst case future scenario

- Personal vision to improve the project

- Situation of ADIO in a national/international context

- What makes ADIO a unique project?

- The costal territories law and changes for the village and association

Guideline Questions:

What is your connection to or involvement in ADIO?

Could you tell me about the history of ADIO its foundation and vision from the beginning?

What was the situation of the community, before the foundation of ADIO?

Who can be member of ADIO?

What are the different groups of ADIO and what is their role?

How does ADIO create income?

- Sale of Eggs

- Volunteer tourism

- Visitors

- Donations 
How is income distributed?

- Wages

- Pensions

- Maternity support

- Community development, infrastructure

- Scholarships

How does ADIO ensure the sustainability of the resource 'turtle egg'?

What are other organisations that are active in Ostional and what is their connection?

- MINAET

- University of Costa Rica

Who is legally responsible for the supervision of the extraction of turtle eggs?

What are some major issues ADIO faces?

What are the most important problems to be solved?

How would you like to see ADIO in the future / 10 years? (Best case scenario)

If things don't improve, how could ADIO look like in the future / 10 years? (Worst case scenario)

What is likely to happen?

How could ADIO possibly be improved?

How do people, men and women, earn their money in Ostional?

What could be done to improve local tourism?

How is ADIO volunteer tourism organised and how are volunteers distributed?

Do you feel that foreign/knew knowledge of things/methods can improve the 'traditional' ways?

Where does ADIO stand on a national level?

What makes ADIO unique or special in comparison with other similar organisations?

Where does ADIO stand on an international level?

Could you tell me about the TECOCOS law project and its relevance for Ostional? 


\section{REFERENCES}

Adams, W. M., Aveling, R., Brockington, D., Dickson, B., Elliott, J., Hutton, J., . . Wolmer, W. (2004). Biodiversity conservation and the eradication of poverty. Science, 306(5699), 1146-1149.

ADIO, UCR, INCOPESCA, SINAC, SNG, \& SENASA. (2012). Plan quintenal... Costa Rica.

Agrawal, A., \& Gibson, C. C. (1999). Enchantment and disenchantment: the role of community in natural resource conservation. World development, 27(4), 629-649.

Agyeman, J., \& Evans, T. (2003). Toward just sustainability in urban communities: building equity rights with sustainable solutions. The ANNALS of the American Academy of Political and Social Science, 590(1), 35-53.

Alsop, R., \& Kurey, B. (2005). Local organizations in decentralized development: their functions and performance in India: World Bank Publications.

Andereck, K. L., Valentine, K. M., Knopf, R. C., \& Vogt, C. A. (2005). Residents' perceptions of community tourism impacts. Annals of Tourism Research, 32(4), 1056-1076. doi: 10.1016/j.annals.2005.03.001

Bailey, R. C., \& Headland, T. N. (1991). The tropical rain forest: Is it a productive environment for human foragers? Human Ecology, 19(2), 261-285.

Ball, L. J., \& Ormerod, T. C. (2000). Putting ethnography to work: the case for a cognitive ethnography of design. International Journal of Human-Computer Studies, 53(1), 147-168.

Barbieri, C., Santos, C. A., \& Katsube, Y. (2011). Volunteer tourism: On-the-ground observations from Rwanda. Tourism Management, 33(3), 509. doi: 10.1016/j.tourman.2011.05.009

Barbieri, C., Santos, C. A., \& Katsube, Y. (2012). Volunteer tourism: On-the-ground observations from Rwanda. Tourism Management, 33(3), 509-516.

Barrantes-Reynolds, M. P. (2011). The expansion of "real estate tourism" in coastal areas: Its behaviour and implications. Recreation and Society in Africa, Asia and Latin America, 2(1).

Belisle, F. J., \& Hoy, D. R. (1980). The perceived impact of tourism by residents a case study in Santa Marta, Colombia. Annals of Tourism Research, 7(1), 83-101. doi: 10.1016/s01607383(80)80008-9

Berkes, F. (1989). Common property resources: ecology and community-based sustainable development: Belhaven Press.

Berkes, F. (1999). Sacred ecology: traditional ecological knowledge and resource management: Taylor \& Francis.

Berkes, F., Feeny, D., McCay, B. J., \& Acheson, J. M. (1989). The benefits of the commons. Nature, 340(6229), 91-93.

Blaikie, P., Brown, K., Stocking, M., Tang, L., Dixon, P., \& Sillitoe, P. (1997). Knowledge in action: local knowledge as a development resource and barriers to its incorporation in natural resource research and development. Agricultural systems, 55(2), 217-237.

Blaikie, P., \& Jeanrenaud, S. (1997). Biodiversity and human welfare. Social change and conservation. Environmental politics and impacts of national parks and protected areas, 46-70.

Botes, L., \& Van Rensburg, D. (2000). Community participation in development: nine plagues and twelve commandments. Community Development Journal, 35(1), 41-58.

Braun, V., \& Clarke, V. (2006). Using thematic analysis in psychology. Qualitative Research in Psychology, 3(2), 77-101. doi: 10.1191/1478088706qp063oa

Brookfield, H., \& Padoch, C. (1994). Appreciating agrodiversity: a look at the dynamism and diversity of indigenous farming practices. Environment: Science and Policy for Sustainable Development, 36(5), 6-45.

Brown, F., \& Hall, D. (2008). Tourism and Development in the Global South: the issues. Third World Quarterly, 29(5), 839-849.

Brugmann, J. (1996). Planning for sustainability at the local government level. Environmental Impact Assessment Review, 16(4), 363-379. 
Buchsbaum, B. D. (2004). Ecotourism and sustainable development in Costa Rica.

Burkey, S. (1993). People first: a guide to self-reliant participatory rural development: Zed Books Ltd.

Cahill, M., \& Fitzpatrick, T. (2001). Editorial Introduction. Social Policy \& Administration, 35(5), 469471.

Cameron, J. (2000). Focussing on the focus group. Qualitative Research Methods in Human.

Campbell. (1998). Use them or lose them? Conservation and the consumptive use of marine turtle eggs at Ostional, Costa Rica. Environmental Conservation, 25(4), 305-319.

Campbell. (2002). Conservation Narratives in Costa Rica: Conflict and Co-existence. Development and Change, 33(1), 29-56. doi: 10.1111/1467-7660.00239

Campbell, Haalboom, \& Trow. (2007). Sustainability of community-based conservation: sea turtle egg harvesting in Ostional (Costa Rica) ten years later. Environmental Conservation, 34(2), 122-131. doi: 10.1017/S0376892907003840

Cash, D. W., Clark, W. C., Alcock, F., Dickson, N. M., Eckley, N., Guston, D. H., . . Mitchell, R. B. (2003). Knowledge Systems for Sustainable Development. Proceedings of the National Academy of Sciences of the United States of America, 100(14), 8086-8091. doi: 10.1073/pnas.1231332100

Chambers. (1997). Whose reality counts?: putting the first last: Intermediate Technology Publications Ltd (ITP).

Chambers, R. (1997). Whose reality counts?: putting the first last: Intermediate Technology Publications Ltd (ITP).

Chambers, R. E., \& McBeth, M. K. (1992). Community encouragement: Returning to the basis for community development. Community Development, 23(1), 20-38.

Chapman, D., Barcikowski, E., Sowah, M., Gyamera, E., \& Woode, G. (2002). Do communities know best?: Testing a premise of educational decentralization: community members' perceptions of their local schools in Ghana. International Journal of Educational Development, 22(2), 181189.

Charmaz, K. (2003). Grounded theory. Strategies of qualitative inquiry, 2, 249.

Chaves, G. (2007). Tendencia poblacional y éxito de eclosión de las anidaciones masivas de tortugas lora (Lepidochelys olivacea Eschscholtz 1829) en el Refugio Nacional de Vida Silvestre de Ostional, Guanacaste. Tesis en grado de Magister Scientae, Universidad de Costa Rica, San Pedro de Montes de Oca.

Chinsinga, B. (2003). The participatory development approach under a microscope: the case of the poverty alleviation programme in Malawi.

Chinsinga, B. (2005). The Clash of Voices: Community-based Targeting of Safety-net Interventions in Malawi. Social Policy \& Administration, 39(3), 284-301.

Chitere, O. (1994). Community development: its conceptions and practice with emphasis on Africa: Gideon S. Were Press.

Clark, M. A. (1995). Nontraditional export promotion in Costa Rica: Sustaining export-led growth. Journal of Interamerican Studies and World Affairs, 37(2), 181-223.

Cleaver, F., Cooke, B., \& Kothari, U. (2001). Institutions, agency and the limitations of participatory approaches to development. Participation: the new tyranny?, 36-55.

Cloete, F. (2006). Happy Kayuni1.

Coleman, J. S. (1988). Social capital in the creation of human capital. American journal of sociology, S95-S120.

Cope, M. (2005). Coding qualitative data. Qualitative research methods in human geography, 2, 223233.

Costanza, R., \& Daly, H. E. (1992). Natural capital and sustainable development. Conservation biology, 6(1), 37-46.

costaricalink.com, h. Map of Costa Rican provinces. http//: costaricalink.com

Cotterill, P. (1992). Interviewing women: Issues of frienship, vulnerability, and power. Paper presented at the Women's Studies International Forum. 
Coyne, I. T. (1997). Sampling in qualitative research. Purposeful and theoretical sampling; merging or clear boundaries? Journal of advanced nursing, 26(3), 623-630.

Crissman, L. W. (1967). The segmentary structure of urban overseas Chinese communities. Man, 2(2), 185-204.

Dahl, R. A. (1994). A democratic dilemma: system effectiveness versus citizen participation. Political science quarterly, 109(1), 23-34.

Davids, I., Theron, F., \& Maphunye, K. J. (2005). Participatory development in South Africa: A development management perspective: Van Schaik Publishers.

Desai, V., \& Potter, R. B. (2013). The companion to development studies: Routledge.

Devas, N., Rakodi, C., Ghai, D., Vivian, J., Myers, D., May, J., . . . Preston, R. (1992). Planning and managing urban development. INTERNATIONAL MIGRATION REVIEW, 26(3), 41-62.

Dongier, P., Van Domelen, J., Ostrom, E., Ryan, A., Wakeman, W., Bebbington, A., . . Polski, M. (2003). Community driven development. World Bank Poverty Reduction Strategy Paper.

Drakakis-Smith, D. (1996). Third world cities: sustainable urban development II-population, labour and poverty. Urban Studies, 33(4-5), 673-701.

Eden, M. J., \& Parry, J. T. (1996). Land degradation in the tropics: environmental and policy issues: Pinter.

. EraVerde. (2009a), Refucio de Vida Silvestre de Ostional: Canal UCR.

. EraVerde. (2009b), Reportaje - Conflicto en el Refugio de Vida Silvestre de Ostional Canal UCR.

Evans, M. (213, 6/11/2013). Ostional Removed From TECOCOS Law Project, Guanacaste News.

Falk, I., \& Kilpatrick, S. (2000). What is social capital? A study of interaction in a rural community. Sociologia ruralis, 40(1), 87-110.

Farrell, B. H., \& Twining-Ward, L. (2004). Reconceptualizing tourism. Annals of Tourism Research, 31(2), 274-295.

Fischer, F. (2000). Citizens, experts, and the environment: The politics of local knowledge: Duke University Press.

Flora, J. L., Sharp, J., Flora, C., \& Newlon, B. (1997). Entrepreneurial social infrastructure and locally initiated economic development in the nonmetropolitan United States. The Sociological Quarterly, 38(4), 623-645.

Fowke, R., \& Prasad, D. K. (1996). Sustainable development, cities and local government: dilemmas and definitions. Australian planner, 33(2), 61-66.

Gabriel, B., Osti, Faccioli. (2011). Residents' perception and attitudes towards tourism impacts. Benchmarking: An International Journal, 18(3), 359-385. doi: 10.1108/14635771111137769

Garcia, J. A. (2011). Latino politics in America: Community, culture, and interests: Rowman \& Littlefield.

Ghai, D., \& Vivian, J. M. (1992). Grassroots environmental action: people's participation in sustainable development: Routledge.

Giddings, B., Hopwood, B., \& O'brien, G. (2002). Environment, economy and society: fitting them together into sustainable development. Sustainable development, 10(4), 187-196.

Grainger, J. (2003). People are living in the park'. Linking biodiversity conservation to community development in the Middle East region: a case study from the Saint Katherine Protectorate, Southern Sinai. Journal of Arid Environments, 54(1), 29-38. doi: 10.1006/jare.2001.0894

Gran, G. (1987). An annotated guide to global development: Capacity-building for effective social change: Resources for Development and Democracy.

Guba, E. G., \& Lincoln, Y. S. (1994). Competing paradigms in qualitative research. Handbook of qualitative research, 2, 163-194.

Guest, G., MacQueen, K. M., \& Namey, E. E. (2012). Applied thematic analysis. Los Angeles: Sage Publications.

Gutierrez, E., Lamoureux, K., Matus, S., \& Sebunya, K. (2005). Linking communities, tourism \& conservation: A tourism assessment process: Conservation International. 
Haddock. (2012). COASTAL CONFLICTS IN COSTA RICA AND THE TERRITORIOS COSTEROS COMUNITARIOS LAW PROJECT (TECOCOS)

Harrill, R. (2004). Residents' Attitudes toward Tourism Development: a Literature Review with Implications for Tourism Planning. Journal of Planning Literature, 18(3), 251-266. doi: 10.1177/0885412203260306

Hay-Smith, L., \& Hunt, J. D. (1995). Nature tourism: impacts and management. Wildlife and recreationists: Coexistence through management and research, 203-219.

Heinen, J. T. (1993). Park-people relations in Kosi Tappu Wildlife Reserve, Nepal: a socio-economic analysis. Environmental Conservation, 20(01), 25-34.

Helling, L., Serrano, R., \& Warren, D. (2005). Linking community empowerment, decentralized governance, and public service provision through a local development framework. World Bank Social Protection Discussion Paper(0535), 1-79.

Hickman, L. (2008). Shades of green. The Guardian. Retrieved on, 06-08.

Hill, R. P. (1993). A Primer for Ethnographic Research With a Focus On Social Policy Issues Involving Consumer Behavior. Advances in Consumer Research, 20(1).

Honey, M. S. (1999). Treading lightly? Ecotourism's impact on the environment. Environment: Science and Policy for Sustainable Development, 41(5), 4-9.

Hotelling, H. (1931). The economics of exhaustible resources. The Journal of Political Economy, 39(2), 137-175.

HPI. (2013). Happy Planet Index.

http://www.infoplease.com. Map of Costa Rica. http://www.infoplease.com

http://www.nosarabeachvillas.com. Map of Nicoya Peninsula. http://www.nosarabeachvillas.com

Hussein, M. (2003). Good Governance and Decentralization at the Local Level: The Case of Malawi. Politeia, 22, 78-93.

Ismail, N. A., Razak, S. M., \& Ismail, M. (2013). The impact of tourism towards the culture practice of indigenous people. Hospitality and Tourism: Synergizing Creativity and Innovation in Research, 369.

Jacobs, J. (1961). The death and life of great American cities: Random House Digital, Inc.

Kearns, R. (2005). Knowing seeing? Undertaking observational research. Qualitative research methods in human geography, 192-206.

Kellert, Mehta, Ebbin, \& Lichtenfeld. (2000). Community natural resource management: promise, rhetoric, and reality. Society \& Natural Resources, 13(8), 705-715.

Kim, B. (2001). Social constructivism. Emerging perspectives on learning, teaching, and technology.

Kleemeier, E. (2000). The impact of participation on sustainability: an analysis of the Malawi rural piped scheme program. World development, 28(5), 929-944.

Ley de Protección. (1993). POBLACIONES DE TORTUGAS MARINAS.

Lincoln, Z. (2014). SOCIO-ECONOMIC AND CULTURAL IMPACTS OF TOURISM IN BANGLADESH. European Scientific Journal, 9(10).

Longhurst, R. (2003). Semi-structured interviews and focus groups. Key methods in geography, 117132.

Lubchenco, J. (1998). Entering the century of the environment: a new social contract for science. Science, 279(5350), 491-497.

Luhtanen, R., \& Crocker, J. (1992). A collective self-esteem scale: Self-evaluation of one's social identity. Personality and Social Psychology Bulletin, 18(3), 302-318.

Lyttleton, C., \& Allcock, A. (2002). Tourism as a Tool for Development. UNESCO-Lao National Tourism Authority (NTAL)/Nam Ha Ecotourism Project, 71.

Mancini, J. A., \& Marek, L. I. (2004). Sustaining Community-Based Programs for Families: Conceptualization and Measurement*. Family Relations, 53(4), 339-347.

Mansuri, G., \& Rao, V. (2004). Community-based and-driven development: A critical review. The World Bank Research Observer, 19(1), 1-39. 
McFarlane, A. G. (2000). When inclusion leads to exclusion: The uncharted terrain of community participation in economic development. Brook. L. Rev., 66, 861.

McGehee, N. G. (2012). Oppression, emancipation, and volunteer tourism: Research propositions. Annals of Tourism Research, 39(1), 84-107.

McGehee, N. G., \& Andereck, K. (2009a). Volunteer tourism and the "voluntoured": the case of Tijuana, Mexico. Journal of Sustainable Tourism, 17(1), 39-51. doi: 10.1080/09669580802159693

McGehee, N. G., \& Andereck, K. (2009b). Volunteer tourism and the "voluntoured": the case of Tijuana, Mexico. Journal of Sustainable Tourism, 17(1), 39-51.

McKean, M. A. (1992). Success on the Commons A Comparative Examination of Institutions for Common Property Resource Management. Journal of theoretical politics, 4(3), 247-281.

McMinn, S. (1998). Tourist typology observations from Belize. Annals of Tourism Research, 25(3), 675-699.

Mhango. (2010). SUSTAINABILITY OF COMMUNITY DRIVEN DEVELOPMENT PROJECTS IN

\section{ZOMBA DISTRICT IN THE CONTEXT OF LOCAL DEVELOPMENT FRAMEWORK.}

University of Malawi.

Miller, J., \& Glassner, B. (1997). The 'inside'and the 'outside': finding realities in interviews. Qualitative research, 99-112.

Ministry of Foreign Relations Costa Rica, M. (2013). Direction of Foreign Policy. Retrieved from http://www.rree.go.cr/?sec=ministerio\&cat=politica\%20exterior.

Morera, R. (2013). Pamphlet Ostional and ADIO. In ADIO (Ed.).

Muir-Cochrane, E. C., \& Fereday, J. (2006). Demonstrating rigor using thematic analysis: a hybrid approach of inductive and deductive coding and theme development.

Murphy, P. E. (1983). Tourism as a community industry-an ecological model of tourism development. Tourism Management, 4(3), 180-193. doi: 10.1016/0261-5177(83)90062-6

Mustonen, P. (2007). Volunteer tourism-Altruism or mere tourism? Anatolia, 18(1), 97-115.

Narayan, D., Patel, R., Schafft, K., Rademacher, A., \& Koch-Schulte, S. (2000). Can anyone hear us? : Oxford University Press New York.

NEF. (2013). Happy Planet Index. Retrieved 07/10/2013 http://www.happyplanetindex.org/

Organisation for Economic, C.-0., \& Development. (2005). Paris Declaration on Aid Effectiveness. Paris: OECD Publishing.

Ostrom, E. (1990). Governing the commons: The evolution of institutions for collective action: Cambridge university press.

Ostrom, E. (2000). Social capital: a fad or a fundamental concept. Social capital: A multifaceted perspective, 172-214.

Page, S. J., Dowling, R. K., \& Page, S. (2001). Ecotourism: Pearson Education Limited.

Palomino Schalscha, M. A. (2011). Indigeneity, Autonomy and New Cultural Spaces: The Decolonisation of Practices, Being and Place through Tourism in Alto Bío-Bío, Chile.

Paul, S. (1987). Community participation in development projects: World Bank Washington, DC.

Pearce. (1980). Host community acceptance of foreign tourists. Annals of Tourism Research, 7(2), 224-233. doi: 10.1016/0160-7383(80)90005-5

Pearce, D. W., Markandya, A., \& Barbier, E. B. (1989). Blueprint for a green economy: a report (Vol. 1): Earthscan.

Peters, P. E. (2000). Development encounters: sites of participation and knowledge (Vol. 4): Harvard Univ Pr.

Pomeroy, R. S., Oracion, E. G., Pollnac, R. B., \& Caballes, D. A. (2005). Perceived economic factors influencing the sustainability of integrated coastal management projects in the Philippines. Ocean \& Coastal Management, 48(3), 360-377.

Potter, R. B. (2008). Geographies of development: an introduction to development studies. New York: Prentice Hall. 
Putnam, R. D. (2000). Bowling alone: The collapse and revival of American community: Simon and Schuster.

Rifkin, S. B. (1986). Lessons from community participation in health programmes. Health Policy and Planning, 1(3), 240-249.

Ritchie, J. B., \& Crouch, G. I. (2003). The competitive destination: A sustainable tourism perspective: Cabi.

Robinson, J. G. (1993). The Limits to Caring: Sustainable Living and the Loss of Biodiversity. Conservation biology, 7(1), 20-28.

Roseland, M. (2000). Sustainable community development: integrating environmental, economic, and social objectives. Progress in planning, 54(2), 73-132.

Rossman, G. B., \& Rallis, S. F. (2011). Learning in the field: An introduction to qualitative research: SAGE Publications, Incorporated.

Sahney, S., \& Benton, M. J. (2008). Recovery from the most profound mass extinction of all time. Proceedings of the Royal Society B: Biological Sciences, 275(1636), 759-765.

Savage, J. M. (2002). The amphibians and reptiles of Costa Rica: a herpetofauna between two continents, between two seas: University of Chicago Press.

Scheyvens, R. (2002). Tourism for development: empowering communites. Upper Saddle River, NJ: Prentice Hall.

Scheyvens, R., \& Storey, D. (2003). Development fieldwork: a practical guide. London: SAGE.

Schuftan, C. (1996). The community development dilemma: what is really empowering? Community Development Journal, 31(3), 260-264.

Schwandt, T. A. (1994). Constructivist, interpretivist approaches to human inquiry. Handbook of qualitative research, 1, 118-137.

Seager, A. (2009). Costa Rica is the world's greenest, happiest country. The Guardian.

Seale, C. (1999). Quality in qualitative research. Qualitative inquiry, 5(4), 465-478.

Selman, P. (1996). Local sustainability: Managing and planning ecologically sound places: Sage.

Siggelkow, N. (2007). PERSUASION WITH CASE STUDIES. Academy of Management Journal, 50(1), 2024.

Simon, D. (2006). Your questions answered? Conducting questionnaire surveys. Doing Development Research, 163-171.

Singla, M. (2014). A Case Study on Socio-cultural Impacts of Tourism in the city of Jaipur, Rajasthan: India. Journal Of Business Management \& Social Sciences Research, 3(2), 10-23.

Snape, D., \& Spencer, L. (2003). The foundations of qualitative research. Qualitative research practice: A guide for social science students and researchers, 11.

Soule, M. E., \& Wilcox, B. A. (1980). Conservation biology. An evolutionary-ecological perspective: Sinauer Associates, Inc.

Stem, C. J., Lassoie, J. P., Lee, D. R., \& Deshler, D. J. (2003). How'eco'is ecotourism? A comparative case study of ecotourism in Costa Rica. Journal of Sustainable Tourism, 11(4), 322-347.

Stewart, W. P., Liebert, D., \& Larkin, K. W. (2004). Community identities as visions for landscape change. Landscape and Urban Planning, 69(2), 315-334.

Sultana, F. (2007). Reflexivity, positionality and participatory ethics: Negotiating fieldwork dilemmas in international research. ACME: An International E-Journal for Critical Geographies, 6(3), 374-385.

Suzuki, L. A., Ahluwalia, M. K., Arora, A. K., \& Mattis, J. S. (2007). The Pond You Fish In Determines the Fish You Catch Exploring Strategies for Qualitative Data Collection. The Counseling Psychologist, 35(2), 295-327.

Takano, S. (1997). The myth of a homogeneous speech community: The speech of Japanese women in non-traditional gender roles.

Taylor, M. (2007). Community participation in the real world: opportunities and pitfalls in new governance spaces. Urban Studies, 44(2), 297-317. 
Terry, A., Hill, J., \& Woodland, W. (2006). Uniting National Aspirations and Local Implementation in Sustainable Development: An Introduction. Sustainable Development: National Aspirations, Local Implementation, 1-13.

Trevor, W. (1999). Community and sustainable development: participation in the future edited by D. Warburton, 1998. Earthscan, 248pp, u14.95 (pbk). ISBN 1-8538-531-5 (Vol. 7, pp. 112). Chichester: Wiley Periodicals Inc.

Ulgiati, S., \& Brown, M. T. (1998). Monitoring patterns of sustainability in natural and man-made ecosystems. Ecological Modelling, 108(1), 23-36.

UNCED. (1992). United Nations Conference on Environment and Development, 3-14 June 1992, Rio de Janeiro, Brazil: outcomes of the conference: Ministry of External Relations and Trade, Ministry for the Environment U6 - ctx_ver=Z39.882004\&ctx_enc=info\%3Aofi\%2Fenc\%3AUTF-

8\&rfr_id=info:sid/summon.serialssolutions.com\&rft_val_fmt=info:ofi/fmt:kev:mtx:book\&rft. genre=book\&rft.title=United+Nations+Conference+on+Environment+and+Development\%2C +3-14+June+1992\%2C+Rio+de+Janeiro\%2C+Brazil\&rft.date=1992-01-

01\&rft.pub=Ministry+of+External+Relations+and+Trade\%2C+Ministry+for+the+Environment \&rft.externalDocID=293351\&paramdict=en-US U7 - Book.

UNDP. (2013). International Human Development Indicators.

UNEP. (2012). Sustainable Tourism.

UNEP.(2014).AboutEcotourism.20/2/2014,from

http://www.uneptie.org/pc/tourism/ecotourism/home.htm.

UNWTO. (2013). Tourism Highlights 2013 Edition.

Vallance, S., Perkins, H. C., \& Dixon, J. E. (2011). What is social sustainability? A clarification of concepts. Geoforum, 42(3), 342-348.

Van Marrewijk, M. (2003). Concepts and definitions of CSR and corporate sustainability: between agency and communion. Journal of business ethics, 44(2-3), 95-105.

Vargas-Sánchez, A., Porras-Bueno, N., \& Plaza-Mejía, M. d. I. Á. (2011). Explaining residents' attitudes to tourism. Annals of Tourism Research, 38(2), 460-480. doi: 10.1016/j.annals.2010.10.004

Vitousek, P. M., Mooney, H. A., Lubchenco, J., \& Melillo, J. M. (1997). Human domination of Earth's ecosystems. Science, 277(5325), 494-499.

Vivian, J. M. (1992). Foundations for sustainable development: participation empowerment and local resource management.

Vodopivec, B., \& Jaffe, R. (2011). Save the World in a Week: Volunteer Tourism, Development and Difference. European Journal of Development Research, 23(1), 111-128. doi: 10.1057/ejdr.2010.55

Wackernagel, M. (1996). Our ecological footprint: reducing human impact on the earth (Vol. 9): New Society Publishers.

WCED. (1987). Report of the World Commission on environment and development:" our common future.": United Nations.

Wearing, S. (2001). Volunteer tourism [electronic resource]: experiences that make a difference: Cabi.

Weaver, D. B., Lawton, L., \& Association, P. A. T. (2000). Sustainable tourism: A critical analysis: Pacific Asia travel Accosiation (PATA).

West. (1993). Economic significance of tourism in Queensland. Annals of Tourism Research, 20(3), 490-504.

West. (2011). Volunteer Tourism: Effective Development Strategy or Feel-Good Travel? (Vol. 50).

Williams, C. C., \& Millington, A. C. (2004). The diverse and contested meanings of sustainable development. The Geographical Journal, 170(2), 99-104.

Woodcraft, S., Hackett, T., \& Caistor-Arendar, L. (2011). Design for social sustainability: A framework for creating thriving new communities: Future Communities. 
Woodland, W., Hill, J., \& Terry, A. (2006). Water management for agriculture in Tunisia: towards environmentally sustainable development. Sustainable Development: National Aspirations, Local Implementation, 229.

WorldBank. (2013). Costa Rica: Identifying the Social Needs of the Poor: An Update.

WTO. (2004). Sustainable Development of Tourism Retrieved 24/2/2014 http://sdt.unwto.org/content/about-us-5

Yin, R. K. (2009). Case study research: Design and methods (Vol. 5): Sage.

Zapata, M. J., Hall, C. M., Lindo, P., \& Vanderschaeghe, M. (2011). Can community-based tourism contribute to development and poverty alleviation? Lessons from Nicaragua. Current Issues in Tourism, 14(8), 725-749. 